(1)
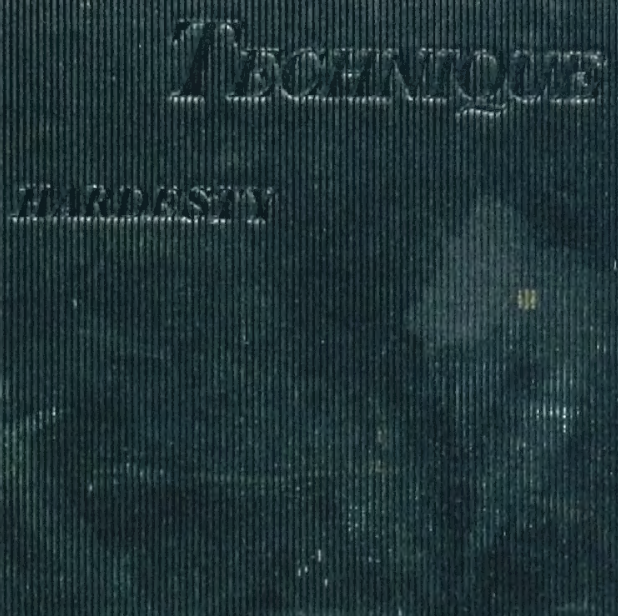

10.
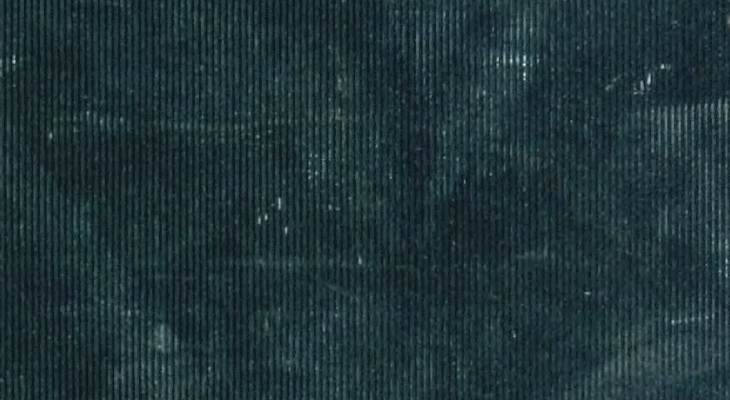

(1)

Ift

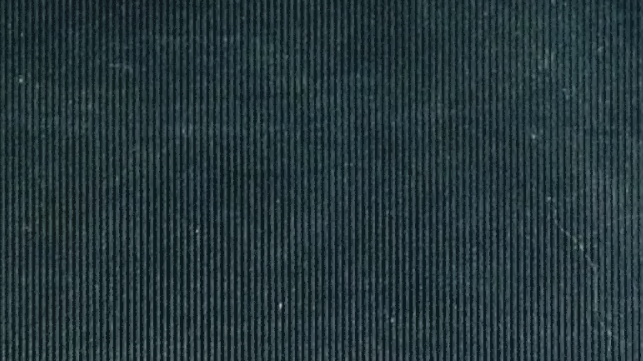

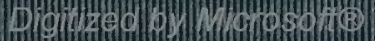


Flower A i Riany

$Q L$

927

$1+25$

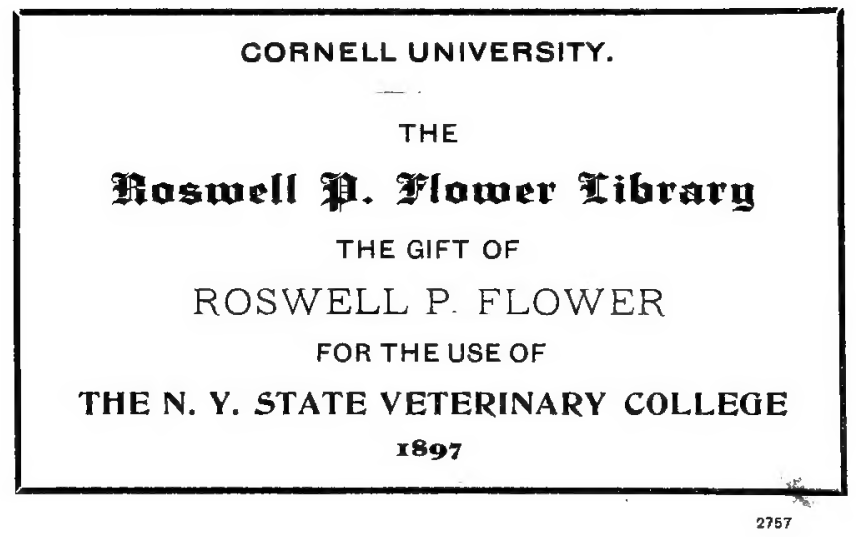


Date Due

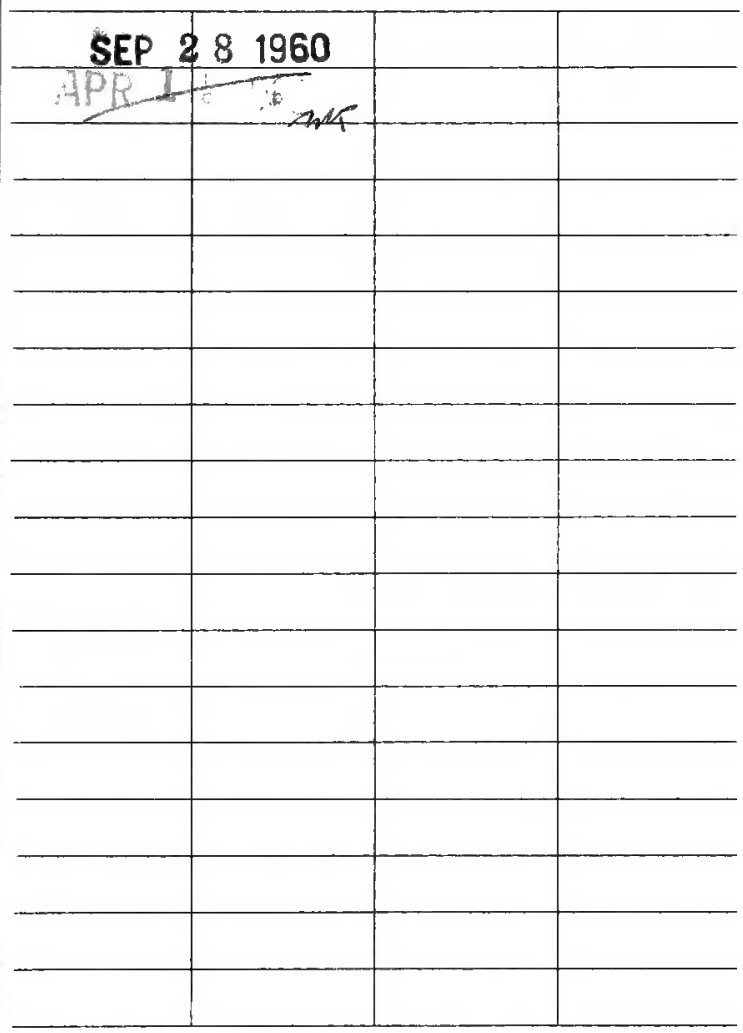

Library Bureau Cat. No. 1137 
This book was digitized by Microsoft Corporation in cooperation with Cornell University Libraries, 2007. You may use and print this copy in limited quantity for your personal purposes, but may not distribute or provide access to it (or modified or partial versions of it) for revenue-generating or other commercial purposes. 


\section{NEUROLOGICAL TECHNIQUE}


Digitized by Microsoft ${ }^{\circledR}$ 


\section{NEUROLOGICAL TECHNIQUE}

SOME SPECIAL HISTOLOGICAL METHODS EMPLOYED FOR THE STUDY OF THE NERVOUS SYSTEM, TOGETHER WITH A LABORATORY OUTLINE FOR THE DISSECTION OF THE CENTRAL NERVOUS SYSTEM AND THE NEUROLOGICAL NOMENCLATURE [BNA] ARRANGED IN A CLASSIFIED LIST

BY

IRVING HARDESTY, Рн.D.

Instructor in Anatomy, The University of California ; formerly Assistant in Neurology, The University of Chicago

1902

THE UNIVERSITY OF CHICAGO PRESS

CHICAGO

WILLIAM WESLEY AND SON

LONDON 
QL.

927

$1+25$

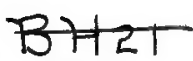

No. 1820

Copyright, 1901, by

The University of Chicago 


\section{INTRODUCTION.}

At the present time an acquaintance with the architecture of the nervous system is sought, not only by those who expect to pursue the practice of medicine, and who, therefore, need this knowledge for clinical work, but also by anatomists, physiologists, zoölogists, and those who are interested in the biological problems that arise in the study of psychology and of its application to education.

The object of this volume on neurological technique is to serve as an introduction and laboratory guide to the study of the architecture of this the most. complicated of the bodily systems.

Like most books with similar aims, it has grown out of the attempt to meet difficulties that arose in our own laboratory, and the effort to bring together, in a compact form, such data as would make the student independent in the conduct of his introductory work. In the first instance this was done in a set of laboratory outlines, and these, after trial and correction, have been embodied in this book.

The material falls into three divisions, each of which may be briefly mentioned. The methods which are here given have stood the test of application in the laboratory. In their presentation special attention has been paid to indicating the quantities of the reagents to be used and the time required for each. There are few occupations in which time can be more easily wasted than in histological technique. To assist, therefore, the student in the art of economizing his working hours, the reagent and the minimal time during which it should act are printed 
in heavy type, so that by glancing down the page he may readily see what is ahead of him, and note the occurrence of intervals that can be advantageously employed in other work.

In the second part, comprising the outline for the examination of the nervous system, it will be noted that both in the examination of the surface and in the study of the sections the aim has been to pick out those topographical features which appear most important for the construction of the mental image of the nervous system for which each student should strive. This image must be built in three dimensions; and while the capacity to do this in the ideal way is by no means a common gift, yet persistent effort never fails of some reward.

In following the directions for the examination of the central nervous system, it is, of course, expected that one or more of the descriptive text-books will be employed to explain the relations of the structures to which attention is directed.

The nomenclature, which forms the last part of the book, is that accepted by the German Anatomical Society, and is already widely used, both on the continent and in England, as well as in the United States. Naturally it has been criticised by many who would have preferred other terms; nevertheless it is destined for years to come to be the standard for neurological nomenclature, and although there are some widely used text-books in which it has not yet been employed, the student of today will find that, in the interests of exactness and economy of expression, it will be well worth while for him to acquire it.

The writing of this introduction might, quite properly, have been left to the author, but since is has fallen 
to my lot, I have accepted the responsibility with pleasure, since it gives me a fitting opportunity to make a partial expression of my indebtedness to the author for years of efficient assistance in the conduct of our classes in neurology, and to point to this volume as evidence of one way in which that assistance has been rendered.

Henry H. Donaldson.

University of Chicago,

October 16, I90I. 
Digitized by Microsoft $\circledast$ 


\section{CONTENTS.}

INTRODUCTION

General Considerations as to the Need and action of Reagents.

Fixation, definition of

Need of fixation

Necessary qualities of a fixing agent

Probable action of a fixing agent

Chemical theory

Physical theory

Dependence of differential methods on the action of a fixing agent

The uses of alcohol:

As a fixative

For washing out

For hardening

For dehydration

"Clearing," why necessary

The grades of alcohol, why necessary

The preparation of the grades of alcohol

Formula

Table

General Instructions.

Applicability of the methods given

Directions for dissection

Removal of tissue in case of very young animals

The amount of fluid necessary

The size of the pieces of tissue to be used

The times during which tissues may remain in a fluid

"Replace" and "transfer"

Clean slides and cover-glasses, why necessary

Explanation of references

Economy of time

THE METHODS.

I. An Erythrosin-Toluidin-Blue Method.

A method for the general internal morphology of the neurone, giving the granulation, "neurosomes, "reticulum, and " axone hillock." Also differential for karyokinesis in the nervous system

II. The Nissl Method.

A method devised especially to demonstrate the tigroid masses or Nissl bodies of the nerve-cell 
III. The Bethe Method.

A special method for the differentiation of the neurofibrillae and "Golgi net." As here given, the method is' applicable to vertebrate nervous tissue

IV. Afáthy"s "Aftergilding" Goid Chloride Method.

An application of gold chloride to sections of material previously fixed. A method for the neurofibrillae, and also adaptable to the study of nerve terminations and the general morphology of the neurone

V. KUPFFER's Method.

A method for the study of the medullated axone - the myelin sheath, the axis cylinder, the "nodes of Ranvier," etc.

VI. A Silver Nitrate Method.

An application of silver nitrate to the fresh nerve-fiber to demonstrate the so-called "cross of Ranvier," Frommann's lines, the neurolemma, etc.

VII. The Intra-vitam Methylen-Blue Method.

Applications of methylen-blue to the fresh tissue for the external morphology of the neurone and to demonstrate the course and terminations of the axone. Especially suited for the architecture of peripheral ganglia and muscle-nerve terminations, but may be applied to the central nervous system

VIII. A Gold Chloride Method.

Applications of gold chloride to either fresh tissue or to tissue which has been fixed in formalin. Especially devised to stain muscle-nerve terminations and peripheral plexuses

IX. The Golgi Method.

A method for the external morphology of the neurone, central and peripheral; to demonstrate the shape of the cell-body, the dendrites and their gemmules or "pin-head" processes, the axone and its branchings, collaterals, and terminations. Also for neuroglia and for the non-nervous tissue elements of the organs of special sense

I. The "rapid method"

2. Application to material fixed and preserved in formalin

X. The Iron-Hematoxylin Method.

A hæmatoxylin method for nerve material preserved in formalin. Differential for the medullary sheath and also stains the nerve-cell. Especially adapted to the central nervous system to show the occurrence and course of medullated fiber-tracts

XI, The Weigert Method (Pal's Modification).

A specific method for the medullary sheaths of the nerve-tracts of the central nervous system. Applicable for the study of both the development and extent of medullation as well as for tracing medullated nerve 
pathways, and thus may be applied for the study of the course of degenerated pathways in the central system. Can be used for determining the number of medullated fibers in a pathway or nerve. The method may be applied to material preserved in formalin

XII. MaRchi's Method.

A differential method for degenerating medullated nerve-fibers. Can be applied for the study of the course and distribution of medullated fiber-tracts after lesions. Applicable to peripheral nerves as well as to the central system. Also differential for fatty degeneration of nervecells and blood vessels

XIII. Stroebe's Method.

A method devised for the study of the processes of degeneration and regeneration of medullated fibers in the peripheral nervous system. May also be applied for the processes of degeneration in the central system. A good general method for sections of the spinal cord

XIV. WEIGERT'S METHOD FOR NEUROGLIA.

A differential stain for neuroglia, showing the relations between the neuroglia fibers and the neuroglia cells. Especially applicable to human tissue, adult preferably

XV. Mallory's Method for Neuroglia.

An application of phosphotungstic-acid-hæmatoxylin as a differential stain for neuroglia. A shorter method than Weigert's with the same purpose and giving practically the same results

XVI. Giacomini's Methon (Modified).

A method for making "dry preparations" of the central nervous system for museum specimens

XVII. The Kaiserling Method.

A method for "wet preparations" of the central nervous system for museum and demonstration specimens. Gives toughness to the specimen and preserves the normal color. Well adapted to pathological specimens, whether of nervous or other tissue

XVIII. Methods For THE Treatment of Embryos.

Some suggestions as to the fixation and preservation of human embryos and foetuses

XIX. Formalin for Purposes of Dissection.

An application of formalin for the fixation and preservation of specimens for dissection. May be applied to the whole or any part of the animal for the dissection of any of its tissues, but is especially adapted to the central nervous system

Directions for the removal of the central nervous system 
$x i i$ Neurological Technique

XX. A Laboratory Outline for the Dissection of the Central Nervous SYSTEM

Anatomical Nomenclature [BNa] for the Nervous System and the SENSE ORGANS

Tables of Equivalent Weights and Measures 173

INDEX I75 


\section{NEED AND ACTION OF REAGENTS.}

GENERAL CONSIDERATIONS AS TO THE NECESSITY FOR REAGENTS AND THEIR PROBABLE ACTION UPON THE TISSUE.

Fixation.-The term "fixation" may be briefly defined as a process by which the tissue is quickly killed and its structure rendered permanent. This definition implies the use of fresh tissue. The structural elements of the tissue should be in their normal or living attitude at the time of fixation, and the fixing reagent should catch and maintain this attitude. To accomplish this, the reagent must render the elements rigid, insoluble, and able to resist without change the action of the reagents to which it may be necessary to subject the tissue during the manipulation following fixation.

While it is very essential for the student to examine tissues in the fresh state, so as to become acquainted with their normal appearances under the microscope, yet such preparations are not only not permanent, but also, after a short time, post-mortem changes set in, and the beginning dissolution gives appearances far from normal. Also, in mounts of fresh tissue, the structural elements are often so homogeneous in their behavior toward light that some special procedure must be resorted to which will result in an optical differentiation of the component parts. In some cases the action of the fixing agent directly results in this differentiation of the tissue elements by altering their indices of refraction. In most cases, however, it is attained by the use of certain stains. In nearly all the special differential methods the selective action of these stains depends to a great degree upon the previous action of the fixing reagent upon the tissue.

A good fixing agent, therefore, must possess at least three qualities: It must have the power to penetrate quickly, and thus fix the tissue elements before post-mortem changes have 
begun. It must kill or fix and render permanent, without distorting the normal shape, size, and position of the tissue elements. It should also either itself have a differentiative action, or its action should be such as to produce, enhance, or allow the best action of the special differentiating reagents (stains, etc.) used in the after-treatment.

As to the fixing value of the various reagents employed, experience has taught that certain qualities must be avoided:

I. A fixing fluid must not be alkaline in reaction. All the bases, and also the carbonates of the alkali metals, kill quickly enough, but tend to dissolve certain of the structures rather than fix them.

2. The fluid may be neutral, but would best be slightly acid in reaction. Most acids, however, when present in too great proportion, produce a swelling more or less distorting, by causing the tissue to take up water. The swelling action of some acids is much more marked than that of others, and therefore the proportion of an acid in a fluid must be considered individually.

3. On the other hand, certain reagents, while fixing rapidly and permanently, cause a violent shrinkage of the tissue. Ordinary alcohol and some of the more neutral salts cause an unbalanced exosmosis of the more fluid cell contents, and the consequent shrinkage or collapse of the cell is decidedly objectionable. Alcohol as a fixing agent will be touched upon later.

The ideal fixing fluid would be one in which the ingredients are mixed in such proportions that the swelling tendency of the one will counteract the shrinking tendency of the other, and that the fixing efficiencies of all would be combined.

There are a few reagents which, when used alone, produce an excellent fixation, and it is sometimes best that they be used alone. But for most purposes these also have their drawbacks.

Osmic acid (the tetroxide of osmium) is one of the best of these. It fixes quickly and well, but is easily reduced by the tissue, especially where there is fat. The reduction product 
appears as a black insoluble precipitate, and thus the reagent has a blackening effect upon the tissue which is often undesirable. Also, the staining qualities of the tissue fixed in 'osmic acid are often greatly impaired. It will be found, however, that occasionally the browning or blackening action of osmic acid is its virtue. Advantage is taken of it in some of the special methods where the object is to differentiate just those structures which are most blackened by the reagent. One of the most serious objections to osmic acid is its poor penetrating power. While fixing rapidly the parts with which it comes in direct contact, it penetrates the tissue so slowly that it can be used alone successfully only upon very small pieces.

The bichloride of mercury (corrosive sublimate) is another example of a reagent which, when used alone, produces very good fixation. Mercuric chloride is also reduced by the tissue, and the resulting, almost insoluble, albuminate of mercury forms crystals in the tissue which are very objectionable.

These objectionable results may be got rid of by some special procedure, which, however, is often long and tedious; and the effect of which upon the tissue may be injurious. Specimens blackened by osmic acid may be bleached by subjecting them to hydrogen peroxide, which reoxidizes the reduced black product. The crystals resulting from corrosive sublimate may be finally removed by long washing in water and 70 per cent. alcohol, or more rapidly by treating the tissue for twenty-four hours or longer with a dilute solution of iodine. The iodine is supposed to gradually convert the crystals into the more soluble iodine compound (probably the biniodide of mercury).

Both corrosive sublimate and osmic acid are frequently used in mixtures, and the formulæ of some of the best fixing fluids call for one or the other as the chief ingredient. When mixed with chromic acid, as in Flemming's fluid, for example, the blackening action of osmic acid is much reduced.

The nature of fixation.- Owing to the fact that so little is known of the chemical processes taking place within the living tissues, both normally and in pathological conditions, very 
little can be said as to the exact action upon the tissue of any fixing fluid. If these processes were known, or even the chemical changes taking place which result in the death of the organism, then there might be formulated what, at least, would more nearly be a working hypothesis as to the action of the various reagents, and a method for the study of some special structure could be devised on a more logical basis.

The procedure has usually been to totally disregard the chemical constitution of the cell, but to use reagents the action of which is to produce death changes modifying as little as possible the normal structure of the cell. The investigator, desiring a method for a specific purpose, quite often has obtained that method either by chance or only after repeated and laborious experimentation. And too often has it been true that his published observations had more to do with what his method gave him than with the normal structures of the tissue he described. A reagent should be proved by comparing its results as far as possible with the appearances of the fresh tissues and also with the results obtained after various other fluids.

Opinion is somewhat divided as to the nature of the process of fixation, or what the exact action of the reagent is upon the tissue. It is held by some ${ }^{\mathbf{I}}$ that fixation consists in the coagulation of the albuminoids, etc., of the tissue, or in rendering more rigid and insoluble certain of the tissue constituents otherwise fluid, semifluid, or soluble; and that, in doing this, the fixing agents in the majority of cases enter into chemical combination with the tissues or with certain of the tissue elements. Many of the various tissue elements are of different chemical composition, and thus reagents acting upon them may produce different chemical compounds. On this basis, in the methods devised for the special differentiation of particular elements, the elective actions of the special mordants and stains must depend upon the chemical action of the likewise special fixing agent which precedes. This may be called a chemical theory.

'See LEE, The Microtomist's Vade-mecum. Fifth edition. Philadelphia, I9oo. 
Others, chief among them Fischer, ${ }^{x}$ offer what, in distinction, may be looked upon more as a physical theory. They hold that fixation is always a phenomenon of precipitation of the fluid and semifluid constituents, and that the subsequent differential action of the stains, etc., depends upon physical rather than chemical differences. This theory admits that a given fixing agent may produce a peculiar or characteristic form of precipitative or cumulative action, and therefore the differential action of the reagents following it, in a special method, may depend upon this characteristic action of the fixing agent.

This idea would lead, and no doubt often correctly, to the belief that structures brought out by any method are often artefacts, or the product of the treatment rather than normal appearances. There is much, however, which goes to show that this is not necessarily the case. The precipitation, if such is true, may occur within the elements of the cell in situ and result in molecular structural differences beyond the domain of the microscope.

Either theory permits of the same result for differentiation. The knowledge of the exact and distinctive action of the reagents, both upon the tissue and upon each other, would be highly advantageous in devising a method for a desired result, but otherwise the important thing for the histologist to know is whether structures are produced in form optically different from the normal structures. To him it makes not so much difference whether the action of a fixing agent or of a special mordant is to produce a change in the chemical composition of the tissue by entering into it chemically and forming with it new compounds upon which the special after-treatment for a desired result depends, or whether the fixing agent produces merely a change in the construction of the tissue, the chief histological result of which is a change in its physical properties, making possible the differentiation of special structures by a special method of treatment. In all probability the question, in many cases, is

${ }^{x}$ FISCHER, Untersuchungen über den Bau der Cyanophyceen und Bakterien Jena, I897. Also, Fixirung, Färbung und Bau des Protoplasmas. Jena, 1899. 
as to which set of changes have most to do with the result obtained. Chemical changes must involve physical changes, and vice versa.

A fixing agent may produce a chemical, and physical, change without itself entering into the composition of the tissue. Alcohol, for example, is supposed to fix by producing a coagulation or precipitation of the substances without further taking part in the resulting changes. Its action is thought to be similar to that of heat, which is a fixing agent much used for the lower forms of animals. The resulting differences no doubt consist in molecular changes as well as physical changes.

Again, that the nucleus and nucleoli of the cell, in all the more general methods, react to stains differently from the other parts of the cell, is no doubt due to inherent chemical as well as to evident physical differences which may or may not be effected by the reagents. The nucleus of the cell in the fresh state exercises a selective action toward the so-called nuclear stains. It stains more deeply, or takes more of the stain, than the other organs of the cell. It cannot be said with certainty whether this is due more to the greater compactness or denser accumulation of substance in the nucleus (physical difference), or to its inherent chemical difference.

That the more highly differential staining methods depend solely upon physical differences, produced or inherent, between the different structural elements of the tissue, is doubtful. Many of the methods devised to bring out certain structures in especial prominence are thought to depend upon certain chemical compounds existing in those structures and not in others, causing them, to react differently toward the reagents. An example of this is the selective affinity which the axone of the nerve cell exhibits toward methylen blue, one of the basic aniline dyes. This affinity, so strongly manifested by the fresh tissue, is almost entirely lost if the stain is applied after the action of a fixing agent. Osmic acid is reduced by the medullary sheath of the axone before it is affected at all by the other structures. This reducing power of the normal structure is lost after treatment with potassium bichromate or chromic acid. 
The required differentiation, on the other hand, often cannot be obtained without previous treatment with a certain reagent. For example, the pictures of the neurone given by silver nitrate (Golgi method), or those given by certain of the specific hæmatoxylin methods for the myeline sheaths (Weigert's method), have not been obtained without previous treatment with a mixture containing chromic acid or one of its salts. The bichromate of potassium, the salt more often used in fluids for these methods, is supposed to form distinct chemical compounds with the special tissue elements. The compounds formed by its action upon the nerve cell react, in the one case, selectively upon silver nitrate or probably silver chromate, while that formed by its action upon the medullary sheath is, in the other case, selectively acted upon by the special hæmatoxylin mixture.

Thus the fixing agents in more general use may be roughly divided into two classes:

I. Those which fix, coagulate, or precipitate without combining chemically with the tissues.

2. Those which in the process of fixation and hardening may form chemical compounds with certain of the structural elements of the tissue.

A reagent of either class may exert a distinctive action, and in the special histological methods advantage is taken of this action.

\section{THE USES OF ALCOHOL.}

As a fixing agent.-Alcohol has, in the past, been much used as a fixing agent, especially by physicians. Because of its shrinking effect upon the tissue it is not altogether satisfactory, but it is sometimes necessary, both because of its ready availability and because it is thought to merely coagulate or precipitate without otherwise altering the chemical composition of the tissues.

Alcohol mixes with water with a violent ionic action. Its molecule is supposed to pass through the cell-wall less readily than that of water, and the resultant shrinkage is therefore due to the water being extracted from the cell. When used as a 
fixing agent, it should either be of such a high per cent. ( 96 per cent. to absolute), and with such small pieces of tissue, that fixation of the cell structures may be accomplished before they become distorted and the cell as much shrunken as results from the longer period of diffusion currents involved in the action of the intermediate grades; or, it should be of such a low grade ( $33 \mathrm{~T} / 3$ per cent.) that the resulting diffusion currents are weak enough to allow a more nearly balanced action between the exosmotic and endosmotic currents. Weak alcohol thus causes little or no shrinkage. However, because it has a dissociating effect upon the tissue, and also because it denies the advantages of rapid fixation, it is seldom used except where dissociation is desired.

The more important uses of alcohol in microscopic technique are (I) washing the tissues after fixation by other fluids; (2) hardening the tissues after fixing fluids which do not give the required rigidity; (3) preserving the tissues after washing or hardening; and (4) dehydration of tissues already fixed.

Washing.-The surplus fixing fluid should always be removed from the tissue before proceeding further. When fixing fluids are used which at the same time harden the tissue, such as fluids containing potassium bichromate or corrosive sublimate, much of the surplus fluid may be washed out with water. The washing, however, is always completed with alcohol. Alcohol, in almost every case, is a better solvent than water, and also in it the washing may be safely prolonged, since it preserves as well as washes. In 70 per cent. or 80 per cent. alcohol, pieces of tissue may remain indefinitely. The only exceptions to this rule are in case of a few of the special methods where, in order to get the best results, it has been found necessary that the preparation be completed within a specified time.

Hardening.- Material fixed in certain of the strongly acid mixtures, for example those in which picric acid is the principal ingredient, becomes softened or even macerated if washed in water. Such material is transferred directly to alcohol, which, while washing out the fluid, completes the process by giving the 
required firmness and rigidity to the tissue. The material is usually washed in several changes of 70 per cent. alcohol and then, for preservation, is placed in several times its volume of 80 per cent. alcohol and set aside till needed.

Dehydration.- In order to imbed by either of the ordinary methods, all water in the tissue must be removed. Not only would water be detrimental in itself, but neither of the imbedding media, paraffin nor celloidin, is miscible with water in the slightest degree. Therefore, to get the necessary infiltration by either, the tissue must be thoroughly dehydrated. The strong affinity which alcohol has for water enables it to remove the water readily.

The grades of alcohol. - The mixing of alcohol with water is accompanied by violent action. The violence of the action varies with the strength of the alcohol. For this reason the tissue should not be transferred from water to a high grade of alcohol, nor vice versa, lest the violence of the diffusion and the consequent violent or unbalanced osmotic action shrink or rupture the cell or break down its internal structure. 'Dehydration, therefore, is usually accomplished by passing the tissue successively through grades of alcohol of gradually increasing strength up to "absolute." The grades ordinarily used in dehydrating are 35 per cent., 50 per cent., 70 per cent., 85 per cent., 95 per cent., and absolute alcohol. These percentages need not be absolutely exact, but should be approximately so.

The water removed, the tissue is subjected to a bath of some reagent which is a better solvent than alcohol is for the imbedding medium to follow. In case of paraffin especially, where this solvent is an oil, this procedure is called clearing.

The preparation of the grades of alcohol.-With the exception of absolute alcohol, the different grades are usually made up in the laboratory from, the ordinary commercial alcohol. The strength of the commercial or "stock" alcohol may be determined by the alcoholometer. It usually varies from 90 per cent. to 97 per cent. 
For convenience in reducing the stock alcohol to the lower grades required, the following formula has been devised:

Let $a=$ the per cent. of the alcohol to be reduced,

$b=$ the per cent. of the alcohol required, and

$x=$ the number of parts of distilled water to be added to Ioo parts of the alcohol to be reduced, in order to obtain the required per cent.

$$
\text { Then } \frac{a}{100+x}=\frac{b}{100} \text {, or } x=\frac{100 a-100 b}{b} \text {. }
$$

For example, suppose the stock alcohol to be reduced is 95 per cent. and 70 per cent. alcohol is required, then substituting :

$$
x=\frac{100 \times 95-100 \times 70}{70}=\frac{2500}{70}=35.7 .
$$

Then 35.7 parts of water added to roo parts of 95 per cent. alcohol will give 135.7 parts of 70 per cent. alcohol.

This formula does not give the exact volume percentages, since it does not take into account the physical action between the alcohol and water, and the consequent contraction in volume. To do this the more complex interpolation formula would be required. However, results amply exact for histological purposes are given by the above formula. It may be applied for the reduction of any grade of alcohol.

Commercial alcohol is usually about 95 per cent. Substituting 95 per cent. for $a$ and applying the formula for the grades of alcohol ordinarily required, the following table has been

\begin{tabular}{|c|c|c|c|c|}
\hline $\begin{array}{l}\text { Grade } \\
\text { required. }\end{array}$ & & $\begin{array}{l}\text { arts a } \\
\text { per cer } \\
\text { alcohol }\end{array}$ & & $\begin{array}{l}\text { Parts of } \\
\text { distilled } \\
\text { water. }\end{array}$ \\
\hline 95 per cent. & $=$ & IOO & + & 0 \\
\hline 85 per cent. & $=$ & IOO & + & I I.7 \\
\hline 70 per cent. & $=$ & 100 & + & 35.7 \\
\hline 60 per cent. & $=$ & IOO & + & 58.3 \\
\hline 50 per cent. & $=$ & IOO & + & 90.0 \\
\hline 35 per cent. & $=$ & IOO & + & I 7 I. 4 \\
\hline
\end{tabular}
derived : 


\section{GENERAL INSTRUCTIONS.}

The following methods are given in such detail in order that they may be followed by the student who has not had much experience in histological technique. In the directions the various steps and manipulations are such as have been found to work best in the actual application of the methods in the laboratory.

The methods given have been devised for the preparation and study of vertebrate nervous tissue. In most cases they are especially applicable to human material and that of the higher mammals generally.

I. In removing the nervous system care should be taken that the portions exposed do not become dry, and that the parts removed are not crushed or stretched. The first object may be attained by exposing only a small portion of the nervous system at a time, or by covering the parts exposed with skin or paraffin paper. When this is not convenient, the exposed parts may be kept moist with normal salt solutions ( 0.75 per cent. $\mathrm{NaCl}$ ) used very sparingly. The second object may be accomplished by using only sharp instruments, and employing scissors whenever practicable.

In case of very young animals, or fœtuses, it is best to fix the pieces of central nervous tissue before removing them completely from the surrounding tissues.

2. Always use an abundance of any fluid. It is safer to use too much than not enough.

3. Always use as small pieces of tissue as the purpose for which they are taken will allow.

4. The time during which the tissue should be subjected to the action of a reagent depends, of course, upon the size of the piece, the nature of the material, and the character of the reagent. When a choice of times is offered in the directions, 
the shortest time mentioned is, in all cases, the minimal. for pieces of tissue of the size suggested. In fixing especially, quite an amount of latitude is often allowable, the tissue not being injured by remaining in some of the fixing fluids several hours, or sometimes days, after the fixation is complete. Likewise in 70 or 80 per cent. alcohol, usually the tissue and sometimes the unstained sections may remain indefinitely.

5. The forms in which the formulæ are given are those which are considered most easy to follow in the making up, and at the same time the resulting fluids will, in most cases, be in sufficient quantity to apply the method to such an amount of tissue as is ordinarily needed.

6. The word "replace" is used in the directions when it is thought more expedient to pour off or remove the fluid in which the tissue then is, and pour on the fluid required. The word "transfer," on the other hand, indicates to remove the material or slide from one fluid and place it into another.

7. The graded alcohols will be necessary in most of the methods, and would best be made in quantity and kept on hand. For preparing them see formula and table, p. Io.

8. Slides and cover-glasses should always be thoroughly cleaned. This is especially necessary for paraffin sections. Sections cannot be fastened permanently to a soiled or oily slide. New slides need cleaning as well as old ones.

The following slide-cleaning fluid may be used with excellent results :

Potassium bichromate, $25 \mathrm{~g}$.

Sulphuric acid, $25 \mathrm{cc}$.

Distilled water, $200 \mathrm{cc}$.

First dissolve the bichromate in the water and then add the acid.

This fluid used in sufficient quantity will also clean slides which have been used for balsam mounts. Warm till the old balsam is softened, remove the cover, scrape off most of the balsam from the slide with a knife, and place both slide and cover into the fluid. After a day or so they may be simply washed well in distilled water and wiped dry with a clean cloth. 
9. In the following directions, when reference is made to another method, the Roman numerals refer to the number of the method, the capital letters refer to the formulæ, and the Arabic numerals and small letters refer to the paragraphs and divisions of paragraphs given in that method. Where no Roman numerals are cited, the references have to do with the method in which they occur. The page containing the detail referred to is also given.

Io. Method I. is given in fuller detail and with more explanatory notes than any of the methods succeeding it. The student is advised to read it over before undertaking any of the methods involving imbedding and sectioning in paraffin.

I I. Before undertaking any method, read the directions over carefully, paying special attention to the time it will take to complete it, and more particularly to the distribution of that time, so that plans may be laid accordingly. Often a series of steps, once started, must be followed without interruption, and much inconvenience may be saved by taking the precaution to know beforehand the time required between two stages at which the procedure may rest. It is also advised that the necessary reagents and vessels be prepared before beginning a method.

Since it is impossible to give rules which will cover all cases, a wide margin is provided, upon which the student may make note of such exceptions or improvements as his experience may suggest. 



\section{METHOD I.}

\section{AN ERYTHROSIN-TOLUIDIN BLUE METHOD.}

A method for the general internal morphology of the neurone, giving the granulation, "neurosomes," reticulum, and "axone hillock." It is also differential for karyokinesis in the nervous system.

\section{REAGENTS REQUIRED.}

A. Van Gehuchten's fixing fluid.-

Absolute alcohol, $60 \mathrm{cc}$.

Chloroform, $30 \mathrm{cc}$.

Glacial acetic acid, ro cc.

B. Contrast stain (alcoholic erythrosin).-

Erythrosin (Grübler's, soluble in alcohol), I g. ${ }^{2}$

70 per cent alçohol, I oo cc.

C. Stain (aqueous toluidin blue).-

Toluidin blue (Grübler's), I $\mathrm{g}$.

Distilled water, Ioo cc.

D. Differentiating fluid (O.I alum).--

Potassium alum, $0.2 \mathrm{~g}$.

Distilled water, $200 \mathrm{cc}$.

E. Clearing fluid.-

Oil of cedar wood, $25 \mathrm{cc}$.

Pure xylol, $25 \mathrm{cc}$.

F. Meyer's albumen fixative.-

White of egg (chop with scissors and filter), $50 \mathrm{cc}$.

Glycerine (pure), $50 \mathrm{cc}$.

Thymol, $0.2 \mathrm{~g}$.

G. Mounting medium.-A xylol or benzol solution of Canada balsam, or, better, gum damar. Colophonium (see II, E, p. 2 I) may be used.

I This method is a modification based upon a method devised by H. HexD, "Beiträge zur Struktur der Nervenzellen und ihre Fortsätze," Archiv fïr Anat. und Physiol., Anat. Abthl., I897.

${ }^{2} \mathrm{~g} .=$ gram. 
H. The graded alcohols.-Absolute, 95 per cent., 70 per cent., 50 per cent., 35 per cent. See formula and table, p. 2 I.

PROCEDURE.

I. To $f i x$, place ganglia or small pieces of spinal cord or brain ( $5 \mathrm{~mm}$. thick) in a quantity of Van Gehuchten's fluid (A) about twenty times the volume of the tissue for 3-12 hours. The vessel should be tightly closed during the period of fixation.

2. To wash and dehydrate, transfer the tissue direct from the fixing fluid to Io to I 5 volumes of absolute alcohol for 2-6 hours. During this period the absolute alcohol should be changed two or three times.

3. To clear, place the tissue in about 10 volumes of the clearing fluid (E), $1 / 2-2$ hours.

NoTE.-Pure xylol will do for clearing, but usually takes a longer time than the mixture. When cleared, the tissue appears slightly translucent instead of white, as when first transferred from the alcohol. In all cases it is better to remove the tissue from the action of the oils as soon as it is thoroughly cleared. The clearing may be hastened by agitating gently from time to time and by slightly warming $\left(40^{\circ} \mathrm{C}\right.$.). All the histological processes which, like dehydration, clearing, staining, etc., depend upon diffusion, may be accelerated with a rise in temperature and by an agitation of the fluid about the specimen. By means of diffusion one liquid replaces another within the tissue.

4. To imbed in paraffin.-(a) From the clearing fluid transfer the tissue to a covered watch-glass or paraffin bath-pan containing about 5 volumes of melted soft paraffin (melting point about $45^{\circ} \mathrm{C}$.) for $20-30$ minutes. The paraffin bath must have been previously prepared and raised to the melting temperature of the paraffin.

(b) Transfer from soft paraffin to an equal amount of hard paraffin (melting point about $55^{\circ} \mathrm{C}$.) for $40-60$ minutes. See to it that the melting point of the paraffin is maintained, but not exceeded.

(c) To imbed, with warmed forceps transfer the pieces of tissue to watch-glasses or (preferably) paper boxes, containing hard paraffin which is kept melted by working with watch-glasses or 
boxes placed upon the paraffin bath. Arrange the pieces in position for sectioning and

(d) Cool quickly by transferring the receptacle to ice water.

Rapid cooling prevents crystallization, and gives much more solid and satisfactory paraffin blocks than often result from slow cooling.

NotE.-Paper boxes are preferable to other means of imbedding in that (I) they can be cooled more quickly; (2) they can be made in any shape and size required; (3) they can be labeled readily; and (4) they can be stored easily. The paper should be thin and tough, and of a quality which does not shed lint. Ordinary thin linen writing paper is excellent. Make the boxes over the end of blocks of the required size and label them in pencil before removing them from the molding block. When paper boxes are used, the depression in the middle of the paraffin resulting from its contraction on cooling may be prevented by lightly pressing the upper edges of the box together as the cooling begins. Imbedded in paraffin the tissue will keep indefinitely.

5. To section.-(a) Remove the paper from the block of paraffin containing the piece of tissue required and mount the block firmly on a warmed object-carrier of the microtome, taking care that the imbedded specimen is so oriented that sections may be obtained in the required plane. Cool quickly.

(b) Trim the block down to the required size, keeping the edges parallel. The sections will ribbon much better if the block is rectangular, or at least has two of its edges parallel, and is so arranged on the microtome that these edges strike parallel to the edge of the microtome knife.

(c) Make sections 4-10 micra thick. The ribbons are laid out on a sheet of clean dry paper and there, with a sharp scalpel, cut up into lengths containing the number of sections required for mounting.

6. Fasten sections on a thoroughly cleaned slide (see general directions 8, p. 12) by the albumen water method. This method is as follows: A very thin film of Meyer's albumen fixative ( $F$ ) is rubbed onto the slide with a clean finger, and a few drops of distilled water are run over the film. Then lay the slide level and place the sections in position on the slide. Floating on the water, they may now be made to straighten out by gently 
warming the slide over a flame, care being taken to hold the slide level and not to melt the paraffin. The safest way to do this is to place the slide in the paraffin bath raised to a temperature just below the melting point of the paraffin.

When the sections are perfectly smooth, drain off the water and put aside to dry in a dry place protected from dust for 4-24 hours.

This drying process may be reduced to one hour or less by subjecting the slide to a temperature just below the melting point of the paraffin. The paraffin bath may be used. The object is to remove the water completely, so as to establish thorough cohesion of the section to the slide.

7. When dry, dissolve off the paraffin by immersing the slide in xylol for 10-20 minutes.

In the xylol and succeeding fluids it is better to stand the slide on end "face to the wall" in covered jars or wide-mouthed bottles containing enough of the fluids to rise well above the sections. Several slides may be carried through at the same time.

8. From the xylol transfer to jar containing absolute alcohol for 5-10 minutes.

The absolute alcohol removes the xylol, which is not readily miscible with the lower grades of alcohol.

9. Transfer from absolute to 95 per cent. alcohol 3-5 minutes.

IO. From 95 per cent. transfer to a jar containing the alcoholic erythrosin solution (B) for 10-15 minutes.

I I. Wash out surplus erythrosin in $\mathbf{5 0}$ per cent. alcohol for 3-5 minutes.

The sections are now a light red.

I2. To stain, rinse the slide by dipping it two or three times through distilled water and place in the toluidin blue solution (C) for about ro minutes.

I3. To decolorize and differentiate, drain off the surplus stain, and dip the slide back and forth through the O.I per cent. alum solution (D) for about 20 seconds. Then complete the 
decolorization by dipping the slide through 70 per cent. alcohol until the sections become pink with just a shade of blue, about 30 seconds.

I 4. To dehydrate, transfer to 95 per cent. alcohol for 20-30 seconds and thence to absolute alcohol for 5-10 minutes.

I 5. To clear, transfer from absolute alcohol to xylol for I5-20 minutes.

I6. To mount, remove the slide from xylol, lay it flat, place a small drop of balsam or colophonium (F) on the sections, and put on the cover-glass.

To avoid air bubbles, begin at one edge of the cover and gradually let the cover down. Handle covers with fine flatpointed forceps.

Do not allow the xylol to evaporate sufficiently for the sections to become dry before covering.

The reticulum of the cell is stained pink, the granulation blue, the neurosomes black-blue. The axone hillock is distinguished by being devoid of the larger granules. In the developing nervous system, cells in the process of karyokinesis stain more deeply blue than do the others.

An oil immersion lens is necessary to study the finer detail of the cell structure. 
>

Digitized by Microsoft $\circledast$ 


\section{METHOD II.}

\section{THE NISSL METHOD.}

A method devised especially to demonstrate the tigroid masses or Nissl bodies of the nerve cell.

\section{SPECIAL REAGENTS REQUIRED.}

A. Fixing agent.-96 per cent. alcohol. Ordinary absolute (97-98 per cent.) may be used.

B. Stain (Nissl's methylen blue).-

Methylen blue (Methylenblau B. pat.), I.3 g.

White Castile soap (Venice soap), $0.7 \mathrm{~g}$.

Distilled water, $332 \mathrm{cc}$.

C. Differentiating fluid (" aniline alcohol").-

95 per cent. alcohol, $90 \mathrm{cc}$.

Aniline oil, ro cc.

D. Clearing fluids.-

1. Cedar oil-xylol, (I, E, p. I 5).

2. Oil of cajeput (pure).

E. Mounting medium ("colophonium").-A xylol or benzol solution of "virgin rosin," a rosin nearly colorless and which is plastic at, or just above, the temperature of the hand $\left(90^{\circ} \mathrm{F}\right.$. or $32^{\circ}$ C.).

\section{PROCEDURE.}

I. To fix, place pieces of tissue (preferably $4-5 \mathrm{~mm}$. thick) into about 20 times their volume of 96 per cent. alcohol (A). The pieces must be small to get the best results from alcohol as a fixative. Tightly close the vessel and let remain for I2-24 hours.

2. To dehydrate, transfer the tissue to about 20 times its bulk of absolute alcohol for 40-60 minutes.

3. To clear, put the dehydrated tissue into 6 or 8 times its volume of cedar oil-xylol (I, E, p. I 5). Pieces of 4 or $5 \mathrm{~mm}$. 
cube usually become cleared, i. e., penetrated thoroughly by the oil, and ready for the paraffin in 30-40 minutes.

Xylol may be used alone (see I, 3, note, p. I6).

4. Imbed in paraffin, make sections 4-6 $\mu$ thick, fasten sections on the slide, and dry as directed in I, 4, 5, and 6, p. I6.

5. To stain.- (a) When dry, dissolve off paraffin in xylol, ro-20 minutes, and then transfer slide from xylol to absolute alcohol for 5-io minutes (see I, 7 and 8, p. I8).

Note. - The stain to be used in this case is a water solution. Should the sections be passed from a high grade of alcohol to a much lower one, or directly to water, the resulting diffusion currents would endanger a breaking up of the cell contents. For this reason it is necessary to pass the slide successively through the grades of alcohol of diminishing strength. Use slide jars or wide-mouthed bottles.

(b) Transfer slide from absolute to 95 per cent. alcohol, 5 minutes. From 95 per cent. transfer to 70 per cent. alcohol, 5 minutes. From 70 per cent. transfer to 50 per cent. alcohol till stain is ready.

(c) In a test-tube, heat about Io cc. of the stain (B) till it steams.

(d) Lay the slide level and pour enough of the warm stain over the sections to cover them well. Let the stain act 4-6 minutes.

6. To differentiate. - (a) Drain the slide and quickly rinse off the surplus stain by gently running distilled water over it.

(b) Wipe the back and edges of the slide dry, again lay it level, and flood with the aniline-alcohol mixture (C).

(c) Let this decolorize till the sections become a pale blue with a slight rose tint,i.e., nearly colorless. This usually occurs in from 20 to 30 seconds. During this period the sections may be observed more closely if the aniline alcohol is changed after the first few seconds.

7. To clear, quickly drain and wipe off the aniline-alcohol from the free surfaces of the slide, lay it level sections uppermost, and flood with oil of cajeput $(D, 2)$. When no cloudiness is seen on viewing the sections over a dark surface, the sections are cleared. It may be necessary to renew the oil. 
8. To mount, prepare a clean cover-glass, then drain the slide, and rinse off the surplus oil by merely dipping it into xylol; lay flat, place a small drop of colophonium (E) on the sections, and put on the cover, avoiding the formation of air bubbles. The rinsing in xylol may be omitted.

Two or three slides may be carried along simultaneously. But if it is necessary to make quite a number of preparations, it will both save time and be more economic with the fluids to have the stain, the aniline-alcohol, and the cajeput oil in jars of suitable size. The stain may be kept warm by working with the jar upon a paraffin bath, e.g., raised to about $90^{\circ} \mathrm{C}$. . 


\section{METHOD III.}

\section{THE BETHE METHOD.}

A special method for the differentiation of the neurofibrillæ and "Golgi net." As here given, the method is applicable to vertebrate nervous tissue.

\section{SPECIAL REAGENTS REQUIRED.}

A. The fixing fluid ( 5 per cent nitric acid).-

Nitric acid (C. P. concentrated), $5 \mathrm{cc}$.

Distilled water, I oo cc.

B. Hardening reagent.-

96 per cent. alcohol, $600 \mathrm{cc}$.

C. Developing fluid (ammoniated alcohol).-

Ammonia (C. P. concentrated, sp. G. 95), $8 \mathrm{cc}$.

Distilled water, $24 \mathrm{cc}$.

96 per cent. alcohol, $64 \mathrm{cc}$.

D. Developing fluid (hydrochloric acid-alcohol).-

Distilled water, $24 \mathrm{cc}$.

Hydrochloric acid (C. P. concentrated). $8 \mathrm{cc}$.

96 per cent. alcohol, $80 \mathrm{cc}$.

E. Molybdating fuid ( 4 per cent. ammonium molybdate).-

Ammonium molybdate, $4 \mathrm{~g}$.

Distilled water, roo cc.

F. The stain (aqueous toluidin blue).-

Toluidin blue, $0.1 \mathrm{~g}$.

Distilled water, $300 \mathrm{cc}$.

'A. Bethe, "Das Molybdänverfahren zur Darstellung der Neurofibrillen und Golginetze im Centralnervensystem." Zeitschrift für wiss. Mikroskopie, Bd. XVII, H. I, May, I900. The procedure given varies very little from that published by Bethe. The method is tedious, and in some of its steps seems to be unnecessarily so, but the few efforts made in this laboratory to shorten or simplify it have proved unsatisfactory. For the possible chemical action of the various reagents the student is referred to Bethe's discussion of the method. Also see the original paper for the application of the method to invertebrates 
This gives a solution of I part of toluidin blue to 3,000 of water. In some instances it has been found necessary to use a still weaker solution.

PROCEDURE.

I. To fix, place pieces of fresh nervous tissue (4-10 $\mathrm{mm}$. thick) in $30-40$ volumes of the 5 per cent. nitric acid solution (A) for 24 hours.

During this period the temperature of the fluid should not rise above $20^{\circ} \mathrm{C}$. There have been trials in which even a lower temperature $\left(15^{\circ} \mathrm{C}\right.$.) was thought to produce better results for neurofibrillæ. In hot weather a weaker solution of the acid ( 3 per cent.) is recommended.

It is essential that the fixing fluid act equally upon the tissue from all sides. To insure this, it is best to lay the pieces on a layer of filter paper and also to turn them over from time to time.

If it is only desired to demonstrate the neurofibrillæ, the spinal cord is suggested as containing cells rich in fibrillæ. The fresh spinal cord of the dog is good material.

At the end of the period of fixation the pieces should be of a light yellow color.

2. To harden and wash, transfer direct from the nitric acid solution to 20-30 volumes of 96 per cent. alcohol (B) for 12-24 hours.

3. Development with ammonia.-Replace 96 per cent. alcohol with an equal amount of the ammoniated alcohol (C) for 12-24 hours.

Here also the temperature must not exceed $20^{\circ} \mathrm{C}$.

The pieces become a dark yellow. If a black-brown color is produced, the indication is that nitrates have been formed in the tissue in excess. Either the nitric solution was too strong or the temperature too high during the action of the acid or of the ammonia.

4. To wash, transfer the tissue again to 96 per cent. alcohol for 6-I2 hours.

5. Development with hydrochloric acid.-Transfer to 20-30 volumes of the alcoholic hydrochloric acid solution (D) and, as 
before, keep the fluid at or below a temperature of $20^{\circ} \mathrm{C}$. for 6-12 hours.

The tissue again becomes a light yellow or almost white.

6. Again place in 96 per cent. alcohol for 10-12 hours.

7. The tissue is now washed in a copious amount of distilled water for $2-6$ hours.

This step is inconsistent with the ordinary procedure. It may be that the tissue is now so thoroughly hardened and the elements so held in place by the various precipitates that it is not injured by the action between the 96 per cent. alcohol and the water.

8. Molybdating. - Replace the water with $30-40$ volumes of the ammonium molybdate solution (E) for 24 hours. During this period it is 'recommended that a temperature even lower than before be maintained (I0-I $5^{\circ}$ C.).

A perceptible white precipitate is formed.

9. Wash the pieces for 3-4 minutes in distilled water and transfer again to $30-40$ volumes of 96 per cent. alcohol for 6-10 hours.

Io. Complete the dehydration in 20-30 volumes of absolute alcohol for IO-I2 hours.

The penetration of the alcohol and the infiltration of the clearing oil and imbedding media to follow occur more slowly than in case of tissues prepared in the ordinary way, and consequently the tissue must be allowed more than the ordinary time in each:

I I. Clear in about Io volumes of xylol or toluol slightly warmed ( $40^{\circ}$ C.), and occasionally agitated (see I, 3 , note, p. I6) for $\mathbf{3}-\mathbf{5}$ hours. It may be necessary to renew the clearing oil.

I2. Imbed in paraffin (celloidin will not do!).

(a) Transfer from clearing oil to melted soft paraffin (I, 4, p. I6) for about 40 minutes.

(b) Transfer to melted hard paraffin for $\mathbf{r}$ hour.

(c) Imbed in labeled paper boxes and cool as directed in I, 4, $(c),(d)$, note, P I 7 
I3. Sections ro micra in thickness afford the best pictures. Arrange the block of paraffin and the microtome knife as directed in $I, 5$, and make serial sections, transverse in case of spinal cord or vertical in case of the cerebral cortex. Save the first sections from the block. Quite often these are better than those from farther in the piece of tissue from the fact of having been exposed to the more immediate and perfect action of the fluids.

I4. Fasten the sections on the slide by the "dry method": Rub a very thin film of Meyer's albumen fixative ( $I, F$, p. I 5) on the slide, lay the sections in position, brush them out flat with a camel's hair brush, and press them down firmly with a clean finger. The use of water for straightening them out, as in I, 6, impairs the staining properties of the sections.

Prepare several slides with a number of sections on each.

I 5. To stain and differentiate.- (a) Remove the paraffin from the sections by immersing the slide in xylol for Io minutes.

(b) Transfer to absolute alcohol for about io minutes, and then pass rapidly through the decreasing grades of alcohol $(\mathrm{I}, \mathrm{H}$, p. I6), I-2 minutes in each, down to distilled water, in which it should remain about 2 minutes, or only long enough to remove the alcohol.

(c) Remove the slide from the water and dry its edges and under side with a cloth. Lay it level, preferably across the edges of a small, thin-walled stender dish, and with a pipette carefully run a layer of distilled water over the sections. The dry edges permit a film of water $\mathrm{r}-2 \mathrm{~mm}$. thick. Then the slide with the water on it is placed immediately in a thermostat or stove, previously raised to a temperature of 55 or $60^{\circ} \mathrm{C}$., for 3-Io minutes.

The optimum time in the thermostat varies for different pieces of tissue, and must be determined by experiment. Usually 6-8 minutes produces good results. The warm water is thought to remove the excess of molybdate compounds, and too much may be extracted.

(d) To stain, pour off the warm water, rinse by merely dipping the slide two or three times through fresh distilled water, 
and again wipe the under side and edges dry. Then again lay the slide level and flood as above with a layer of the toluidin blue solution ( $F$ ), and again place in the thermostat (same temperature) for Io-I2 minutes.

(e) To decolorize and differentiate: Drain off the warm stain, quickly rinse off the surplus by merely dipping through distilled water, and then transfer the slide to a vessel of 96 per cent. alcohol till the color is no longer given off. This will take anywhere from 2 to 8 minutes.

The sections should now appear a light reddish violet or lilac. If they appear a deep or murky blue, further attempts to differentiate will avail little toward improving the preparation. On the other hand, if, at the end of 2 minutes, the sections are pale blue and do not show the violet color, shortening the time of differentiation avails little.

I6. To dehydrate, transfer the slide from the differentiating 96 per cent. alcohol to fresh absolute alcohol for ro minutes.

I7. To clear, transfer from absolute alcohol to a covered vessel of pure fresh xylol for I5-20 minutes.

It is essential that the xylol be free from water or alcohol. Clouds should not be produced as the slide is placed in the xylol. It is better to have special jars of absolute alcohol and xylol for this part of the process.

I8. Mount in xylol balsam (I, G) or colophonium (II, E, p. 21 ).

The neurofibrils can be observed in detail only with an oil immersion lens and with good light.

Even if the previous steps have been carefully and correctly followed, failures may often result from unfortunate manipulation in the staining and differentiation in step 15 . The most favorable duration of the action of the water in the thermostat and the optimum strength and duration of the stain must necessarily be determined by some experimentation. The two seem to be interdependent to some extent. The action of the water, which Bethe calls "differentiation," is thought to extract a certain amount of the molybdate remaining in the tissue either free 
or in loose chemical combination, and the subsequent treatment is modified by the amount of this extraction. For sections from the same block even the propitious moments are found more or less by chance.

In sections which appear pale blue with very little or no violet at the end of 2 minutes in the 96 per cent. alcohol, the staining may be improved to some extent by using either a weak solution ( 2 per cent.) of ammonium molybdate instead of the water as in step $15(c)$, or by using a stronger solution of the toluidin blue. But results obtained from such material are generally poor.

Cells rich in fibrillæ take longer in differentiating than cells poor in fibrillæ. For this reason sections of the spinal cord take longer than sections from the cerebral cortex, for example.

Mount slides enough to allow considerable experimentation. 


\title{
METHOD IV.
}

\section{APÁTHY'S AFTERGILDING GOLD CHLORIDE METHOD. ${ }^{x}$}

An application of gold chloride to sections of material previously fixed. A method for the neurofibrillæ and also adaptable to the study of nerve terminations and the general internal morphology of the neurone.

SPECIAL REAGENTS REQUIRED.

A. Fixing fluid.-

\author{
Sodium chloride, $0.25 \mathrm{~g}$. \\ Distilled water, $50 \mathrm{cc}$. \\ Corrosive sublimate $\left(\mathrm{Hg} \mathrm{Cl} \mathrm{Cl}_{2}\right), 3 \mathrm{~g}$. \\ I per cent. osmic acid, $50 \mathrm{cc}$.
}

NotE.- Mix in the order given. The corrosive sublimate would best be dissolved before the osmic acid is added. The osmic acid solution is generally kept in stock. Osmic acid is sold in sealed glass tubes containing a stated weight of the crystals. Owing to the great readiness with which it becomes reduced in the presence of impurities, great care must be taken in making solutions. Clean the sealed tube thoroughly, finally rinsing in distilled water, place in a clean bottle, add the required amount of distilled water and crush the tube with a clean glass rod.

B. Washing fluid.--

Potassium iodide, I g.

Distilled water, roo cc.

Iodine, $0.5 \mathrm{~g}$.

C. Impregnating fuid (I per cent. gold chloride).-

Gold chloride (aurum chloratum fuscum or flavum), $\mathrm{g}$.

Distilled water, $100 \mathrm{cc}$.

D. Reducing fluid (I per cent formic acid).-

Formic acid (pure), 6 cc.

Distilled water, $600 \mathrm{cc}$.

"Stefan Apáthy, "Das leitende Element des Nervensystems und seine Beziehungen zu den Zellen," Mitth. Zool. Station Neapel, Bd. XII, I897. See also APÁтHY, Zeitschrift für wiss. Mikroskopie, Bd. XV, H. I, I898. 
E. Mounting medium (glycerine jelly), Kaiser's formula.Finest French gelatin, $5 \mathrm{~g}$.

Distilled water, $30 \mathrm{cc}$.

Put the gelatin in the water and set aside for two hours or more in a covered vessel.

Then add pure glycerine, $35 \mathrm{cc}$.

and pure carbolic acid, $0.5 \mathrm{~g}$.

Warm the mixture (about $70 \mathrm{C}$.) for I 5-20 minutes and stir till the whitish flakes produced by the carbolic acid have all disappeared. Then, while warm, filter. carefully. Fine-spun glass, wet in warm water and placed in the neck of the funnel, may be used for filtering. The carbolic acid is added as a preservative. An equal amount of thymol may be used instead. In mounting, the glycerine jelly must first be warmed till melted, then it may be used after the manner of balsam (I, I6, p. I9).

\section{PROCEDURE.}

I. To fix, place sections of fresh spinal cord, 2-4 millimeters thick, or small pieces of tissue such as ganglia, or pieces of tissue containing sense organs, in 20-30 times their volume of the osmic acid-sublimate solution (A) for 24 hours. This, and the succeeding process up to the point of imbedding in paraffin, is carried on in the dark. A cool thermostat or specially prepared dark-box may be used. A good dark-box may be made of an ordinary tight wooden box with a closely fitting hinged cover or door. The inside of the box should be painted black.

2. To wash, remove the tissue from the fixing fluid, rinse well with distilled water, and transfer to I 5-20 volumes of the iodine solution (B) for ro-r2 hours.

If, during the washing period, the fluid becomes decolorized, renew it.

The iodine solution, by forming the more soluble iodide, frees the tissue of products which otherwise cause crystals in the preparations, brittleness, and imperfect staining.

The time necessary for washing may be very much reduced by treating the sections on the slide with the iodine solution instead of the tissue in bulk, but neglect to wash out before the process of imbedding sometimes gives rise to serious artefacts. 
The dehydrating, clearing, and imbedding should be done as quickly as possible.

3. Dehydrate by transferring the pieces from the washing fluid to IO-I 2 volumes of 70 per cent. alcohol for 15 minutes.

Replace 70 per cent. with 95 per cent. alcohol, 20 minutes.

Replace 95 per cent. with an equal volume of absolute alcohol for 30-40 minutes.

Agitate frequently in each grade.

4. Clear with chloroform. The small pieces of tissue should remain in IO-I 5 volumes of chloroform for 30-50 minutes. Usually the tissue is cleared soon after it sinks to the bottom of the vessel.

5. Imbed in paraffin. (a) Transfer from pure chloroform to 4-5 volumes of a mixture of equal parts chloroform and hard paraffin (melting point about $58^{\circ} \mathrm{C}$.) for $20-30$ minutes.

(b) The tissue may now be removed from the dark-box and transferred to melted hard paraffin in the paraffin bath-pan, where it must remain 30-40 minutes.

(c) Imbed and cool paraffin as in $I, 4,(c)$ and $(d)$, p. I6.

6. Make sections ro-15 $\mu$ or thinner, according to the tissue and the object in view. For the study of neurofibrils in large nerve-cells the sections should be thick. For section-cutting see I, 5, p. I 7 .

7. Fasten sections to the slide by the albumen water method (I, 6, p. I7). Use as little albumen fixative as possible, since the film has a tendency to stain.

8. Dissolve off paraffin by placing the slide in chloroform for Io-15 minutes.

9. Transfer from chloroform to absolute alcohol for io minutes.

I0. From absolute alcohol the slides are passed successively through the decreasing grades of alcohol (95 per cent., 7o per cent., and 50 per cent.), about 3 minutes in each, down to distilled water. In the water it is recommended that the slides either remain for at least 6 hours, or that they be simply well rinsed ( 2 or 3 minutes) in the water. 
I I. In either case transfer them from water to the I per cent. formic acid solution (D) for about 2 minutes.

I2. Rinse by dipping each slide several times through fresh distilled water and then,

I 3. To impregnate, immerse the slides in a vessel of the I per cent. gold chloride solution (C) for 24 hours.

Avoid direct sunlight during this period.

I 4. To reduce, rinse off surplus gold chloride by simply dipping each slide into distilled water and transfer to a copious amount of the I per cent. formic acid solution (D), and expose to continuous sunlight till sufficient reduction of the gold has taken place. This usually occurs in from 4 to 8 hours. The sections assume a rich purple color.

The following precautions are urged as essential to the attainment of the best results: (I) The period of sunlight should be unbroken. (2) The light should be as bright, and at the same time the temperature as low, as possible, or not above $20^{\circ} \mathrm{C}$. In winter the vessels may be placed in direct sunlight on a window sill in a cool part of the room. In summer direct sunlight must be avoided or artificial means of maintaining a low temperature be employed. (3) The illumination must be as uniform as possible. To insure this it is advised that sheets of white paper be placed under the vessels and, as reflectors, also on the side opposite the light. (4) In order to prevent the collection of falling precipitates on the sections, the slides must be placed in a sloping position with the sections on the under side. Stoppered tubes are suggested for this purpose, one for each slide. These may be inclined at any angle. (5) If the formic acid solution becomes colored, it should be renewed.

(6) During the reduction, the preparations should be jarred or moved about as little as possible.

I 5. To mount. After reduction, rinse a few minutes in distilled water and mount directly in glycerine or glycerine jelly (E). Warm the jelly before using.

Or, equally well, the sections may be dehydrated by passing them successively through the increasing grades of alcohol (50 
per cent., 70 per cent., 95 per cent.), 3 or 4 minutes in each, up to absolute alcohol, where they should remain for Io minutes:

They are then cleared in chloroform for IO-I 5 minutes and mounted in balsam as in I, I6, p. I 9 .

After reduction and washing, the sections will permit of counterstaining, if desired. An immersion of 10-20 minutes in a I per cent. aqueous solution of safranin is recommended for this purpose. Often it is best not to counterstain. Neurofibrillæ are more distinct without it.

If successful, the nerve-fibrils of the cell or terminal branches of the axone appear dark violet to black; other structures, pink to purple.

Among vertebrates, the cells of the spinal cord of the calf and the large cells in the spinal cord of the goose fish (Lophius) are especially recommended.

For invertebrates, Apáthy recommends fixing the fresh tissue for 6-I 2 hours in the simple saturated aqueous solution of corrosive sublimate.

Corrosive sublimate $\left(\mathrm{Hg} \mathrm{Cl}_{2}\right), 6 \mathrm{~g}$.

Distilled water, $100 \mathrm{cc}$.

Heat till dissolved and let cool before using. Then the tissue is washed out with the iodine solution (B). This and the succeeding treatment are the same as for vertebrates.

Apáthy obtained some of his best results on the medicinal leech (Hirudo medicinalis). 
Digitized by Microsoft $\circledast$ 


\section{METHOD V. \\ KUPFFER'S METHOD.}

A method for the study of the medullated axone - the myelin sheath, the axis cylinder, nodes of Ranvier, etc.

\section{SPECIAL REAGENTS REQUIRED.}

A. Fixing agent ( 0.5 per cent, osmic acid).-

Osmic acid crystals (in sealed tube), $0.5 \mathrm{~g}$.

Pure distilled water, soo cc.

The bottle must be chemically clean. For directions as to making osmic acid solutions see IV, A, note, p. 3I. A stronger solution may be reduced by adding the necessary amount of distilled water.

B. Stain (saturated aqueous acid fuchsin).-

Fuchsin S (Säurefuchsin, Grübler), I.5 g.

Distilled water, I $00 \mathrm{cc}$.

\section{PROCEDURE.}

I. To fix.-Carefully lay bare a small nerve and, without stretching, gently force under it the end of a strip of cardboard about $1 / 2$ inch wide. Cut so that the resulting piece of nerve will be 2 or 3 millimeters longer than the cardboard is wide. The nerve will adhere to the cardboard, and thus, when cut at each side, a piece is obtained held straight, but, at the same time, under very nearly its normal tension. The end of the cardboard holding the bit of nerve is then clipped off into a clean vial containing IO-I $5 \mathrm{cc}$. of the 0.5 per cent. osmic acid solution (A), and allowed to remain in the fluid for 4-24 hours.

The nerve should be quite small to insure the best penetration of the osmic acid. The spinal nerve-roots afford an opportunity to get nerve-bundles of good penetrable size, and also those from the lumbar region can be easily removed, since they lie free in the vertébral canal. 
During the period of fixation the tissue should be kept in the dark.

2. To wash.-Remove the now blackened pieces of nerve from the cardboard, with scissors clip off the bent and ragged ends, and wash in several changes of distilled water for 4-12 hours.

3. To harden, replace the water with 70 per cent. alcohol for 15-20 minutes, and then replace 70 per cent. with 95 per cent. alcohol for 12-24 hours.

4. Stain in toto.-Replace 95 per cent. with 70 per cent. alcohol for Io minutes, and then transfer to IO-I $5 \mathrm{cc}$. of the aqueous fuchsin solution (B) for 12-24 hours.

5. Wash in $\mathbf{7 0}$ per cent. alcohol for ro-15 minutes.

6. To complete the washing and to dehydrate, transfer the pieces of nerve to 20-30 volumes of absolute alcohol and let remain for 2 or 3 days.

7. Clear and imbed in paraffin as quickly as possible (for detail see I, 3 and 4 , p. 16).

(a) Clear in about 20 volumes of fresh xylol for 20-25 minutes.

(b) Transfer to melted soft paraffin for about 15 minutes.

(c) Melted hard paraffin for 20-30 minutes.

(d) Imbed and cool as directed in I, 4, (c) and (d), p. I6. The proper orientation is of great importance, since the appearances obtained depend much upon the plane at which the specimens are cut. Place the pieces of nerve in the paper box of melted hard paraffin, laying same across and at right angles to others, so that both transverse and longitudinal sections may be obtained at the same stroke of the knife.

8. Make sections about 6 micra or less. (See I, 5, p. I 7.)

9. Fasten sections to the slide by the water method (I, 6, p. I7).

Io. When dry, dissolve off the paraffin by immersing the slide in xylol for ro-r5 minutes. Then lay the slide level, put a small drop of balsam on the sections, and put on the coverglass (I, I6, P. I9). 
The myelin sheaths are colored black. In longitudinal sections the axone or axis cylinder shows red fibrils more or less parallel, distributed in the axial space and imbedded in the colorless neuroplasm. In transverse sections the fibrils appear as dots. Due to imperfect fixation or to shrinkage otherwise produced, some fibers will show the contents of the axial space fused into a more deeply stained central mass, sometimes stellate in form.

The clefts of the segments of Lantermann may be observed in longitudinal section of the sheath.

The sheath is blackened by a reduction product of the osmic acid. 
Digitized by Microsoft $\circledast$ 


\section{METHOD VI.}

\section{A SILVER NITRATE METHOD.}

A method applied to the fresh nerve-fiber to demonstrate the so-called "cross of Ranvier" and "Frommann's lines" and the neurilemma.

SPECIAL REAGENT REQUIRED.

An aqueous 0.75 per cent silver nitrate solution.

Silver nitrate crystals, I.5 g.

Distilled water, $200 \mathrm{cc}$.

The bottle should be chemically clean, and the solution keeps better in the dark.

\section{PROCEDURE.}

I. Remove pieces of small nerve or better, spinal nerveroots, using cardboard as directed in V, I, p. 37. Place the pieces thus prepared in a vial containing about 20 volumes of the 0.75 per cent silver nitrate solution. Place the vial in the dark and let remain for $\mathbf{1 2 - 2 4}$ hours.

The spinal nerve-roots are better than other parts of the nerve for the subsequent teasing process, from the fact that their perineural sheaths of connective tissue are much thinner.

2. Remove a piece of nerve from the cardboard, rinse by merely dipping into distilled water, and transfer it to a drop of pure glycerine on the slide.

Under a dissecting lens, with fine teasing needles tease the fibers apart thoroughly and put on the cover-glass.

The teasing can be best done over a black surface. To avoid the tangle of the fibers, which often results, it is better to leave one end of the shred of nerve intact. With one needle, hold the piece down by this end, and with the other needle the fibers are gently frayed apart. Use only small shreds for this final teasing. The ordinary nerve-root may be split into enough pieces for several mounts. 
3. Expose the teased and covered preparations to the sunlight for about $\mathrm{x} / 2$ hour, or until the "crosses" begin to appear.

4. The preparations may be made permanent by mounting in glycerine jelly (IV, E) or by sealing down the cover-glass with "gold size" or any of the cements specially prepared for coverglasses.

MODIFICATIONS.

I. If in haste, fairly good demonstrations may be obtained by teasing a small shred of flesh nerve in a few drops of the silver nitrate solution on the slide, and, after 20-30 minutes, replacing the silver solution with glycerine, covering and exposing to sunlight as before.

2. Sections.-Pieces of nerve which have been in the silver nitrate solution I 2-24 hours may be dehydrated by passing through the increasing grades of alcohol (50 per cent., 70 per cent., 95 per cent., and absolute), remaining $15-20$ minutes in each, then cleared in 10-1 5 volumes of xylol for 20-30 minutes, and imbedded in paraffin as in $\mathrm{V}, 7, \mathrm{p} .38$.

Make longitudinal sections about 15 micra thick. Fasten section to the slide, dissolve off the paraffin with xylol, and mount in balsam as in $\mathrm{V}$, Io, p. 38 .

If by now the reduction of the silver is not complete, expose slides to diffuse sunlight for an hour or so. 


\section{METHOD VII.}

\section{THE INTRA VITAM METHYLEN-BLUE METHOD.}

Applications of methylen-blue to the fresh tissue for the external morphology of the neurone and to demonstrate the course and termination of the axone. Especially suited for the architecture of peripheral ganglia and muscle nerve terminations, but may be applied to the central nervous system.

SPECIAL REAGENTS REQUIRED.
A. Physiological (normal) salt solution.-
Sodium chloride, $3 \mathrm{~g}$.
Distilled water, $400 \mathrm{cc}$.
B. The stain (I per cent. methylen-blue).--
Methylen-blue (rectificiert nach Ehrlich, Grübler), $2 \mathrm{~g}$.
Physiological salt solution (A), $200 \mathrm{cc}$.

Warm the mixture till it steams, shake well, let cool, and filter.

Several brands of methylen-blue have been suggested by different authors. The above, however, is that most generally recommended.

C. Fixing fluids.-

I. Saturated aqueous solution of ammonium picrate.-

Ammonium picrate (pure), $2 \mathrm{~g}$.

Distilled water, $200 \mathrm{cc}$.

Let undissolved picrate settle, and decant the fluid when needed.

2. Bethe's fixing fluid.-

Ammonium molybdate, $2 \mathrm{~g}$.

Distilled water, $40 \mathrm{cc}$.

Hydrochloric acid (C. P. conc.), 2 drops.

Place on ice before using.

D. Preserving and mounting medium.-

Saturated ammonium picrate (C, I), $50 \mathrm{cc}$.

Pure glycerine (acid-free), $50 \mathrm{cc}$.

x The following applications of methylen-blue are based upon methods pursued by Ehrlich, Bethe, Dogiel, and Huber. 


\section{PROCEDURE.}

Since it has been found that the tissues need not necessarily be actually living, but need only be fresh to insure the best action of the stain, two methods for bringing the stain in contact with the nerve elements are now in common use: (I) by injection of the stain through the blood vessels into the fresh tissue; (2) by immersing small pieces of the fresh tissue in a limited quantity of the methylen-blue solution.

\section{BY INJECTION.}

I. As soon as the animal is chloroformed, insert and tie a canula in the main artery supplying the part containing the nervous elements which it is required to stain, and with a syringe or gravity apparatus inject the vessels full of the I per cent. methylen-blue solution (B), taking care not to add pressure sufficient to burst them. The part should assume a decidedly blue color. If a syringe is used, leave it attached. Let the stain diffuse through the walls of the blood vessels for an interval of Io or I 5 minutes, then inject more stain, and let the part remain undisturbed for about 30 minutes.

If a gravity apparatus is used, it may remain in connection with the part for 30-40 minutes, thus keeping the blood vessels distended with the stain solution.

If the animal is small, it is best to inject the whole body through the carotid artery or the abdominal aorta, using a $T$-shaped canula if necessary.

2. To develop.-After the part has remained subjected to the undisturbed action of the stain for 30-40 minutes, small pieces (2-3 $\mathrm{mm}$. thick or less), containing the nerve elements desired, are removed and exposed to the air on slides wet with physiological salt solution. The pieces may be gently spread out with teasing needles. Exposure to the air (probably due to ammonia) seems to facilitate the selective staining of the nervous elements by the methylen-blue. The tissues must remain exposed to the air on the slide and, uncovered, must be examined under the microscope every 2 or 3 minutes until the nerve-cells, axones, or 
nerve terminations, as the case may be, show a satisfactory blue color not possessed by the other tissues. Care must be taken to catch the stage at which the stain has reached its full development, for the color is very apt to soon fade or become diffuse, and thus result in inferior preparations.

3. To fix.-As soon as the stain has satisfactorily developed, plunge the pieces of tissue immediately into a vessel containing 20-30 volumes of the saturated aqueous solution of ammonium picrate $(C, I)$, and let remain for 6-24 hours. In this solution the blue color is changed to a brownish purple hue.

4. To preserve and mount.--Transfer from the aqueous picrate solution to 4 or 5 volumes of the ammonium picrate-glycerine mixture (D) for another 6-24 hours. The tissues, however, may remain in this mixture for days, or even weeks, without injury.

To mount, transfer small pieces to the slide, tease as much as examination under the microscope shows to be necessary, and mount in a fresh drop of this same ammonium picrate-glycerine mixture.

If the preparation is good, and it is desired to keep it for study or demonstration, it is safer to seal down the coverglass with zinc cement or gold size. It is sometimes suggested to mount in glycerine jelly (IV, E, p. 32) which has been saturated with ammonium picrate, but such preparations often prove less permanent than those mounted in the above mixture.

The jelly is warmed till well melted and the ammonium picrate crystals added in such an amount that, after an hour, undissolved crystals remain in the mixture, which has been kept warm and shaken from time to time.

Preparations are fixed and mounted in the ammonium picrateglycerine mixture as above, when it is desired only to study the relations of the elements to each other in their coarser detail. The general course of the axones, the general arrangement of their terminal branches in end-organs, their arrangement in nerve plexuses, or the relation of the efferent and afferent axones to the cell bodies in ganglia may, indeed, be better studied in 
teased preparations. For a more detailed study of the intimate nature of these relations, sections are required. Directions for sections will be given below.

BY IMMERSION.

Material difficult to inject, or such as failed to take the stain after injection, may be stained by a local application of the stain.

Make a O.I per cent. solution of the methylen-blue by diluting ro volumes of the I per cent. solution (B) with 90 volumes of the physiological salt solution (A.)

From a freshly killed animal remove small pieces of the tissue required and place on a slide or in a shallow watch-glass wet with physiological salt solution. Gently divide into smaller pieces of suitable size $(2-3 \mathrm{~mm}$. thick), and add a few drops of the o. I per cent. solution of the stain. At intervals of about 5 minutes add a fresh drop of the diluted stain, always keeping the tissue well moistened by the solution, but never covered by it. The pieces are thus exposed to the action of the stain and to the air at the same time.

Examine the pieces from time to time under the microscope without covering them. The length of time in which the nerve elements become satisfactorily stained by this method varies. It usually takes from one-half hour to one hour, but it may take much longer.

When examination shows that the elements are well stained, fix in the ammonium picrate solution as directed above (4), and preserve and mount in the ammonium picrate-glycerine mixture as directed in step 5 .

\section{FROZEN SECTIONS.}

When the necessary teasing would too much distort the arrangement of the nerve elements, or when it is especially desired to study a structure in situ, frozen sections are sometimes employed. Frozen sections, however, are liable to stain diffusely, and indeed seldom, if ever, give the distinct pictures obtained by the injection of the stain directly into the fresh tissues. 
The piece of tissue is wet in the physiological salt solution, is then frozen and sectioned on the freezing microtome, ${ }^{\mathrm{I}}$ and the sections are transferred to the slide, and there treated with the dilute stain and fixed according to the procedure given above for the application of the stain by immersion. The fixation must, of course, be done on the slide.

\section{PARAFFIN SECTIONS.}

When, on the other hand, it is found necessary to make a more detailed study of the relations of the elements stained intra vitam than is possible from the thicker mounts according to the above directions, a method has been devised by which the tissues may be imbedded in paraffin, and by this means sections obtained as thin as desired. A method for imbedding which gives uniform success, however, has not yet been devised, and it must be remembered that, in the necessary manipulation for imbedding, frequent failures are produced upon material which the preliminary examination may show to be excellently stained.

Preliminary to imbedding in paraffin, Bethe's fixing fluid $(C, 2)$ is prepared. Pulverize the ammonium molybdate. Heat in a flask with the required amount of distilled water till the molybdate is entirely dissolved. Then add the hydrochloric acid. A yellowish white precipitate is formed which dissolves upon shaking. Place the fluid in the vessel in which it is to be used and surround it with ice, since both at the time of its application and during the first hours of its action it must be kept at a temperature below $10^{\circ} \mathrm{C}$.

I. In the meantime the tissue to be used is stained either by injection (preferably) or by immersion, and the stain developed by exposure to the air as directed under the procedure chosen.

2. As soon as examination under the microscope shows the nerve elements satisfactorily stained, the tissue must be placed immediately in $20-30$ volumes of the cold Bethe's fixing fluid and kept in the fluid for 12-24 hours. During the first 6-8

"The Bardeen Freezing Microtome, manufactured by the Bausch \& Lomb Optical Co., is recommended. Directions as to its use may be obtained with the apparatus. 
hours the fluid with the tissue in it must be kept on ice. During the rest of the period of fixation the fixative may be allowed to assume the ordinary room temperature without injury.

3. After fixation, the tissues must be washed in distilled water for I-I $1 / 2$ hours to remove the surplus molybdate, which otherwise will produce crystals in the preparations.

4. To harden and dehydrate, the pieces are transferred from the water directly to absolute alcohol. It is necessary to hasten the dehydration as much as possible without endangering its completeness. To do this use 3 or 4 changes of absolute alcohol, 20-30 volumes at a time, and agitate the alcohol about the specimens from time to time. Pieces of tissue of 3-4 millimeters' thickness should become dehydrated in about $I$ hour.

5. Clear in 1 O-I 5 volumes of xylol for $I-I / 2$ hours.

6. Imbed in paraffin and cool paraffin block as in $I, 4,(a)$ to (d), p. 16 .

7. Make sections of the thickness desired (see I, 5, P. I 7).

8. Fasten sections to the slide by either the "albumen water method" (I, 6, p. I7) or by the "dry method" (III, I 4, p. 28).

9. Dissolve off paraffin in xylol (I, 7, p. I8) and mount directly in balsam (I, I6, p. I9), or, if desired, the sections may be counterstained in alum-carmine or alum-cochineal. To do this transfer from xylol to absolute alcohol for 5-Io minutes; then pass successively through 95 per cent., 7o per cent., and 50 per cent., about I minute in each. Transfer from 50 per cent. alcohol to the stain for about $1 / 2$ hour.

Wash off stain in 50 per cent. alcohol and dehydrate by passing up through the grades of alcohol, 70 per cent. I minute, 95 per cent. 2 minutes, absolute alcohol ro minutes. Clear in oil of bergamot or pure xylol for Io or 15 minutes and mount in balsam as before. If oil of bergamot is used, and it is better for the clearing, rinse off the surplus oil in pure xylol before mounting.

Bethe ${ }^{\text {has }}$ recommended a procedure by which the neces-

'A. Bethe, "Eine neue Methode der Methylenblaufixation," Anatomische Anzeiger, Bd. XII, p. 438, I 896. 
sity for the low temperature in fixing may be avoided. After staining and exposure to the air, the pieces of tissue are first placed for IO-I 5 minutes in the saturated aqueous solution of ammonium picrate $(\mathrm{C}, \mathrm{I})$ as a preliminary fixing fluid. Without

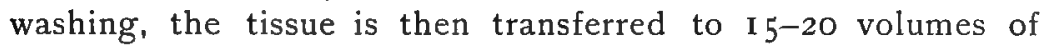
Bethe's fixing fluid $(\mathrm{C}, 2)$ for about I hour. The Bethe's fluid should acquire a temperature as low as that of the ordinary room before using, but does not need to be on ice.

After fixing, the pieces of tissue are washed in water, dehydrated, cleared, and imbedded in paraffin, as directed above.

With regard to the necessity that the tissues be fresh in order to stain by the intra vitam methylen-blue method, it is agreed by all that the fresher the tissues the better. However, Dogiel $^{\mathbf{r}}$ found that sympathetic ganglia of the human heart, as well as some of the sensory axones of that organ, may be stained by the method several hours after death.

"A. S. Dosiel, "Zur Frage über den feineren Bau der Herzganglien des Menschen und der Säugethiere," Archiv für mikros. Anat., Bd. LIII, p. 237, I898. 
Digitized by Microsoft $\circledast$ 


\section{METHOD VIII. \\ A GOLD CHLORIDE METHOD.}

Applications of gold chloride to either fresh tissue or to tissue which has been preserved in formalin. Especially devised to stain muscle-nerve terminations and peripheral plexuses.

REAGENTS REQUIRED.

A. Fixing agent (Io per cent. formalin).-

Formalin (com. 40 per cent. formaldehyde), $20 \mathrm{cc}$.

Distilled water, $200 \mathrm{cc}$.

B. Mordant and fxing agent ( 10 per cent. formic acid).-

Formic acid (C. P. conc.), Io cc.

Distilled water, go cc.

C. The stain (I per cent. gold chloride).-

Gold chloride (aurum chloratum fuscum or flavum), I g.

Distilled water, Ioo cc.

Expose fresh solutions to sunlight one hour before using.

D. Reducing agent ( 2 per cent. formic acid).-

Formic acid (C. P. conc.), 2 cc.

Distilled water, $98 \mathrm{cc}$.

PROCEDURE.

I. Fix the pieces of tissue containing the regions required in 30-40 volumes of Io per cent. formalin (A) for at least 24 hours.

The tissue may be preserved in ro per cent. formalin indefinitely and small portions be taken as occasion requires. Good preparations of muscle-nerve terminations have been obtained from material kept in formalin for two years.

The short muscles, such as the ocular or intercostal muscles, will be found best for motor endings, since the length of the muscle-fiber allows the endings to be found more readily.

2. Examine the muscle for a branch of the nerve which supplies it and clip out small pieces of the muscle ( $5 \mathrm{~mm}$. long) from 
the region at which the nerve is seen to enter it. Place the pieces in 8-IO volumes of Io per cent. formic acid (B) for about 30 minutes.

3. To impregnate.-Drain off the surplus formic acid solution and place directly in 6-8 volumes of the I per cent. gold chloride solution for 30-40 minutes. Avoid direct sunlight during this period. The tissue becomes yellow in color.

4. To reduce.- Transfer the pieces, without washing, from the gold solution to $20-30$ volumes of the 2 per cent. formic acid solution (D), and place in the dark for 24-48 hours, or until the specimens acquire a rich purple color when viewed with the unaided eye by reflected light. Muscle-fibers best adapted to show nerve terminations appear reddish violet when viewed by transmitted light under the microscope. If the fibers appear bluish purple under the microscope, the reduction has gone too far.

5. The reduction being sufficient, the tissue is washed in distilled water for about I hour, and then, if teased preparations are contemplated, the pieces are placed in glycerine. Here they may be preserved indefinitely.

6. To tease and mount, remove a small piece of the muscle from the glycerine to the slide, and under a dissecting lens carefully tease the fibers apart with needles. The teasing should not be carried too far, lest the nerve-fibers be torn from their terminations or "end plates" on the muscle, or be broken off at their entrance into the "muscle spindles." Much separation of the muscle-fibers can be accomplished by gently pressing down the cover-glass with the rounded needle handle, using a rubbing motion.

If the preparation is satisfactory when examined under a compound microscope, it may be made more permanent by replacing the glycerine with glycerine jelly (IV, E). To do this, carefully remove the cover, take up the glycerine with filter paper without disturbing the position of the muscle-fibers, put a drop of warm glycerine jelly on the preparation, put on a clean cover, press it down, and allow the jelly to solidify. The preparations keep perfectly well mounted in pure glycerine, the only 
danger being that the cover is easily moved, and thus the preparation may be lost. The cover-glass may be sealed down with any of the cements used for that purpose.

\section{SECTIONS.}

When it is desired to demonstrate only muscle-nerve terminations or certain of the nerve plexuses, teased preparations are amply sufficient, or even better than sections. However, occasions arise when it is desired to study the more intimate relations between the nerve elements and the cells upon which they terminate, or when it is found that teased preparations are difficult to obtain, as, for example, in case of sensory nerve terminations in the skin. In these cases sections are necessary. Material stained with gold chloride admits of sectioning perfectly well.

After reduction (4) and washing in distilled water (5), the pieces of tissue (any tissue) may be dehydrated by passing them through the increasing grades of alcohol (50 per cent., 70 per cent., 95 per cent.), I 5-20 minutes in each, up to absolute alcohol, where they should remain 30-40 minutes. Use 8-10 volumes of alcohol in each case. When dehydrated, clear in xylol, imbed in paraffin, section, fasten sections to, the slide, and remove the paraffin, as directed in Method I, 3 to 7 , inclusive (p. 16).

Or, equally well, after dehydration, the tissues may be transferred to 8-io volumes of ether-alcohol, imbedded in celloidin, hardened, sectioned, and the sections dehydrated, cleared, and mounted, as directed in Method X, p. 64.

In either case the sections are mounted in balsam (I, I6, p. I9).

A more rapid application of gold chloride for nerve terminations may be made by placing small pieces of the fresh tissue directly into I 5-20 volumes of Io per cent. formic acid (B) for 20-30 minutes. In this the tissue takes up water, and becomes greatly swollen and somewhat translucent.

The pieces are then placed in 6-8 volumes of the I per cent. 
gold chloride solution for I 5-20 minutes. Here they become yellow and slightly shrunken. They are then placed in the 2 per cent. formic acid solution (D) for reduction, and further treated as in 4,5 , and 6

While the use of formic acid as the first fluid seldom fails to give stained nerve terminations, the action of the acid causes the tissue elements to swell and become much distorted. When first fixed and preserved in formalin, the tissues pass through the formic acid unaltered, and consequently preparations made from formalin material are more nearly normal and trustworthy in their appearances. Again, if it is desired to imbed the material swollen by the action of formic acid, the action of the alcohol in dehydration produces a violent shrinkage which tends to increase the defects of the preparations. For these reasons formalin material is recommended, though its use may result in more frequent failures to get well-stained nerve terminations. 


\section{METHOD IX. \\ THE GOLGI METHOD.}

A method for the external morphology of the neurone, central and peripheral ; to demonstrate the shape of the cell-body, the dendrites and their "gemmules," the axone and its branchings, collaterals, and terminations. Also for neuroglia and for the non-nervous tissue elements of the organs of special sense.

I. "The rapid method."

2. Application to material preserved in ro per cent. formalin. REAGENTS REQUIRED FOR BOTH APPLICATIONS.

\section{A. Fixing fluids. -}

I. 3.5 per cent. potassium bichromate (B), $85 \mathrm{cc}$.

I per cent. osmic acid, I 5 cc.

One per cent. osmic acid is made by dissolving one gram of osmic acid $\left(\mathrm{Os}_{4}\right)$ crystals in $100 \mathrm{cc}$. of distilled water. For precautions in making the solution see IV, A, note, P. 3I,

$$
\text { 2. Io per cent. formalin (see VIII, A). }
$$

Prepare a quantity of the fluid which will be 8-I o times the volume of the tissue to be fixed.

B. Mordant ( 3.5 per cent. potassium bichromate)--

Potassium bichromate (crystals pulverized), $7 \mathrm{~g}$.

Distilled water, $200 \mathrm{cc}$.

C. Impregnating fluid ( 0.75 per cent. silver nitrate).-

Silver nitrate (crystals), $1.5 \mathrm{~g}$.

Distilled water, $200 \mathrm{cc}$.

Formic acid (conc.) I drop.

The formic acid is thought to aid in the reduction of the silver nitrate, but it may be omitted.

D. Ether-alcohol.-

Absolute alcohol, $150 \mathrm{cc}$.

Sulphuric ether (pure), I $50 \mathrm{cc}$. 
E. Imbedding media.-

I. Thin celloidin.--

Celloidin (thoroughly dried), $5 \mathrm{~g}$.

Ether-alcohol (D), I oo cc.

2. Thick celloidin.-

Celloidin (thoroughly dried), $12 \mathrm{~g}$.

Ether-alcohol (D), roo cc

\section{F. Clearing fluid.-}

Carbolic acid (melted), or creosote, $50 \mathrm{cc}$.

Oil of thyme or cedar wood, $50 \mathrm{cc}$.

Bergamot oil, $25 \mathrm{cc}$.

Pure creosote will do for clearing, but sections do not cut in it so well, nor does it mix so readily with balsam, which follows in the mounting, as when mixed with the oils.

\section{PROCEDURE.}

The modifications of the Golgi method are many and varied, and all are more or less inconstant in their results. The two here given are thought to possess the qualities of being more constant in their results, of having a more general application, and of requiring less time in their procedure.

The first given, "the rapid method," is especially adapted to foetal nervous tissue. When applied to adult nervous tissue, its failures are much more frequent.

The second modification has been found especially efficient for the central nervous system of the adult as well as for that of the older fotuses. When successful, it possesses two advantages over the first modification: (I) It obviates the necessity for fresh material whenever it is found desirable to use the method. The material may be preserved indefinitely in Io per cent. formalin, and in large quantities, from which small pieces may be taken as occasion requires. (2) It gives a much greater amount of contrast. The black-stained neurone or neuroglia cell lies in an almost white field. The material once preserved in formalin, this application is fully as rapid as the first. Wellstained cells of the spinal cord and of the cerebral cortex have been obtained by it in 48 hours after removal from the formalin. 
It must be remembered that all the elements of a piece of tissue are never blackened in the same preparation by the Golgi method. Far from being a defect, this is of great advantage. If all the elements were to stain at one time, it would be extremely difficult to discriminate one from another or to decide the extent of any one, owing to the dense interweaving of their branches.

Also it is an advantage at times that the same structures are not always brought out. In some preparations it may be the neuroglia cells almost alone; in others, the cell-body of the neurone or the axone chiefly; while in still others it may be that only the vessels are stained. The latter, however, is but too often the case.

Fœtal material, by either modification, is generally more fortunate for the peripheral ganglia or for the Purkinje cells of the cerebellum.

THE RAPID METHOD.

I. To fix.- From the chloroformed animal or from the fresh foetus carefully remove pieces of the tissue required (not thicker than $5 \mathrm{~mm}$.), place them in about 30 times their volume of the osmium-bichromate mixture (A, I), and set aside, preferably in the dark, for $\mathbf{1 2 - 2 4}$ hours.

2. Replace the fixing fluid with an equal quantity of the $\mathbf{3 . 5}$ per cent. potassium bichromate solution (B) for 3 days or more. The length of time required in this fluid is thought to vary for the different structures: neuroglia, 2-3 days; cortical cells, 3-4 days; Purkinje, spinal cord, and peripheral ganglion cells, 4-5 days; and for the nerve-fibers of the spinal cord, 5-7 days.

3. To impregnate.-Remove the surplus bichromate by placing the pieces of tissue on filter paper, then place them in a clean vessel, and agitate a small amount of the silver nitrate solution (C) about them till the brown precipitate of silver chromate no longer appears in the fluid, and then place them in about 30 times their bulk of fresh silver nitrate solution for 3 days or more.

It is thought best to keep the vessel in the dark during this 
period to prevent a too rapid reduction of the silver on the surface of the pieces of tissue.

Change the silver solution after 8-I 2 hours. The tissue may remain in the silver solution 5 or 6 days without injury.

4. To imbed in celloidin. - Sections of the tissue may be made "free-hand" with a razor and examined under the microscope to see whether the elements are stained. For permanent use microtome sections are best. The tissue should be carried through the imbedding and sectioning process and mounted as quickly as possible, since the metallic deposit, which is the nature of the impregnation, tends to break up in fluids other than the silver solution.

As a matter of caution, imbed only a few of the pieces at a time, leaving the remainder in the silver nitrate solution, lest further treatment should prove necessary.

(a) To dehydrate, transfer the dark-brown pieces from the silver solution directly to about 20 times their volume of 95 per cent. alcohol for 20 minutes. Renew the alcohol after the first five minutes and occasionally agitate.

(b) Replace the 95 per cent. with the same amount of absolute alcohol for 30 minutes.

Renew the absolute after Io minutes, agitating as before.

(c) Replace the absolute alcohol with 20-30 volumes of ether-alcohol (D) for 20 minutes.

(d) Transfer to enough thin celloidin $(E ;$ I $)$ to well cover the pieces for 25 minutes.

(e) Replace thin celloidin with thick celloidin $(\mathrm{E}, 2)$ for Io minutes.

( $f$ ) Prepare wooden or cork blocks of suitable size and such as will fit the object-carrier of the microtome. Dip the end of a block into ether-alcohol and then place upon it, in position for sectioning, one of the pieces of tissue well covered in thick celloidin. Keeping the piece in position, harden the celloidin by placing the whole in a small amount of chloroform for about ro minutes.

(g) Transfer the block from chloroform to a stender dish of the clearing fluid (F) for I 5-30 minutes. 
The pieces may remain in the clearing fluid two or three days without serious injury. It is better to section immediately.

5. To section and mount.-(a) Use a sliding microtome such as the Thoma. Set the knife obliquely, so that, in making the section, the stroke will involve two or three inches of the edge. Fasten the block in the object-carrier with the piece of tissue arranged so that its longest horizontal diameter is parallel to the edge of the knife. Keep the knife and the block flooded with the clearing fluid and make sections 50-100 micra thick. Sections can be made much thinner, but for general purposes it is best to have them thick enough to include as much of the neurone as possible and at the same time allow enough light to examine it.

In making sections of the cerebral cortex, e.g., the plane of the section should be perpendicular to the surface of the cortex or parallel to the long axis of the pyramidal cells.

The sections cut much better in clearing fluid than in alcohol, which is generally used for celloidin sections and, at the same time, they are either cleared or are clearing in the fluid preparatory to mounting. Handle the sections with a camel's hair brush. Transfer them from the knife to the slide and keep them there flooded with the clearing fluid until examination under the microscope shows them to be thoroughly cleared. Several slides of sections may be cut before any are mounted.

(b) To mount, discard such sections as examination has proved to be undesirable, arrange the remainder in position, remove the clearing oil and press the sections down to the slide by blotting them with several thicknesses of filter paper. Then with a pipette flood the sections with pure xylol for about five minutes to replace the oil in the sections, xylol being more miscible with the balsam which is to follow. Remove the xylol by again pressing several layers of filter paper over the sections and immediately place on enough thick Canada balsam or, better, colophonium (II, E, P. 2I) to make a complete layer over them, and, without using a cover-glass, lay the preparations level in a warm, dry place, free from dust, to allow the balsam to harden. 
If a cover-glass is used, the hardening of the mounting medium is much retarded, and the consequent long period of diffusion currents causes the metal deposits upon the elements to break up, and the preparation becomes worthless. The xylol may be omitted.

Sections may be mounted under a cover-glass with results which are sometimes permanent, by first applying heat to the balsam to quickly drive off the solvent oil. After covering the sections with balsam, place the slide in a thermostat at $100^{\circ} \mathrm{C}$. for about one-half hour, or carefully heat it over a bunsen flame ${ }^{x}$ for 4 or 5 minutes, and then, before the balsam cools, put on a large cover-glass and press it down to drive out the bubbles and to make the layer of hardened balsam as thin as possible. It is better to omit cover-glasses, however, except when it is necessary to study the preparations under high power.

Without the cover-glass the balsam tends to leave the sections and run out over the slide, thus requiring several renewals during the first $12-24$ hours. This may be obviated to some extent by first wiping the free surface of the slide about the sections with a cloth wet in absolute alcohol before putting on the balsam.

APPLICATION TO MATERIAL PRESERVED IN TEN PER CENT. FORMALIN.

I. Remove the brain and spinal cord, subdivide them, and place in a tightly closed vessel containing 8-ro volumes of ro per cent. formalin $(A, 2)$. In this fluid the tissues may remain indefinitely. It is not necessary to divide the nervous system into small pieces. Good results have been obtained from the cortex of an'adult human cerebral hemisphere preserved entire, and also after it had been kept in the formalin solution for more than a year. It is better, however, to divide somewhat, in order to hasten the fixation.

2. On occasion, any time after 3 or 4 days of fixation, remove small pieces of the tissue $(4-5 \mathrm{~mm}$. thick) from the regions required and place them in a vessel containing IO-20

${ }^{x}$ HUBER, Anat. Anz., Bd. VII, I8ga. 
volumes of the 3.5 per cent. potassium bichromate solution (B) for 2-5 days. Renew the fluid after the first 12 hours.

The action of the bichromate solution may be hastened by exposing the vessel to a temperature of $38-40^{\circ} \mathrm{C}$. for $\mathrm{I} 2$ hours, then renew the fluid, and set aside for a day or two.

3. Thence, for impregnation, transfer to the silver nitrate solution and further proceed to imbed, section, clear, and mount precisely as instructed for the "rapid method," 3,4 , and 5 inclusive.

\section{DOUBLE IMPREGNATION.}

The Golgi method, in any of its modifications, is frequently unsuccessful. If, after the usual time has elapsed, the preliminary examination shows that the material is not well impregnated, the pieces may be transferred from the silver nitrate solution (C) back to the potassium bichromate solution (B) and placed in the dark 2 or 3 days, when they are returned to fresh silver solution for $36-48$ hours. ${ }^{x}$ Thence proceed to imbed and section as before.

Only when the material is valuable is it advised to attempt double impregnation. Otherwise, in case of failure begin again with fresh material.

Among the more important modifications of the Golgi method, that of $\mathrm{Cox}^{2}$ should be referred to. His method gives an impregnation by the use of mercuric chloride instead of silver nitrate. Among other investigators, Strong ${ }^{3}$ and Kopsch 4 substitute formaldehyde for the osmic acid in the fixing fluid for the "rapid method." Failures to obtain good, clear preparations, however, seem to be more frequent with this use of formaldehyde.

'Ramón y CaJal, Anat, Anz.; Bd. V, I890; or Zeit. f. wiss. Mikros., Bd. VII, H. $2, \mathrm{I} 890$.

"Cox, "Imprägnation des centralen Nervensystems mit Quecksilbersalzen," Arch. f. mik. Anat., Bd. XXXVII, T. 2, 1891 .

${ }_{3}^{3}$ Strong, Anat. Anz., Bd. X, 1895. 4 KOPSCH, Anat. Anz., Bd. XI, 1896. 
Digitized by Microsoft $\circledast$ 


\section{METHOD $\mathrm{X}$.}

\section{THE IRON-HAMATOXYLIN METHOD.}

A hæmatoxylin method for nerve material preserved in formalin. Differential for the medullary sheath and also stains the nerve cell. Especially adapted to the central nervous system to show the course and occurrence of medullated fiber tracts.

\section{REAGENTS REQUIRED.}

A. Fixing agent ( 10 per cent. formalin).-

Formalin (40 per cent. formaldehyde, com.), $10 \mathrm{cc}$.

Distilled water, roo cc.

B. Mordant (4 per cent. iron alum).-

Ammonio-ferric sulphate (iron alum), $4 \mathrm{~g}$.

Distilled water, $100 \mathrm{cc}$.

C. Stain (0.5 per cent. hæmatoxylin).-

Hæmatoxylin crystals, $0.5 \mathrm{~g}$.

Distilled water, $100 \mathrm{cc}$.

D. Counterstain (aqueous orange G.).-

Orange G. (Grïbler's), $0.5 \mathrm{~g}$.

Distilled water, $100 \mathrm{cc}$.

E. Ether-alcohol, thin celloidin, and thick celloidin will be required for imbedding, and also a clearing fluid for celloidin sections. For formulæ see IX, D, E, and F, p. 55.

\section{PROCEDURE.}

I. To fix, carefully remove the fresh tissue and place in about 20 times its volume ro per cent. formalin (A). Tightly close the vessel and let remain for $\mathbf{2 - 5}$ days.

Note.-Two days is the minimal time. The tissues in bulk may remain in o per cent. formalin indefinitely, and pieces of required size may be taken from time to time as occasion demands. Tissue thus preserved will be found also available for several other methods.

The nervous system of the fœtus can more easily be 
completely removed from the tissue surrounding it after fixation in formalin. If it is desired to study the development of medullation, it is particularly important to avoid any stretching or crushing which might result from complete dissection of the fresh tissue. In case of the spinal cord, for example, simply lay it bare, clip out entire such parts of the vertebral column as contain the regions desired, and place the whole in the formalin for several hours before further dissection. To allow better penetration of the fluid it is best to complete the dissection as soon as possible without injury to the tissue.

2. Any time after $2-5$ days of fixation remove such pieces as are desired and wash out the formalin in distilled water I-4 hours.

For imbedding in celloidin the pieces may be much larger than it would be well to attempt to imbed in paraffin. The larger the piece, the longer it should remain in the various fluids preparatory to imbedding. The times given in the following directions apply to pieces not thicker than $\mathrm{I} \mathrm{cm}$.

3. To dehydrate and imbed in celloidin.-(a) Transfer from water to about io volumes of 50 per cent. alcohol for 30 minutes to I hour. (b) Replace 50 per cent. with 70 per cent. alcohol for I hour.

(c) Replace 70 per cent. with 95 per cent. alcohol for 2 hours or more.

(d) Change to Io or I 5 volumes of absolute alcohol for 4-12 hours.

(e) Change to the same amount of ether-alcohol (IX, D) for 4-12 hours.

(f) Replace ether-alcohol with thin celloidin (IX; C) for 12-24 hours.

(g) Replace thin colloidin with thick celloidin (IX, F) for 24-48 hours.

4. With a spatula or section lifter, mount the specimen in position for sectioning on a wooden or vulcanized fiber ${ }^{+}$block

${ }^{1}$ Vulcanized fiber blocks are far better for general purposes. It is often desirable to preserve the block containing the tissue, so that sections may be taken from it 
that will fit the object-carrier of the microtome, and, with the specimen well covered with thick celloidin, harden the celloidin by placing the whole in a small amount of chloroform in a covered vessel. Let remain till the celloidin is firm. This may take anywhere from 30 minutes to 2 or 3 hours, according to the size of the block of celloidin.

The block is then put into 80 per cent. alcohol, in which it may remain indefinitely.

5. To section, use a sliding microtome. Set the knife obliquely, so that, in making the section, the stroke will involve two or three inches of the edge. Fasten the block in the objectcarrier, preferably with the longest horizontal diameter of the specimen parallel to the edge of the knife, keep the block wet and the knife flooded with 70 per cent. alcohol, and make sections 20-30 micra thick.

Transfer the sections as cut to a dish of 70 per cent. alcohol. Handle the sections entirely with a camel's hair brush. With the brush wet in the alcohol each section may be easily removed from the knife with a rolling wiping motion across the knife toward the edge. The brush may be used without danger to the edge of the knife and also, in passing from the dish of alcohol to the knife, keeps the knife sufficiently flooded with the alcohol.

6. To mordant.- (a) With a pipette carefully remove the 70 per cent. alcohol from the sections and replace it with 50 per cent. alcohol for $\mathbf{5}$ minutes.

(b) Replace 50 per cent. alcohol with distilled water for

\section{5 minutes.}

(c) Then subject the sections to 25 or $30 \mathrm{cc}$. of the mordant (B) for 4-12 hours.

from time to time as needed. The preservation is necessarily done in alcohol, and the resulting extracts from wooden or cork blocks are often injurious to the staining qualities of the tissue, or at least color it. The right kind of vulcanized fiber gives no extracts, sinks in the preserving fluid, and furnishes a rigid support most desirable in sectioning the imbedded tissue. Vulcanized fiber, or "compressed fiber," as it is sometimes called, can be obtained in boards or strips of the desired thickness and may be sawn into blocks of any dimensions. The upper surface of each block may be grooved with the saw so as to hold the celloidin more firmly. 
7. To stain.-Remove the mordant and wash in several changes of distilled water for 20-30 minutes.

Then replace the water with $40-50 \mathrm{cc}$. of the stain (C) for 4-24 hours.

8. To decolorize. - Remove the stain and wash well in 2 or 3 changes of water. The sections are now a deep blue-black.

Next dilute $20-30 \mathrm{cc}$. of the mordant (B) with an equal volume of distilled water ( 2 per cent. iron alum) and place the sections in it. Use a shallow dish and work over a white surface in order to watch the decolorization better. When the gray substance of the nervous tissue becomes clearly differentiated and the white substance is a steel blue, the section is decolorized sufficiently. This usually occurs in less than 5 minutes, but may take I 5 minutes.

As soon as a section becomes sufficiently decolorized, remove it to distilled water. To stop the decolorization it is necessary that all the decolorizer be washed out. Use plenty of water, and change it whenever it becomes cloudy. Wash for at least 20 minutes.

9. If desired, the sections may now be counterstained by transferring them to I $-20 \mathrm{cc}$. of the Orange G. solution (D) for 5-10 minutes. Counterstaining is not always desirable. It gives more prominence to the nerve-cells and brings out the connective tissue investments and trabeculæ which are left unstained by the hæmatoxylin, but for the study of the medullated fibers it detracts from the clearness and brilliancy of the section.

ro. To dehydrate, clear, and mount.- (a) After counterstaining or omitting the same, wash in distilled water for 2 or 3 minutes. Then replace the water with 50 per cent. alcohol for 3-5 minutes. Replace 50 per cent. with 70 per cent. alcohol, 5 minutes; change to 95 per cent. alcohol for ro-r 5 minutes.

(b) With a section lifter carefully transfer the sections, one at a time, from the 95 per cent. alcohol to a shallow dish of the clearing fluid (IX, F, p. 56). The section, as it is placed in the fluid, will usually straighten out and become cleared thus. The sections will become cleared in 5-10 minutes. 
(c) To mount, when cleared, transfer the sections to the slide, arrange in position, remove the surplus clearing fluid by pressing several thicknesses of filter paper over them, and mount in balsam as in I, I6, p. I9.

If the filter paper is of such a quality as to shed lint upon the section, place a piece of porous tissue paper over the sections first, and then press over it the filter paper. Ordinary cigarette paper will do.

Since it is much better that the decolorizing fluid act upon the section from both sides with equal freedom, it is not practicable to fasten them to the slide. If serial sections are desired, it will be best to proceed as directed under Method XI, p. 72, for serial sections. 


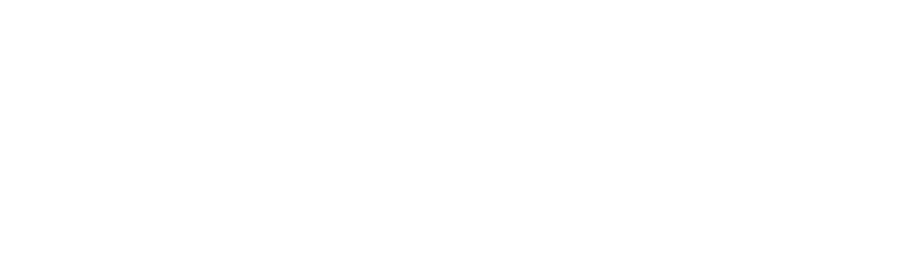

Digitized by Microsoft巴 


\section{METHOD XI.}

\section{THE WEIGERT METHOD (PAL'S MODIFICATION).}

A special method for the medullated nerve-tracts of the central nervous system. Applicable for determining both the development and extent of medullation as well as for tracing medullated nerve pathways, and hence is also adapted for the study of the course of degenerated pathways in the central system. Can be used for determining the number of medullated fibers in a pathway or nerve.

The method may be applied to material preserved in formalin.

SPECIAL REAGENTS REQUIRED.

A. Fixing agent (Müller's fluid).-

Potassium bichromate, $2.5 \mathrm{~g}$.

Sodium sulphate, I $\mathrm{g}$.

Distilled water, roo cc.

Decide upon the amount needed before making up the fluid. It keeps well.

B. Stain, Weigert's hæmatoxylin.-

Dissolve hæmatoxylin crystals, I g.

in absolute alcohol, Io cc.,

and add distilled water, go cc.,

and cold saturated aqueous solution

of lithium carbonate, I cc.

Lithium carbonate goes into solution I g. in $80 \mathrm{cc}$. of cold water. Use distilled water and make up about roo cc., since it may be needed further in the method.

C. Differentiating fluids.-

I. Potassium permanganate, $0.25 \mathrm{~g}$.

Distilled water, Ioo cc.

2. Equal parts of a I per cent. aqueous solution of oxalic acid and a I per cent. aqueous solution of acid potassium sulphite. 
While the solutions of oxalic acid and potassium sulphite are often made up in the same bottle, the mixture will be found to work better if the solutions are made separately and, when needed, mixed in equal quantities. When mixed, the liberation of sulphur dioxide should be evident.

\section{PROCEDURE.}

I. To fix and harden.- Place the material in about 5 times its volume of Muiller's fluid (A). Brains and spinal cords of the larger animals should be divided into several parts to insure a more rapid penetration of the fixing fluid. On the second and fifth days renew the fluid and put away in a closed vessel, preferably in the dark, for one month or more. This time may be reduced to 8-10 days by keeping the vessel in an incubator at a temperature of about $40^{\circ} \mathrm{C}$. In the incubator the fluid should be changed daily for 3 or $^{2} 4$ days.

The method is based upon the action of the bichromate of potassium upon the tissue. After 4 or 5 months in the fluid, the tissue may become over-hardened and will imbed with greater difficulty, and its staining properties may be impaired.

2. Having been subjected to the fluid the required time, take such pieces of the tissue as are wanted and, to remove the surplus bichromate, wash in several changes of distilled water for 2-I 2 hours. Over-hardened tissue may be greatly improved by two or three days' washing in distilled water frequently changed.

3. Transfer from the water to 8-10 volumes of 70 per cent. alcohol. Here the pieces may remain for several weeks, if desired. Too long in alcohol, however, injures the staining qualities.

4. From the 70 per cent. alcohol, proceed to dehydrate, imbed in celloidin, mount on block, and section as in $\mathrm{X}, 3,4$, and 5 , p. 64. For ordinary purposes make sections $30 \mu$ thick.

5. To stain.-In a porcelain dish or test-tube heat some of the freshly made Weigert's hæmatoxylin (B) till it begins to boil, and then let it cool to about the temperature of the body. The action of the heat serves to complete the "ripening" of the stain.

While the stain is cooling, replace the 70 per cent. alcohol in which the sections are with 50 per cent. for 5 minutes. 
Then replace 50 per cent. alcohol with distilled water.

When the stain is cool enough (too great heat will injure the celloidin sections), withdraw the water and pour the warm stain over the sections, and set aside for 6-24 hours.

The sections are now colored a deep brown-black.

6. To differentiate.-Wash the sections in several changes of tap water. This removes the surplus stain and, tap water being alkaline in reaction, converts the color into a blue-black. If found necessary, a few drops of a saturated solution of lithium carbonate (see formula B) may be added to the water to hasten the removal of the surplus stain and to produce the blue reaction. Wash out the lithium carbonate with fresh water.

The sections are now ready to be decolorized.

Place three watch-glasses or shallow dishes on a white surface. In the first pour a thin layer of the potassium permanganate solution (C, I); fill the second with distilled water and the third with the oxalic acid-potassium sulphite mixture $(\mathrm{C}, 2)$. Have handy a larger vessel of distilled water.

With section lifter and small forceps place the sections, one or two at a time, in the permanganate solution until the gray substance can be clearly distinguished from the white as a dark yellowish brown. While this usually occurs in 20-30 seconds, it may take several minutes.

Next wash in the distilled water for $2-5$ minutes, and then transfer to the oxalic acid-potassium sulphite mixture. Let remain in this till the gray substance becomes a light yellowish-brown and the white substance a light steel blue. This usually occurs in less than I minute, but for thick sections or over-hardened material it may take a longer time.

After differentiation the sections are transferred immediately to a large amount of distilled water for several minutes, and then they may be placed in tap water, in which the blue color will deepen slightly. It is essential that all the differentiating fluid be washed out. This may be accomplished in I 5-20 minutes, the water frequently changed, but it does not injure the sections to remain in water several hours. 
7. To counterstain. - The nerve-cell bodies and all the connective tissue elements are usually completly decolorized. Their position, however, may be seen without further treatment. If it is desired to bring out the cell-bodies more clearly, the sections may be transferred from the water to a small amount of Upson's carmine ${ }^{\mathrm{I}}$ for 5-Io minutes. If the object is to study the medullated fiber-tracts, it is best not to counterstain at all. For the study of developing medullation or degenerated fibertracts, the more nearly colorless the background is in which the steel-blue fibers are situated, the better.

8. After counterstaining or omitting the same, the sections are to be dehydrated, cleared, and mounted as in X, Io, p. 66.

\section{SERIAL SECTIONS.}

Before staining, the sections cannot be fastened to the slide serially, since each section must be differentiated individually and also since the differentiation takes place evenly only when the section is free, so that the differentiating fluids may act upon it equally from both sides.

When serial sections are desired, the following simple device may be employed: Prepare I 2 or I 5 shallow dishes with covers and number them in series. As the sections are cut, place them in the dishes in the order in which they come from the knife. Usually, in an organ or structure from which serial sections are necessary, each twelfth or fifteenth section will show some variation by which. it may be distinguished. If not, then after each set of fifteen sections trim or notch the celloidin block in such a way that the sections belonging to the next set can be distinguished by the contour of the celloidin about them. Make a note of the characteristic marking of each set in the order in which it is made. Thus the fifteen dishes will contain the sections in series, each dish containing sections taken at intervals of fifteen.

Then stain, differentiate, dehydrate, and clear each dish of

-Upson's carmine:-Boil 5 grams of ammonia alum and I gram of powdered carmine in $100 \mathrm{cc}$. of distilled water for 10-20 minutes. When cool, filter and to each $50 \mathrm{cc}$. add' $2 \mathrm{cc}$. of a 10 per cent. aqueous solution of phosphomolybdic acid. 
sections separately. When all are cleared, again place the dishes in series and begin to mount, arranging the sections on the slide in the order of the dishes, taking the first section from the first dish, the second from the second dish, and so on, around and back again, till all the sections have been mounted on slides which are also numbered in series.

\section{APPLICATION OF THE WEIGERT METHOD TO MATERIAL PRESERVED IN FORMALIN.}

Material fixed and preserved in 10 per cent. formalin as in Method X, I, p. 63, may be stained by the Weigert method with fairly good results and with a procedure requiring less time than the regular method. The preparations are sometimes not so brilliant, however, as by the regular process.

Remove such pieces from the formalin as are desired and place them in 8-IO volumes of Müller's fluid (A). In an incubator or thermostat, expose the vessel to a temperature of about $40^{\circ} \mathrm{C}$ for $4-8$ days, changing the fluid daily for the first 3 or 4 days. The Müller's fluid in this case serves as a mordant by virtue of the potassium bichromate in it. A $1 / 2$ per cent. solution of chromic acid may be used, but, exposed to the heat, this breaks down more readily than the Müller's fluıd. A 3.5 per cent. solution of potassium bichromate will give better results than chromic acid, but the Müller's fluid by some virtue of its formula is better than either. The method depends upon the formation in the substance of the medullary sheath of a so-called lake between the hæmatoxylin and the chrome salt.

After mordanting in the Müller's fluid, wash and proceed to imbed in celloidin, and further treat as before, beginning at step 2, p. 70 . 
Digitized by Microsoft $\circledast$ 


\section{METHOD XII. \\ MARCHI'S METHOD.}

A differential method for degenerating medullated nerve fibers. Useful for the study of the course and distribution of medullated fiber-tracts after lesions. May be applied to peripheral nerves as well as to the central nervous system. Also differential for fatty degeneration of nerve-cells and blood vessels.

\section{A. Mïller's fluid.-}

\section{REAGENTS REQUIRED.}

For formula see XI, A, p. 69. For the amount of tissue ordinarily required, make up $500 \mathrm{cc}$.

B. Differentiating fuid.-

Müller's fluid (A), 2 parts.

Prepare just before using.

I per cent. osmic acid (see IX, A, p. 55), I part.

C. Clearing fluid (carbol-xylol).-

Xylol, 3 parts.

Carbolic acid (melted by heat), I part.

Pure xylol will do, but the mixture clears more rapidly.

Various modifications of the method have been tried since its publication by Marchi in $1887,{ }^{\mathrm{I}}$ and since his late paper in I $893,{ }^{2}$ but little or no improvement has been made.

The differential action of the osmic acid results from the fact that chromic acid and its salts deprive the normal myeline sheaths of the nerve fibers of their power of reducing the osmic acid (tetroxide of osmium), while the chemically changed degenerating or abnormal sheaths retain this power. The method, therefore, gives positive black images of the fibers in a state of degeneration, while the normal fibers remain unstained, or rather are

${ }^{x}$ MARCHI, Revista sperim. di Freniatria e di Med. legale, 1887.

${ }^{2}$ Zeitschrift für wissenschaftliche Mikroskopie, Bd. IX, H. 3, I893. 
only colored a light yellow, due to the bichromate in the Müller's fluid. The other ingredients of the Müller's fluid only serve to improve its fixing properties.

A critical discussion of Marchi's method and its modifications up to that date may be found in Ergebnisse der Anatomie (Merkel and Bonnet), Bd. VII, 1897.

\section{PROCEDURE.}

I. The lesion or operation leading to the degeneration of the fibers the course of which is to be studied should take place 2-4 weeks before the animal is killed and the tissue removed for fixation. This time may vary for different species of animals. The optimum time is when the degenerative changes upon which the method depends are at their height. In human pathology it has been found that results may be obtained even after the processes of degeneration have been going on for several months.

It is not necessary that the tissues be absolutely fresh. It has even been recommended that the animal be killed and allowed to lie in a cool place 24 hours before the tissues are removed. This, however, is now considered by no means essential to the method.

2. Remove pieces of tissue (not thicker than $10 \mathrm{~mm}$.) from the required locality and place in 20-30 volumes of Müller's fluid (A), and set aside, preferably in the dark, for ro-r5 days.

Change the fluid after the first and third days. The time may be reduced to 8 days by keeping the temperature of the fluid at $35^{\circ}$ or $40^{\circ} \mathrm{C}$.

3. If the material is from the central nervous system, cut the pieces into sections not thicker than $4 \mathrm{~mm}$. (the thinner the better), and place them in IO-I 5 volumes of the osmic acid mixture (B), and keep in the dark for 4-6 days. For peripheral nerves 2-4 days in the fluid is sufficient.

Change the fluid after the first and third day. The mixture should be freshly made each time by adding the osmic acid to the Müller's fluid.

4. Wash in several changes of distilled water for 8-24 hours. 
5. Transfer from water to 70 per cent. alcohol, changed two or three times, 4-12 hours.

6. To dehydrate, transfer to 6-8 volumes of 95 per cent. alcohol for I hour.

Then replace 95 per cent. with an equal quantity of 97 per cent. alcohol (equal parts 95 per cent. and absolute) for I-2 hours.

Pure absolute alcohol had better be avoided, since the myeline of the sheaths sometimes shows indications of having been partially dissolved by it. For the same reason cedar oil or clove oil must be avoided in the clearing.

7. To clear, transfer the pieces from 97 per cent. alcohol to 8-Io volumes of the carbol-xylol (C) for I-4 hours, then place in pure xylol for $1 / 2$ hour. Pure xylol is a better vehicle for the paraffin.

8. Imbed in paraffin as in I, 4, p. I6.

9. Mount the block in position to make sections in the required plane (usually transverse to the fibers) and make thick sections - I 5-20 $\mu$.

I0. The sections may be fastened to the slide by the dry method (III, I 4, p. 28). Arrange the sections serially.

I I. To mount, dissolve off paraffin in xylol, 20-30 minutes, and mount in balsam (see I, I6, p. I9).

When cut transversely, the degenerating fibers appear as black, granular spots, while all the other structures appear as a light yellow.

If it is merely desired to follow a degenerating tract, and if that tract is large, the material may be imbedded in celloidin and sectioned as in $\mathrm{X}, 3,4$, and $5, \mathrm{p} .64$. If, however, it is desired to study the processes of degeneration, and especially if the degeneration is slight, to imbed in celloidin would involve risk, since both the ether-alcohol and the absolute alcohol equired in the celloidin method may have a dissolving effect upon the medullary sheaths.

When material from the central nervous system has been imbedded in celloidin, time and trouble may be saved in making 
the required serial sections by the following simple device ${ }^{\mathbf{x}}$ : Keep the disks of tissue in the order in which they were cut previously to placing them in the osmic acid mixture (B) and, in mounting them on the block in thick celloidin preparatory to hardening, pile the disks in their order one upon another and harden the whole as one piece. If mounting directly on the wooden block proves difficult, the pieces may be arranged in a paper box filled with thick celloidin, and the whole hardened and afterward fastened on the block for sectioning, the paper having been removed. Then section and mount serially; throw nothing away.

Results similar to those obtained by the Marchi method have been obtained from material fixed in formalin. ${ }^{2}$ Pieces of tissue $(3-5 \mathrm{~mm}$. thick) are taken from material preserved in 10 per cent. formalin (X, A, p. 63) and placed for 5-7 days in a mixture containing I gram of osmic acid, 3 grams of the iodate of sodium $\left(\mathrm{NaI}_{3}\right)$, and $300 \mathrm{cc}$. of distilled water.

The pieces may then be washed, dehydrated, and imbedded in paraffin or celloidin in the usual way.

It is claimed that sharper contrast is gained in this way than by the original method of Marchi, from the fact that the normal tissues are more colorless.

The sodium iodate must have the same effect on the medullary sheath as does the chromic salt in Marchi's method, for normal medullary sheaths fixed in formalin will blacken in osmic acid.

× A. Hoche, "Ueber secundäre Degeneration, speciell des Gowersschen Bündels, etc.," Archiv f. Psychiatrie, Bd. XXVIII, 1896.

"Buscr, Zeit.f. wiss. Mik., Bd. XV, 1899. 


\section{METHOD XIII. \\ STROEBE'S METHOD.}

A method devised for the study of the processes of both degeneration and regeneration of medullated nerve-fibers in the peripheral nervous system. May also be applied for the processes of degeneration in the central system. A good general method for sections of the spinal cord.

REAGENTS REQUIRED.

A. Fixing fluid, Müller's fluid.-For formula see XI, A, p. 69. For ordinary purposes make up about $500 \mathrm{cc}$.

B. The stain.-

Aniline blue (Grübler) I g.

Distilled water, I $00 \mathrm{cc}$.

The freshly made solution is more trustworthy.

C. Counterstain.-

Safranin (soluble in water), I g.

Distilled water, I00 cc.

Dilute with an equal volume of distilled water at the time of using.

D. Differentiating fluid.-

Absolute alcohol, I oo cc.

Caustic potash (pure), I g.

Let stand 24 hours and then filter. To use, add about 40 drops $(2 \mathrm{cc}$.) to 30 or $40 \mathrm{cc}$. of pure 95 per cent. alcohol.

PROCEDURE.

I. To fix.-Anywhere from 8 to 40 days (depending upon the animal) after the lesion or operation, remove the portion of the nervous system which includes the point of injury and place it in 20-30 volumes of Müller's fluid (A) and set aside for 8-r2 weeks. If kept in a thermostat at $38^{\circ} \mathrm{C}$., the time may be reduced to 4-6 weeks. In either case the fluid should be changed after the first and third days, and several times during the rest of the period of fixation. 
For convenience in sectioning, the piece of nerve or spinal cord should be held straightened out while fixing and hardening. This can be done by tying it at the ends to a strip of glass small enough to go into the vessel of fixing fluid.

2. Cut out the region from which sections are desired and wash in several changes of distilled water, 4-8 hours.

3. Dehydrate with alcohol, imbed in celloidin, and section as directed in $\mathrm{X}, 3,4$, and 5, p. 64. Make sections about I5 $\mu$ thick. If serial sections are desired, proceed as in XI, p. 72.

4. To stain.-Withdraw 70 per cent. alcohol from the sections and replace it with $\mathbf{5 0}$ per cent. for about $\mathbf{5}$ minutes. Then replace 50 per cent. alcohol with the aniline-blue solution (B) for 20-60 minutes.

5. To differentiate - (a) Rinse in 2 or 3 changes of distilled water for not more than 5 minutes. The sections are now a blue-black.

(b) Then transfer the sections, one at a time, to a shallow dish of 95 per cent. alcohol, to every $30 \mathrm{cc}$. of which there has been added $2 \mathrm{cc}$. of the alcoholic I per cent. caustic potash solution (D). Agitate the fluid about the section till it acquires a light brownish-red color. This usually takes from I-3 minutes.

If it takes more than 5 minutes, either the section is too thick or a few more drops of the alkaline alcohol are necessary.

6. Wash in several changes of distilled water for I0-I5 minutes.

Here the sections should become a clear bright blue. If any appear black-blue, return them to the differentiating fluid for a few minutes longer, and then wash as before.

7. To counterstain.- Place the thoroughly washed sections in a small amount of the saturated aqueous safranin solution $(c)$, to which an equal amount of distilled water has been added, for I5-30 minutes.

8. To clear and mount, quickly wash out the excess of safranin in 97 per cent. alcohol (8-10 seconds in about $50 \mathrm{cc}$. in a shallow dish), and then, to clear, place the sections in oil of origanum or carbol-xylol (XII, C, p. 75), IO- 15 minutes. 
Arrange the sections on the slide in series, remove the surplus clearing fluid with filter paper, and mount in balsam (X, Io, (c), p. 66).

The axis cylinders should appear deep blue; normal medullary sheaths, yellowish red; myelin globules of abnormal sheaths, yellow; nuclei, bluish red; cytoplasm, bright red.

For a description of the fibers in various stages of degeneration and regeneration, the literature must be consulted. Stroebe's paper of $1893^{x}$ gives a complete list of the literature up to that date, as well as a description of the appearances brought out by his method.

The method does not always succeed, and may require considerable experiment before success is attained. Differentiate and counterstain only a few sections at a time. If the material is in more than one piece, prepare one piece at the time, leaving the rest in the Müller's fluid.

xH. Stroebe, "Experimentelle Untersuchungen über Degeneration und Regeneration peripherer Nerven nach Verletzungen," Beitr. zur path. Anat. u. zur allgem. Pathol., Bd. I3, p. 160, 1893. 


\section{METHOD XIV. \\ WEIGERT'S METHOD FOR NEUROGLIA. ${ }^{x}$}

A differential stain for neuroglia, showing the relations between the neuroglia fibers and neuroglia cells. Has given best results with adult human tissue.

\section{SPECIAL REAGENTS REQUIRED.}

A. Fixing fuid ( 10 per cent. formalin).-

For preparing, see X, A, p. 63 .

B. Chrom-alum solution.-

Chrom-alum, $5 \mathrm{~g}$.

Distilled water, $200 \mathrm{cc}$.

Acetic acid (C. P. conc.), Io cc.

Neutral acetate of copper, Io g.

The alum is first added to the water, and the water raised to the boiling point. Then the acetic acid, and finally the copper acetate (pulverized) are added.

C. Potassium permanganate solution.-

Potassium permanganate, I g.

Distilled water, $300 \mathrm{cc}$.

D. Chromogen solutions.-

I. Chromogen, $5 \mathrm{~g}$.

Distilled water, roo cc.

Formic acid (conc.), 5 cc.

When the chromogen has dissolved, filter the solution and to each go cc. of the filtrate add ro cc. of a ro per cent. aqueous solution of sodium sulphite.

2. Chromogen, $5 \mathrm{~g}$.

Distilled water, $100 \mathrm{cc}$.

E. The stain.-

Methyl violet, $2 \mathrm{~g}$.

70 per cent. alcohol, $100 \mathrm{cc}$.

"C. Weigert, "Beiträge zur Kentniss der normalen menschlichen Neuroglia," Abh. Senkenb. Ges., Frankfurt a. M., Bd. XIX, 1895. The slightly modified procedure given here is taken largely from that followed by Aguerre: J. A. AGUERRE, " Menschlichen Neuroglia, etc.," Archiv für. mikros. Anat., Bd. 56, August, 1900. 
Warm the mixture, set aside to settle, and decant after cooling. Then to each $100 \mathrm{cc}$. of the methyl violet solution add $5 \mathrm{cc}$. of a 5 per cent. aqueous solution of oxalic acid.

F. Physiological salt solution ( 0.75 per cent. $\mathrm{NaCl}$.).-

Sodium chloride, C. P., I.5 g.

Distilled water, $200 \mathrm{cc}$.

G. Lugol's solution.-

Potassium iodide, $6 \mathrm{~g}$.

Distilled water, I oo cc.

Iodine, $4 \mathrm{~g}$.

H. Differentiating fluid.

Aniline oil (pure), $50 \mathrm{cc}$.

Xylol (pure), $50 \mathrm{cc}$.

\section{PROCEDURE.}

I. To fix.-Place pieces of spinal cord or cerebral cortex (human preferred) in $30-40$ volumes of Io per cent formalin (A) in a tightly closing vessel, and let remain for 4 days or more.

In the formalin, the tissues may be preserved for years without disadvantage.

2. From the formalin solution remove such pieces as are desired (not thicker than $5 \mathrm{~mm}$.), and, without washing, place them in I $5-20^{-20}$ volumes of the chrom-alum solution (B). Place the vessel in an incubator or thermostat and keep at a temperature of $38^{\circ} \mathrm{C}$. for $6-8$ days.

The chrom-alum solution must be changed after the first and third days, and better once or twice more during the period of its action.

3. Wash in 2 or 3 changes of distilled water for ro-I5 minutes.

The pieces are now a light greenish gray in color.

4. Dehydrate with graded alcohols, imbed in celloidin, and section, as in $X, 3,4$, and 5, p. 64.

Make sections of varying thicknesses. For general purposes $20 \mu$ is recommended, but often thinner sections are better.

5. Pass sections through decreasing grades of alcohol down to water $(X, 6)$, and from water transfer to the potassium permanganate solution (C) for ro minutes. 
The sections now appear brownish gray.

6. Rinse well in distilled water ( $3-5$ minutes) and transfer to a covered vessel containing 20-30 volumes of the chromogen solution (D, I) for 2-6 days.

Change the fluid after the first i 2 hours.

7. Replace chromogen solution (D, I) with I0-20 volumes of the pure chromogen solution $(\mathrm{D}, 2)$ for $12-48$ hours.

8. To stain.-Merely rinse the sections ( $\mathrm{I}-2$ minutes) in distilled water, withdraw the water, and pour over them, in a wellcovered shallow dish, 10-20 volumes of the methyl violet-oxalic acid solution $(E)$, and let the stain act for $1 / 2-2$ hours.

9. To differentiate.-(a) Rinse the sections, one at a time, quickly (about I second) in physiological salt solution ( F). To do this, have the salt solution in a shallow dish; with a needle hold the section by its celloidin margin on a section lifter, or spatula, and simply dip it through the salt solution two or three times.

Then, still holding it, transfer it immediately to Lugol's solution (G) for 2-8 seconds.

Finally plunge it into a vessel containing a copious amount of distilled water. Here it may remain for $10-15$ minutes. The sections are now a brownish black.

The time the section should remain in the Lugol's solution (iodine) can be ascertained only by experiment. The time required varies for different specimens of tissue. Complete a few sections at a time, and examine them before removing others from the stain.

(b) From the water the sections must be dried with filter paper. Place the sections, two or three at a time if desired, on a slide, place over them a piece of thin porous tissue paper, and over this several thicknesses of filter paper. With an ironing motion, press the filter paper down, changing its position till the part over the sections ceases to become moist. This not only dries the sections, but irons them out flat.

(c) Carefully remove the paper, and the sections will be left sticking to the slide. Then with fine pointed forceps grasp a 
section by its celloidin margin and carefully peel it off the slide and place it in a covered dish containing 25 or $30 \mathrm{cc}$. of the aniline-xylol mixture $(H)$. This extracts the excess of the stain. The optimum time required for this extraction varies. It may require only 15 minutes or it may take $1 / 2$ hour or more. No final test of the decolorization can be made till the section can be examined with a high-power lens.

Io. To mount.- Rinse the sections in pure xylol for a few seconds, arrange them on the slide, and mount in balsam as in I, I6, p. I 9 .

The neuroglia fibers can be satisfactorily studied only with an oil immersion lens. Much can be seen, however, with a highpower dry lens.

The nuclei of the neuroglia cells show brownish blue and neuroglia fibers appear pale blue. 


\section{METHOD XV.}

\section{MALLORY'S METHOD FOR NEUROGLIA. ${ }^{x}$}

An application of phosphotungstic acid-hæmatoxylin as a differential stain for neuroglia. A shorter method than Weigert's, with the same purpose, and giving practically the same results.

\section{SPECIAL REAGENTS REQUIRED.}

A. Fixing fluids.-

I. Io per cent. formalin (X, A, p. 63), $200 \mathrm{cc}$.

2. Saturated aqueous picric acid.

Picric acid crystals, I g.

Distilled water, $200 \mathrm{cc}$.

Warm, shake repeatedly, let cool, and decant for use.

B. 5 per cent. ammonium bichromate.-

Bichromate of ammonium, $5 \mathrm{~g}$.

Distilled water, I oo cc.

C. 0.5 per cent. potassium permanganate.-

Potassium permanganate, I g.

Distilled water, $200 \mathrm{cc}$.

D. I per cent. oxalic acid.-

Oxalic acid crystals, I $\mathrm{g}$.

Distilled water, I oo cc.

E. The stain (phosphotungstic acid-hæmatoxylin).-

Hæmatoxylin crystals, $0.2 \mathrm{~g}$.

Distilled water, I60 cc.

Phosphotungstic acid, pure (Merck), 4 g.

Distilled water, $40 \mathrm{cc}$.

Peroxide of hydrogen (U. S. P.), $0.4 \mathrm{cc}$.

First dissolve the hæmatoxylin in the $160 \mathrm{cc}$. of water, then add it to the $40 \mathrm{cc}$. of Io per cent. phosphotungstic acid also made up separately, and finally, add the hydrogen peroxide. This results in about $200 \mathrm{cc}$. of the stain. It keeps well.

×F. B. Mallory, "A Contribution to Staining Methods," Journal of Experimental Medicine, Vol, V, No. I, October, 1900. 
F. Differentiating fluid.-

Ferric chloride (pure), $30 \mathrm{~g}$. 70 per cent. alcohol, $100 \mathrm{cc}$.

G. Clearing agent.-Origanum oil (oleum origani cretici). PROCEDURE.

I. To fix.-Place pieces of central nervous system, preferably spinal cord, in 20-30 times their volume of ro per cent. formalin (A, I), for 4 days or more. Change the fluid after the first day. In the formalin solution the tissue may remain indefinitely and pieces taken when desired. Keep the vessel closed.

2. Transfer small pieces $(2-5 \mathrm{~mm}$. thick) to I 5-20 volumes of the saturated picric acid solution $(A, 2)$ and let remain for 4 or 5 days.

3. Rinse off surplus picric acid quickly in distilled water, and then place the pieces in $30-40$ volumes of the 5 per cent. ammonium bichromate (B) and keep at a temperature of about $38^{\circ} \mathrm{C}$. for 4 days.

Change the solution at the end of 24 hours to avoid the effects of precipitation.

4. Wash in distilled water, 5-ro minutes.

5. Transfer to 70 per cent. alcohol for $1 / 2$ hour.

Thence dehydrate, imbed in celloidin, and section as directed in $\mathrm{X}, 3,4$, and $5, \mathrm{p} .64$. Cut the sections as thin as the size of the piece will allow $(5-15 \mu)$.

6. Withdraw the 70 per cent. alcohol from the sections and replace it with $\mathbf{5 0}$ per cent. for $\mathbf{5}$ minutes. Then replace 50 per cent. alcohol with distilled water for 5-10 minutes.

7. Replace the water with the potassium permanganate solution (C) for I5-20 minutes.

8. Wash in distilled water, $\mathbf{I}-\mathbf{3}$ minutes.

The sections are now a dark brown.

9. Replace water with the oxalic acid solution (D) for 20-30 minutes.

This converts the color into a light brown.

Io. Wash in two or three changes of distilled water for 5-ro minutes. 
Ir. To stain, replace the water with about 20 volumes of the hæmatoxylin solution ( $E$ ), cover, and set aside for $\mathbf{2 4}$ hours.

12. To differentiate and fix the stain, rinse quickly in distilled water, one section at a time. With a needle hold the section by celloidin margin on a section lifter, and merely dip it through the water three or four times, and, still holding the section, transfer it to a dish containing the ferric chloride solution ( $F$ ). Here the sections should remain anywhere from 5-20 minutes. To determine the optimum time, expose different sections for varying lengths of time.

I3. From the ferric chloride, wash in distilled water for 5-1o minutes.

14. To clear and mount, dehydrate quickly by transferring directly to a copious amount of 95 per cent. alcohol, agitating the alcohol about the sections for 20-30 seconds.

Then to clear, transfer to a covered dish containing a small amount of origanum oil $(G)$. The clearing should take place in 5-10 minutes.

Place the section on the slide, remove the surplus oil by pressing over it several layers of tissue paper, and mount in xylol balsam.

Filter paper is avoided because it is liable to shed lint on the section. Filter paper may be-used over one thickness of tissue paper.

The above procedure should give a permanent isolated stain for neuroglia fibers. Nuclei, neuroglia fibers, and fibrin should stand out sharply in a clear blue. Everything else is decolorized or appears a pale yellowish-gray tint.

If the ferric chloride bath is omitted and the sections transferred directly from water (I2) to 95 per cent. alcohol and cleared and mounted (I4), then, in addition to nuclei, neuroglia fibers, and fibrin staining blue, the axis cylinders and nerve cells stain a pale pink, and the ordinary connective tissue a deep pink. Without the ferric chloride, however, the blue is not permanent, and for the study of neuroglia it is better if other structures are decolorized. 


\section{METHOD XVI. \\ GIACOMINI'S METHOD (MODIFIED).}

A method for making "dry preparations" of the central nervous system for museum specimens.

REAGENTS REQUIRED.

A. Saturated zinc chloride solution.-

Zinc chloride, 2,ooo g.

Water, $600 \mathrm{cc}$.

The solution is of a sirupy consistency and of high specific gravity.

B. Commercial alcohol (95 per cent.), about 5 liters.

C. Oil of turpentine, about 3 liters.

D. Ordinary "soft" paraffin, about 2 kilos.

E. Oil varnish or, preferably, shellac varnish.

Shellac varnish is a thick solution of shellac in strong alcohol.

The reagents are called for in quantities, sufficient for the preparation of the adult human encephalon. Smaller specimens will require correspondingly smaller quantities.

PROCEDURE.

I. Place the freshly removed brain (with spinal cord attached, if desired) in 2-3 times its volume of the saturated zinc chloride (A).

If possible, before removing the brain, inject about $600 \mathrm{cc}$. of the zinc chloride into it by way of the internal carotid artery. Previous injection is especially necessary, if there is reason to believe that the tissue has become soft through having been left too long after the death of the subject.

The brain will float in the fluid during the first 2 or 3 days, and must therefore be turned frequently so that the fluid may penetrate equally from all sides. To further hasten the penetration, keep the top side of the specimen covered with absorbent cotton wet in the fluid. Enough fluid must be used to well cover 
the specimen when it does sink, but any effort to hold it submerged should be avoided, lest such effort result in a distortion of its normal shape.

2. After 48 hours in the zinc chloride solution, the brain will become sufficiently hardened for the pia mater to be removed. To do this use blunt-pointed dissecting forceps and proceed carefully, avoiding injury to the surface of the gyri.

3. The pia removed, put the brain back into the zinc chloride solution for 3 or 4 days more, or for about I day after it has sunk to the bottom of the vessel.

4. To complete the hardening and to dehydrate, transfer directly to $\mathbf{I}$ or 2 volumes of commercial alcohol for 2 or 3 weeks, change the alcohol after the first and third days, and two or three times during the rest of the period. Keep the vessel closed.

The bottom of the vessel should be padded with absorbent cotton, and the brain should be turned repeatedly during the first 3 or 4 days to prevent any malformation which may result from pressure upon the bottom of the vessel.

The specimen will shrink somewhat in the alcohol, but this can hardly be avoided.

5. Replace the alcohol with enough oil of turpentine to cover the brain, and let remain for 2-4 weeks.

The more complete the dehydration by the alcohol, the better will be the penetration of the oil of turpentine.

The oil of turpentine should be changed two or three times during the first two weeks, and the vessel should be kept closed.

In the oil of turpentine the brain assumes a semi-translucent, brownish appearance.

6. Transfer from the turpentine to a vessel in a thermostat containing enough melted "soft" paraffin to cover the specimen, for 4-6 days.

The paraffin should melt at about $40^{\circ} \mathrm{C}$., and the thermostat should be kept at a temperature but a few degrees above the melting point of the paraffin, lest further shrinkage result.

7. After the brain has become well infiltrated with the 
paraffin, remove it from the vessel and, still keeping it warm, drain the surplus paraffin from out of the sulci. It may be placed on several thicknesses of filter paper in the thermostat and turned repeatedly for IO-I 5 minutes, care being taken not to press it while the paraffin is in the melted condition.

It may then be laid out to cool. When cool, it is a permanent preparation and permits of much handling, the paraffin giving it a plastic rather than a brittle consistency.

If desired, a coat of shellac or oil varnish may now be applied. This will give the preparation a more finished appearance, and also be of some protection to it.

The chief objection to this method is that it results in a considerable shrinkage of the specimen. However, with this exception, the preparation is excellent for purposes of study and demonstration, since the finer relations of the different parts and the general physiognomy of the organ are well preserved.

The original method of Giacomini ${ }^{x}$ produces somewhat less shrinkage, but results in inconveniences which more than counterbalance. Giacomini transferred the brain from the alcohol (4) to a bath of pure glycerine to which had been added about 2 per cent. of carbolic acid for aseptic purposes.

After complete infiltration by the glycerine (8-1o days) the specimen is removed and set aside for a few days for the glycerine to "evaporate" from the surface. Then it may be given a coat of shellac varnish, and the process is complete.

The specimen prepared in this way is equally capable of being kept in the open air for years, but it is always somewhat sticky and unpleasant to handle, and the glycerine is continually oozing out of it.

If the brain be fixed and hardened for three or four months in Müller's fluid (XI, A, p. 69) and then dehydrated in alcohol (4), followed by either glycerine or paraffin ( 5 and 6), a preparation will be obtained which is less shrunken than those hardened in zinc chloride, but the preparation is black instead of the more nearly natural color resulting from the use of zinc

- Arch. per le Scienze Mediche, 1878. 
chloride, and also, especially if glycerine is used, it is more liable to crumble, the Müller's fluid having made it brittle.

If glycerine is to be used in the preparation, by all means use it upon specimens which have been preserved in 10 per cent. formalin (X, A, p. 63).

In the above procedures most of the shrinkage results from the action of the alcohol in dehydration. After fixation in formalin the use of alcohol may be avoided entirely by simply prolonging the time in glycerine.

Fix and harden in to per cent. formalin for 2 weeks or more; transfer direct to pure glycerine, changed once, for $2-3$ weeks, set out to "evaporate," and then shellac as before. This will give a preparation of very nearly the normal dimensions. 


\section{METHOD XVII. \\ THE KAISERLING METHOD. ${ }^{x}$}

A method for "wet preparations" of the central nervous system for museum and demonstration specimens. Results in a specimen tough enough to resist much handling, and at the same time one in which both the normal size and especially the color are retained to a remarkable degree. Well adapted for pathological specimens, whether of nervous or other tissues.

\section{SPECIAL REAGENTS REQUIRED.}

A. Fixing and hardening fuid.-

Formalin (40 per cent. formaldehyde), $200 \mathrm{cc}$.

Distilled water, I, ooo cc.

Potassium nitrate (saltpetre), $15 \mathrm{~g}$.

Potassium acetate, $30 \mathrm{~g}$.

B. Preserving fuid.-

Potassium acetate, $200 \mathrm{~g}$.

Glycerine, $400 \mathrm{cc}$.

Distilled water, 2,00o cc.

The formulæ as given will result in fluids sufficient in amount for a human brain, provided the vessels used are small enough.

\section{PROCEDURE.}

I. The brain or spinal cord is removed and placed in a vessel containing enough of the fixing fluid (A) to cover it well, and kept in the dark for 5-8 days.

It is advisable to inject about $400 \mathrm{cc}$. of the fluid through the internal carotid artery before removing the brain, especially if there is reason to believe that the post-mortem softening has begun. Do not inject too much, lest the blood, and consequently the color, be washed out of the blood-vessels.

The bottom of the vessel should be padded with absorbent cotton, and during the period of fixation, the position of the

${ }^{\circ}$ C. Kaiseritng, Virchow's Archiv, Bd. 147, Heft 3, P. 389, 1897. 
specimen should be changed from time to time to prevent flattening or distortion.

2. Drain the specimen for 2 or 3 minutes, and place it in 95 per cent. alcohol for 5 or 6 hours.

3. Then place in a glass vessel containing the preserving fluid (B). Here it remains indefinitely.

Even in the preserving fluid it is advised to keep the preparation in the dark as much as possible, since the long duration of light seems to cause it to lose its natural color.

When on exhibition or in use for study or demonstration, the preparation may be improved in appearance by placing it in 80 per cent. alcohol for the time being. This seems to brighten the colors to a certain extent. Too long duration in alcohol, however, will extract the color.

The preparation is well adapted for dissection. If dissection is made, it is suggested that it should be delayed till after the specimen has been in the preserving fluid for about two weeks. 


\section{METHOD XVIII.}

\section{METHODS FOR THE TREATMENT OF EMBRYOS.}

Some suggestions as to the fixation and preservation of human embryos and foetuses.

The most valuable embryonic material, and that most desired by neurologists as well as embryologists, is that of the human subject. As yet our knowledge is badly deficient concerning many points in the development of the human embryo, and especially so concerning some of the early stages. This is due, of course, to the difficulty with which human material is obtained.

Opportunities to obtain human embryos are offered almost exclusively to the physicians, and quite often these opportunities are sadly neglected. Most often, perhaps, the material is not saved, either because the physician does not realize its value, or because he does not know how to treat it or is not prepared to do so.

Most of the fluids recommended in the books for the fixation of embryos contain ingredients which the physician not only does not usually have in his office, but which are not obtainable from the stock of the ordinary drug store.

The object of these suggestions, therefore, is not to give such fluids and procedure as are considered absolutely the best by embryologists for the fixation and preservation of embryos, but to mention such efficient fixing fluids as the physician can easily obtain from his druggist or can quickly make up from his own stock of drugs, and which allow as much latitude as possible in the subsequent treatment for the preservation of the specimens.

It is presumable that every physician has, or can quickly obtain, the bichloride of mercury, potassium bichromate, commercial 40 per cent. formaldehyde, chloroform, acetic acid, strong commercial alcohol, and distilled water. From these reagents he can make the following excellent and inexpensive fixing fluids: 
A. Van Gehuchten's fluid.-

Strong alcohol (absolute preferably), 6 parts.

Chloroform, 3 parts.

Acetic acid (glacial or concentrated), I part.

Use in a tightly closed vessel.

After 6-24 hours of fixation in this fluid the specimen should be transferred to 80 per cent. alcohol, or commercial alcohol (95 per cent.) to which has been added about one-fourth its volume of distilled water. In this it may remain indefinitely.

B. Zenker's fuid.-

To each I oo cc. of distilled water add $5 \mathrm{~g}$. of mercuric bichloride,

$5 \mathrm{cc}$. of acetic acid (glacial or conc.),

$2 \mathrm{~g}$. of potassium bichromate.

When first devised (I 894), this fluid was made by dissolving 5 per cent. of mercuric bichloride and 5 per cent. of glacial acetic acid in the required amount of Müller's fluid (XI, A, p. 69). If Müller's fluid be had already made up, this will be the quickest way of making Zenker's fluid. The sodium sulphate called for in the formula for Müller's fluid is now considered unnecessary in Zenker's fluid, but it does no harm. In other respects it will be seen that the mixture is the same.

Zenker's fluid has excellent penetrating powers, and therefore may be used with larger objects than expedient with Van Gehuchten's fluid. It is also one of the very best fixing agents for general histological purposes.

Several days in the fluid does not usually injure the tissue, but it is thought best to remove it after $12-24$ hours. Wash in water and then with an iodine solution to remove the crystals (see 2 below), and then preserve in 70 per cent. or 80 per cent. alcohol.

C. Lavdowsky's mixture (modified).-

Distilled water, 40 volumes.

95 per cent. alcohol (com.), 50 volumes.

40 per cent. formaldehyde (com.), Io volumes.

Acetic acid (glacial or conc.), 2 volumes. 
It will be seen that this mixture consists of weak alcohol to which has been added Io per cent. of formaldehyde and about 2 per cent. of acetic acid. The alcohol tends to counteract the swelling effects of the other two ingredients. The mixture penetrates and fixes well. Material may remain in it indefinitely, but it is thought better to transfer it to 70 per cent. alcohol after 24-48 hours. It needs no special preliminary washing.

D. ro percent. formalin (see X, A, p. 63).

All of the above fluids keep well, and may be made up in quantity and kept in stock. Bottles containing them should have tightly fitting stoppers to prevent dilution by evaporation. It is recommended that either the fluids themselves or the reagents for making them be kept on hand, so that, when a specimen is obtained, it may be subjected to the fixing fluid with as little delay as possible.

It is also advised that wide-mouthed bottles of various sizes be kept on hand. The ordinary $3 \mathrm{oz}$. quinine bottle will be found excellent for the smaller embryos, and fruit jars of $1 / 2$ pint, I pint, and I quart sizes will do for the larger fotuses.

\section{REMOVAL AND FIXATION.}

In case of the smaller embryos (3-5 mm. in length), carefully open the chorion before placing them in the fixing fluid. When the embryo is located, a portion of the chorion may be removed and openings made in the amnion so that the fluid may directly come in contact with the specimen.

If there is reason to believe the embryo is less than $2 \mathrm{~mm}$. in length, it is necessary to proceed with much caution. Examine the specimen under a lens, either in its own fluid or in a watch-glass of physiological salt solution (VII, A, p. 43), and, if there is reason to believe that the stage of the infolding of the blastoderm is not yet complete, place the whole specimen directly in the fixing fluid. In this case the specimen will be quite small.

If, on the other hand, the chorion with its villi seem to surround the specimen apparently forming a ciliated sphere, and 
still there is reason to believe that the embryo is less than $3 \mathrm{~mm}$. in length, simply make small openings in the chorion to allow the free entrance of the fluid. Place the whole in a copious amount of the fixing fluid and change the fluid after I-2 hours.

The smaller human embryos are the most difficult to obtain, and so are the most rare and most desired. So far the human embryos on record which have been obtained of lengths less than $2 \mathrm{~mm}$. (less than Io days) are very few.

Embryos of more than $5 \mathrm{~mm}$. in length will safely allow both the chorion and the amnion to be removed. The allantois at this stage has become a part of the umbilical cord. In removing the amnion, leave the umbilical cord attached to the embryo, so that the embryo may be handled by means of it.

The length of an embryo, roughly speaking, is the length of a straight line passing through its longest axis. This measurement, therefore, does not include either of the flexed ends, although in the stages from 3 to 6 weeks considerable of the actual length is represented in the flexures. To measure the smaller embryos it will be safer to lay the embryo on the scale rather than the scale on the embryo. Measurement of the smallest should be postponed till after fixation.

As to the fixation of the embryos, the following suggestions are offered:

I. Embryos of IO-25 days or less (2-7 mm. or less) should be placed in I 5-20 times their volume of Van Gehuchten's fluid (A) for 6-24 hours.

At the end of this time the fluid should be replaced with 80 per cent. alcohol. Tightly close the vessel and set aside. In the alcohol the specimen will be preserved indefinitely.

While Van Gehuchten's fluid does not have so great a penetrating power as Zenker's fluid (B), it will fix the smaller embryos perfectly well, and is recommended here because it is one of the best of fixing fluids for the study of karyokinesis and general cytology (see Method I).

2. Embryos of from 4 to 8 weeks $(8-25 \mathrm{~mm}$. in length) should be removed entirely from the amnion and fixed in I 5-20 
times their volume of Zenker's fluid (B). After remaining in this for $12-24$ hours, the embryo should be washed for 4-6 hours in several changes of distilled water and then preserved in 70 or 80 per cent. alcohol. The alcohol should be changed after the first $24-48$ hours.

If the specimen is to be dehydrated and imbedded immediately, it should, after 2 to 6 hours' washing in the water, be placed in an iodine solution (IV, 2, p. 32) 6-8 hours, or long enough to remove the crystals resulting from the action of the bichloride of mercury. Otherwise the crystals will eventually be dissolved out by the alcohol in which the specimen is preserved.

3. Fœtuses of from 2 to 4 months $^{x}$ should be treated in still a different way. They are rather large to insure good fixation throughout if placed whole in either of the two fluids used above. The specimen should be divided, or, if it is desired to make a detailed cell study of any of its organs, those organs should be removed and placed separately in the fluid. If, however, as is often the case at the time a specimen is obtained, it is more convenient to place it in the fluid whole, Lavdowsky's mixture (C) is recommended as one of the best in that case. Use a copious amount of the fluid and open the body cavity before placing the specimen in it. This fluid will produce very little distortion of the specimen, and its penetrating power is such that it will fix the tissues fairly well for general histological purposes. It is not recommended for cytological work. The specimen may remain in the fluid indefinitely.

I TABLE GIVING APPROXIMATE LENGTH AND WEIght OF FCETUSES AT DIFFERENT MONTHS OF GESTATION.

\begin{tabular}{c|c|c}
\hline Length in cm. & Weight in grams. & Time in months. \\
\hline & & \\
$2.5-3$ & 4 & 2 \\
$7-9$ & $5-20$ & 3 \\
$10-17$ & 120 & 4 \\
$18-27$ & 284 & 5 \\
$28-34$ & 434 & 6 \\
$35-38$ & 1218 & 7 \\
$39-4 \mathrm{I}$ & 1549 & 8 \\
$42-44$ & $197 \mathrm{I}$ & 9 \\
$45-47$ & 2334 & 10 \\
\hline
\end{tabular}


If the foetus is to be kept as a museum specimen, the Kaiserling method (XVII, p. 95) is especially recommended as producing the least amount of change in its normal macroscopic appearances.

4. Fotuses of from 5 months to term are too large to be fixed in toto. Ten per cent. formalin (D) will come nearer to fixing them than any fluid known. If Io per cent. formalin be injected into the blood vessels and the alimentary tract of even a large fœtus, and then the body cavity opened and the specimen placed in the fluid, the specimen will be well preserved for all purposes of dissection, but it cannot be depended upon that the tissues will be sufficiently well fixed for microscopic purposes.

Formalin used alone as a fixing agent gives better results when applied to the central nervous system than when applied to other tissues of the body (see Methods IX, X, and XIX). If it is especially desired to study the central nervous system of the fœtus, either expose it before placing the fœtus in the formalin or, better, remove it entire and place it separately in the fluid. Also, if it is desired to study any of the other organs microscopically, remove such pieces as are wanted:and fix them in a fluid more suited to the purpose in mind. The remainder of the fœetus may then be preserved in ro per cent. formalin. The more exposed portions may be sufficiently fixed for general microscopic anatomy, but formalin is by no means recommended for this purpose. 


\section{METHOD XIX.}

\section{FORMALIN FOR PURPOSES OF DISSECTION.}

An application of formalin for the fixation and preservation of specimens for dissection. May be applied to the whole or any part of the animal for the dissection of any of its tissue, but is especially adapted for the central nervous system.

Directions for the removal of the central nervous system.

\section{ADVANTAGES OF FORMALIN.}

To make a satisfactory and detailed dissection of any specimen, and especially of the central nervous system of the larger animals, the following conditions are essential:

I. The specimen should possess a greater rigidity and resistance to handling than its natural softness in the fresh state will allow.

2. The normal shape and color of the specimen should be preserved as far as possible, and shrinkage avoided.

3 . The hardening process should result in the greatest possible amount of toughness and elasticity, so that the specimens may not only be sectioned without danger of breaking or crumbling, due to brittleness, but also may permit of the greatest possible extent and ease in tearing and teasing apart its different structures, for torn preparations are often more instructive than sections.

4. The gross structural and optical differences between the different tissue elements should be maintained in the specimen. "White substance" should be readily distinguishable from "gray substance," so that a nerve pathway may be easily followed in the central nervous system. Also in the peripheral system the conditions should be such that the course of a nerve may be easily followed.

5. The preserving fluid should be of such a nature that 
specimens may remain in it indefinitely without injury to the specimen and consequent inconveniences to the operator.

Also the preservation should be of such a character that during the dissection the material may, without injury, be so treated that it may be handled freely without discomfort to the hands.

In case of the central nervous system especially, the above conditions are more nearly attained by the use of formalin as the fixing and preserving agent than by the use of any other agent known. Alcohol, for example, decolorizes, shrinks, and distorts the specimen, and also renders it brittle. Chromic acid and the bichromates do not sh-ink the specimen; rather they produce an increase in its volume, which, for dissecting purposes, is not very objectionable. But, on the other hand, they do produce a brittleness of the tissue which, especially after a long period of action, renders satisfactory dissection impossible. They also color the specimen either black or dark brown. It may be said, though, that the salts of chromic acid, especially the bichromate of potassium, give rise to fewer objectionable qualities than do any of the other salts usually employed for fixation. Again, brains fixed in acids (nitric or acetic usually) become greatly swollen and discolored, and, while possessing a fair degree of toughness, they soften in a very objectionable way when placed in water, and repeated washing in water is necessary that the specimen may be handled without injury to the hands.

Commercial formalin is a 40 per cent. aqueous solution of the gas, formic aldehyde or formaldehyde. Formaldehyde $\left(\mathrm{CH}_{2} \mathrm{O}\right)$ is the intermediate product in the oxidation of methyl alcohol $\left(\mathrm{CH}_{4} \mathrm{O}\right)$ into formic acid $\left(\mathrm{CH}_{2} \mathrm{O}_{2}\right)$. Methyl alcohol when used as a fixing agent produces a violent shrinkage of the tissue, while formic acid, by causing the tissue to take up water, produces a greater swelling than is produced by any of the acids used in histological technique. Theoretically, therefore, formalin, the median product between methyl alcohol and formic acid, should produce a median effect upon the tissues. 
As a matter of fact, formalin produces a slight swelling of the tissues, not enough, however, to be at all objectionable for purposes of dissection. In this respect it partakes somewhat of the nature of formic acid. But, beyond this, the specimen fixed and preserved in formalin so nearly fulfils the conditions desired for dissection as to recommend the use of formalin above all other reagents now employed for such purposes.

For the simple preservation of the specimen, solutions of formalin ranging in strength anywhere from I per cent. to 5 per cent. are sufficient. But for fixation, especially of large specimens, the solution should be stronger. A ro per cent. solution has been found to give entirely satisfactory results with whole human brains. The cortex of fresh brains thus prepared has been found sufficiently well fixed even for histological purposes, particularly for Golgi preparations.

The solutions of formalin are usually made by adding the required number of volumes of the 40 per cent. formaldehyde to Ioo volumes of distilled water. Thus, the so-called Io per cent. formalin is prepared by adding io volumes of the commercial 40 per cent. solution to I 00 volumes of water.

\section{PROCEDURE.}

I. Removal. - In removing the brain and spinal cord it will be found that the organ holds its shape better if the dura mater is left on. A part at least of the dura mater should be left in position, that its relations to the organ may be studied in the subsequent dissection.

It will be found a comparatively easy matter to remove the spinal cord with the dura intact. The simplest procedure will be to lay bare the vertębral column from the dorsal side, removing the attached dorsal muscles from about the column, and then, with strong bone forceps, clip the pedicles (radices) of each neural arch just below the superior articular processes, or as close to the intervertebral foramena as possible. Thus the spinal cord inclosed in the dura will be laid bare. Next, free each spinal nerve from its attachment in the intervertebral foramen and 
clip the nerve on the peripheral side of the spinal ganglion. In this way the spinal ganglion and the fusion of the dorsal and ventral nerve-roots to form the nerve-trunk will be obtained intact. The finer divisions of the roots and their attachment to the spinal cord, being inclosed by the dura mater, will be protected. Removal from the vertebral canal will now be an easy matter. Begin at the sacral end. Gently lift the organ by applying the forceps to the dura, being careful not to press or crush the spinal cord, and with a small scalpel, frequently using the handle, free the organ from its adherence to the ventral side of the vertebral canal. Then, with sharp scissors, separate the spinal cord from the medulla at the level of the first cervical nerve, and place the whole into the fixing fluid. If it has been removed with dura mater intact, it will be better to make small openings in the dura at intervals to facilitate the penetration of the fluid.

In order that the spinal cord may become fixed in its normal extended shape, it should either be laid straight in a vessel long enough to accommodate it, or, better, a tall glass cylinder may be used. In the latter case it will be best to use a strip of glass narrow enough to fit into the cylinder. Extend the specimen on the strip of glass and tie it at each end. Let the dura only be involved in the tying. It may be necessary to use a needle and thread.

During the process of removal the specimen should be kept moist either with physiological salt solution (VII, A, p. 43) or with water.

To remove the brain with the dura mater intact is more difficult than it is with the spinal cord. It is not so difficult to remove the brain with that part of dura in position which covers its dorsal and lateral aspects. This, together with the falx cerebri and the tentorium and falx cerebelli, will give little trouble. But that part of the dura inclosing the ventral surface of the brain, because of the various grooves, fossæ, and foramena, is so firmly attached to the base of the cranium that the attempt to remove it will endanger the brain and especially the cranial 
nerves. Since it is very desirable to remove the brain with all the cranial nerves attached, it will be safer not to try to remove this ventral portion of the dura.

Make the necessary incisions in the scalp and pull it aside far enough to be out of the way of the saw. Let the line of the saw pass through about the middle of the frontal bone, and around and downward on each side through the inferior portions of the parietal bones near the temporo-parietal suture. Then turn the lines farther downward so as to pass through the occipital bone in line with the occipital condyles, thus forming a wide $\mathrm{V}$ with its point opening into the foramen magnum.

Use the saw carefully lest it pass through to the brain. It is best not to saw through the bones entirely; when almost sawed through they may be more safely wrenched apart with a chisel.

When the bones are separated along the entire length of the saw, the cap thus detached may be pulled off, leaving the dura mater covering the brain intact. Now, with blunt-pointed scissors, the dura mater may be cut around just below the line of the saw, and the brain is ready to be removed.

The brain may be removed with less danger of pulling off the cranial nerves if the removal is begun from behind at the medulla oblongata. First, however, gently press back the frontal lobes and carefully detach the olfactory bulbs from the cribriform plates. Then, with the hand, lift the medulla carefully, and as the cranial nerves come into view, clip them off close to their entrances into their respective foramena.

2. To $f x$ and harden, place the freshly removed brain (and spinal cord if kept attached) in 3 or 4 times its volume of ro per cent. formalin.

The bottom of the vessel in which the brain is placed should be padded with absorbent cotton to prevent the fresh specimen from becoming flattened by contact with the bottom, and thus hardening in that shape. For the same reason it will be well to turn the specimen three or four times during the first 24 hours.

Change the fluid, after 24 to 48 hours. If the specimen is small, a 5 per cent. solution may be used in the change. 
It is best not to attempt dissection until the organ is thoroughly hardened. Human brains should be given 8-I0 days in the fluid. Smaller brains will harden sufficiently in 6-8 days; $3-5$ days will be amply sufficient for the spinal cord.

The specimens may remain in the formalin solution for years without injury in any way. Only the vessel should be kept tightly covered, lest the solution become too much diluted by the evaporation of the formaldehyde.

3. Dissection.-Before beginning dissection place the specimen in water long enough to remove the formalin sufficiently that it may not be objectionable to the hands, eyes, and nose. During the dissection keep the specimen moist with water.

When it becomes necessary to rest the dissection for I 2 hours or more, simply return the specimen to the vessel of formalin and, when the dissection is to be resumed, transfer it to water again, and so on, till the dissection is complete. For an interval of 12 hours or less the specimen may remain in the water without injury. A longer time may possibly cause maceration.

Specimens prepared in the above way will be found to possess the normal shape and very nearly the normal size; they will be tough and elastic, and capable of much tearing and teasing; their color will be little altered and the blood pigments so little extracted that the blood vessels may be followed in considerable detail. 


\section{METHOD XX.}

\section{AN OUTIINE FOR THE DISSECTION OF THE CENTRAL NERVOUS SYSTEM.}

In the following outline or guide for the direction of the central nervous system the [BNA] nomenclature is used almost exclusively. This was thought advisable, since its adoption is rapidly becoming universal, and the earlier the student is familiar with it, the better. In cases in which a name given in the [BNA] differs intrinsically from the name usually given in the older English text-books for the same structure, the latter name is given in addition to the [BNA] name. A full classified list of the [BNA] will be found on pp. I 36 to 172 .

The outline is based upon the anatomy of the human central nervous system. However, with the exception of certain of the external features of the cerebrum and cerebellum, it will apply equally well to the central nervous system of any of the larger mammals.

The dissection is restricted to the macroscopic anatomy of the organ, and therefore the outline calls for the identification and study of such structures only as can be seen with the naked eye. A dissecting lens magnifying 8-10 diameters will be of frequent aid in making the more detailed observation of the parts.

That part of Toldt's Anatomical Atlas which deals with the nervous system ${ }^{x}$ is especially recommended as an aid in the dissection. The atlas is bound in separate volumes, any of which may be obtained from the dealers in medical books. It uses the [BNA] exclusively, and each illustration has the names of the various structures represented in it attached to the structures.

IDR. CARL ToldT, Anatomischer Atlas, 6. Lieferung ("Die Nervenlehre, etc."), 1901 
For a description of the various structures and their interrelations, microscopic as well as macroscopic, that part of Quain's Anatomy entitled "The Spinal Cord and Brain"x is suggested. This, being one of the older books, does not use the [BNA] but many of the older terms are the same as the [BNA] and the text of Quain is clear and brief, and the figures are good.

If it is desired to make a more elaborate and critical study of the histology and microscopic anatomy of the central nervous system, the best reference-book up to date for this purpose is The Nervous System, by Dr. L. F. Barker. ${ }^{2}$ This work contains a very large number of figures, gives a very complete bibliography, and also discusses the bearing of the more important papers.

In the following dissection it is presupposed that the specimen has been removed and preserved in formalin as directed in XIX, p. I05. Before the dissection begins, the specimen is supposed to have been removed from the formalin and placed for an hour or so in water (see XIX, p. 108). When it is necessary to suspend the dissection for twelve hours or more, the specimen should be returned to the formalin solution.

If the student has more than one specimen at his disposal, so much the better. It was thought advisable, however, to restrict the outline to only such dissection as can be accomplished with one spinal cord and one brain.

\section{DISSECTION.}

A. MEDULla SPINALIS (SPINAL CORD).

I. EXTERNAL FEATURES.

(a) Meninges and general topography: Separate the medulla spinalis from the medulla oblongata at the level of the first N. ${ }^{3}$ cervicalis and lay the medulla spinalis out straight, dorsal side up. Observe that the organ proper is enveloped by inclosing I Quain's Anatomy (Schäfer), Vol. III, Part I, 1895.

"The Nervous System and its Constituent Neurones. Appleton \& Co., I899. ${ }^{3} \mathrm{~N}=$ nervus $; \mathrm{Nn}=$ nervi. 
meninges. On the surface of the specimen look for parts of the plexus venosus vertebralis left on after its removal from the foramen spinale (vertebral canal). Attached at regular intervals (segments) observe the thirty-one pairs (human) of Nn. spinales and the small enlargement on each nerve, the ganglion spinale. How do the ganglia differ in appearance from the rest of the nerve? Do they vary in size? At what levels do the largest occur?

With scissors, on the dorsal side, longitudinally slit a portion of the outer of the investing membranes, the dura mater spinalis, and pin it back from both sides. Note a middle membrane, the arachnoidea spinalis. Separating the arachnoidea spinalis from the dura mater spinalis is the cavum subdurale. How are the two membranes connected?

Closely investing the medulla spinalis, identify a third membrane, the pia mater spinalis. Along the dorsal mid-line and passing through or dividing the cavum subarachnoideale, note the septum subarachnoideale connecting the pia mater with the arachnoidea.

Observe the ligamenta denticulata performing the same office along the lateral aspects of the medulla spinalis. Which of the three investing membranes is the thickest? Which the most vascular? Make a sketch showing the relations of the membranes to each other and to the medulla spinalis. Remove a small piece of the dura mater and tease it under the dissecting lens. What is its structure?

(b) Blood supply: On either side of the dorsal mid-line, note the small arteriae spinales posteriores. The venae spinales posteriores are somewhat larger and usually course nearer the mid-line.

Carefully remove a portion of the outer membranes so as to expose a part of the ventral surface of the medulla spinalis, and note the larger irregular Arteria spinalis anterior and the smaller Venae spinales anteriores. Both the anterior and posterior arteries are fed by small branches (the rami spinales) from the larger arteries lying outside the vertebral column. How do the rami spinales pass from the dura mater to the pia mater? 
(c) The nervi spinales. I. Subdivisions: complete the exposure of the medulla spinalis by continuing the opening of the dura mater and arachnoidea along the entire dorsal mid-line. Again lay the specimen straight, dorsal side up, and identify the pars cervicalis with its intumescentia cervicalis (cervical enlargement) and its eight pairs of nerves (nervi cervicales); the pars thoracalis with its twelve pairs of nervi thoracales; the pars lumbalis with its intumescentia lumbalis (lumbar enlargement) and its five pairs of nervi lumbales; and the pars sacralis with its six pairs of nerves (nervi sacrales et coccygei).

2. Radices nervorum spinalium: Note that each nerve is formed by the fusion of its radix posterior (dorsal root) and its radix anterior (ventral root), and that each radix before its attachment to the medulla spinalis is broken up or subdivided into a number of rootlets, fila radicularia. Passing from the pars cervicalis to the pars sacralis, note the progressive increase in the length of the radices. Where are the shortest and most horizontal radices? Explain the increase in length on the basis of an unequal growth of the medulla spinalis and the columna vertebralis. What is the cauda equina? Sketch it.

3. Ganglia spinalia: Remove the dura mater from about the radices and ganglion spinale of a nerve, then clip the radices, and, keeping in mind the orientation of the nerve, place it under the dissecting lens and carefully separate the radices at their junction in the region of the ganglion spinale. Which radix is in more intimate connection with the ganglion? What is the behavior of the other radix? Make a sketch showing the relations of both radices and attach their names. Tease one of the radices and then tease the ganglion itself. What differences are to be noted in the appearance of the tissue of the two ? Of what is the ganglion composed? What is the more exact relation of the ganglion to the radix observed above to be connected with it?

(d) Medulla spinalis proper: What are the relative dimensions of the pars thoracalis as compared with the partes cervicalis and lumbalis? At the levels of what nerves, approximately, 
are the greatest and least diameters of the medulla spinalis? On the basis of function, explain the occurrence of the intumescentiae (enlargements).

Carefully remove the radices forming the cauda equina and, beginning at the intumescentia lumbalis, note the manner in which the medulla spinalis tapers on approaching its termination. Identify the conus medullaris and the filum terminale. Make a sketch of the entire medulla spinalis, attaching the names of the various parts. Remove a piece of the filum terminale and tease it under the dissecting lens. Is it nervous?

\section{SECTIONS OF MEDULLA SPINALIS.}

(a) With a sharp scalpel divide the medulla spinalis at the level of the seventh $\mathrm{N}$. cervicalis, and then remove a thin transverse section of the region. Keeping its orientation in mind, place it under the dissecting lens in a watch-glass of water. Note the bilateral symmetry of the section. How is the substantia grisea (gray matter) to be distinguished from the substantia alba (white matter)? What is the general shape of the substantia grisea? Note differences between dorsal and ventral portions.

(b) Make a careful sketch of the section, identifying the following structures:

I. Meninges, etc.-Dura mater spinalis. Arachnoidea spinalis. Pia mater spinalis. Septum sub-arachnoidale. Ligamenta denticulata. Arteriae spinales posteriores and anteriores. Venae spinales externae posteriores and anteriores. Sulcus medianus posterior. Septum posterius. Fissura mediana anterior. Septa lateralia. Sulci laterales posterior and anterior. What is the relation of the latter to the radices posterior and anterior respectively?

2. Substantia grisea.-Columna posterior (dorsal horn) with its apex, caput, cervix, and substantia gelatinosa (Rolandi). Formatio reticularis (gray trabeculae). Columna anterior (ventral horn), Columna lateralis (lateral horn). Commissura grisea with its canalis centralis, substantia grisea centralis, its 
commissura posterior alba and commissura anterior alba. Of what is the com. ant. alba (ventral white commissure) composed? What is the relation of the columna posterior to the radix posterior? Columnae anterior and lateralis to radix anterior?

3. Substantia alba (white matter).-Funiculi posteriores, composed of the funiculus gracilis (Goll's column) and the funiculus cuneatus (Burdach's column). Funiculi anteriores (direct pyramidal tract, etc.). Funiculi laterales (crossed pyramidal tract, direct cerebellar tract, etc.). Radix anterior and radix posterior. Attach the names to all structures represented in the drawing.

(c) Comparison: Make careful drawings, exclusive of the meninges, of sections taken in a similar way (I) at the level of the seventh $\mathrm{N}$. thoracalis, (2) at the level of the fifth N. lumbalis, and (3) through the conus medullaris. In the pars thoracalis, on the mesial side of the cervix columnae posterioris, note the nucleus dorsalis (Clark's column). Make the drawings to the scale of the first one. Attach the names to such structures as are not found in the first section or are greatly modified.

When complete, lay the four drawings in series and by careful comparison verify the following statements :

I. In the conus medullaris (sacrococcygeal region) the substantia grisea is surrounded by a comparatively thin mantle of substantia alba. The columnae posteriores are nearly as thick as the columnae anteriores, and the commissura grisea is relatively thicker than in any of the other sections. Is there a columna lateralis? Why should the substantia grisea here be more abundant in proportion to substantia alba than at other levels?

2. In the pars lumbalis the substantia alba begins to predominate. Why? The columnae posteriores are still relatively thick as compared with those of the more cephalad sections. Are there columnae laterales in this region? Compare the funiculi posteriores with those of the other sections.

3. The pars thoracalis is characterized by its relatively small amount of substantia grisea. The columnae posteriores and 
anteriores form two slender crescents united across the midline by a narrow commissura grisea which occurs relatively nearer to the ventral side of the medulla spinalis. In this region the substantia alba is both relatively and absolutely greater in amount than in the regions below it. Especially note the increase in the funiculi posteriores. Can the funiculus gracilis be distinguished from the funiculus cuneatus? How does the nucleus dorsalis modify the shape of the columna posterior? Is there a columna lateralis? Formatio reticularis?

4. In the pars cervicalis there is a decided increase in the absolute amount of substantia alba. The columnae anteriores are much thicker than the columnae posteriores, and there is a well-marked columna lateralis and formatio reticularis. In the funiculi posteriores, the funiculus gracilis is now more easily distinguished from the funiculus cuneatus. The funiculi laterales have so increased as to give the section an oval shape. What is the relative size of the funiculi anteriores?

5. A section taken at about the level of the second $\mathrm{N}$. cervicalis will show that the substantia grisea has assumed a shape and thickness similar to that in the pars thoracalis, while the substantia alba has decreased but little. Why should it decrease at all? What are the funiculi proprii (ground bundles)? To what causes are the intumescentiae due? Explain the fact that both the ascending and the descending funiculi increase in amount as we pass from the conus medullaris toward the encephalon (brain).

\section{B. ENCEPHALON (THE BRAIN).”}

\section{EXTERNAL FEATURES.}

(a) Meninges:-Lay the encephalon dorsal surface upward. From one side gently lift the cap of dura mater encephali left on in the removal of the specimen, and identify the arachnoidea encephali, the cavum subdurale, the cavum subrachnoidale, the pia mater encephali, and the subarachnoid trabeculae connecting

I It is assumed that the specimen has been removed and preserved for dissection as directed in Method XIX. 
the arachnoidea to the pia mater. By way of these trabeculae the blood vessels pass from the one membrane to the other. Next, note the following ingrowths or processes of the dura mater:

I. The falx cerebri, extending into the fissura longitudinalis cerebri.

2. The tentorium cerebelli, extending between the cerebrum and cerebellum.

3. The falx cerebelli, a less extensive ingrowth occupying the groove between the cerebellar hemispheres (the incisura cerebelli).

Do the membranes of different parts of the surface vary in thickness? Along the mid-line on either side of the falx cerebri, look for granulationes archnoidales (Pacchonian bodies). Are all three of the membranes of the encephalon thicker than those of the medulla spinalis?

(b) Blood supply:

I. Veins.-Note that the dura mater may be separated into two layers. Between these layers, identify the following sinuses :

The large sinus transversus situated in the tentorium cerebelli. At the mid-line this sinus is connected with the sinus sagittalis superior which runs the entire length of the falx cerebelli and falx cerebri.

Also emptying into the sinus transversus are numerous venae cerebelli superiores and inferiores. Emptying into the sinus sagittalis superior, note the various venae cerebri superiores.

Remove the falx cerebri and, running along in its inferior border, note the sinus sagittalis inferior.

On the ventral aspect of the encephalon, lying in the groove between cerebrum and cerebellum and emptying into the lateral extremities of the sinus transversus, note the two sinus petrosi superiores.

Now remove the tentorium cerebelli and observe that the sinus sagittalis inferior is a continuation of the sinus rectus 
which, in its turn, opens into the sinus transversus near, and perhaps to the left of, its junction with the sinus sagittalis superior.

Among the other larger veins may be noted the venae cerebri mediales, passing from the ventral surface of the brain by way of the fissura cerebri lateralis (fissure of Sylvius).

2. Arteries. - The arteries of the encephalon are derived from two sources, the two vertebral arteries and the two internal carotids. These approach the brain from its ventral surface. Only the larger arteries will be noted.

Lay the specimen ventral surface upward and identify the following: The two arteriae vertebrales, along either side of the medulla oblongata, fuse at the posterior border of the pons to form the larger single arteria basalis. The A. basilaris passes along the pons in its sulcus basilaris, giving off the Aa. cerebelli inferiores and superiores and the smaller rami ad pontem.

When the $A$. basilaris reaches the anterior border of the pons, it divides into the two Aa. cerebri posteriores which spread out over the occipital portion of the brain.

Almost immediately after their origin from the A. basilaris, the Aa. cerebri posteriores give off a branch each. These are the Aa. communicantes posteriores which connect the arterial system arising from the vertebral arteries with that arising from the internal carotids.

Each A. carotis interna is joined by the A. communicans posterior just at the side of the chiasma opticum.

The $A$. carotis interna divides into three branches. The A. choroidea, the smallest of these, passes posteriorly around the pedunculus cerebri (crus), and inward to the ventricles of the brain. The A. cerebri media, the largest branch, passes along the fissura cerebri lateralis (Sylvii), and its branches spread over the lateral aspect of the brain. The third branch of the $A$. carotis interna is the A. cerebri anterior which supplies the frontal lobes, and is the chief source of supply to the mesial surface of the brain.

Across the mid-line and just in front of the chiasma opticum, 
the Aa. cerebri anteriores of the two cerebral hemispheres are connected by the short $A$. communicans anterior.

Thus it will be seen that the communicating branches of the larger arteries form, at the base of the brain, a circle about the chiasma opticum and the corpora mamillaria. In the English texts this is known as the "circle of Willis." It is made by the Aa. cerebri posteriores, Aa. communicantes posteriores, Aa. carotides internae, Aa. cerebri anteriores, and the A. communicans anterior.

(c) External features of the brain proper.- I. Facies convexa (dorsal and lateral aspects).-Carefully remove whatever may remain of the dura mater and arachnoidea, and lay the specimen dorsal surface upward. Identify polus frontalis, polus occipitalis, and fissura longitudinalis cerebri. Gently pull apart the cerebral hemispheres and note the corpus callosum. What is its appearance compared with the rest of the encephalon? Why?

Identify fissura cerebri lateralis (fissure of Sylvius), sulcus centralis (fissure of Rolando), and gyri centralis posterior and centralis anterior. Why is the fissura cerebri lateralis called fissure instead of sulcus?

Lift apart the polus occipitalis from the cerebellum and note the mesencephalon (corpora quadrigemina). Resting upon the colliculi superiores (anterior corpora quadrigemina) may be seen the corpus pineale.

Note the cerebellar hemispheres and vermis superior. Lift the posterior margin of the cerebellum from the medulla oblongata below, and note the vermis inferior and lobulus centralis. With the aid of an atlas or illustrated text, identify more fully the various external features of the cerebellum. What can be said of the size, depth, and arrangement of the gyri and sulci of the cerebellum as compared with those of the cerebrum? Are there any variations to be noted in the bilateral symmetry of the encephalon?

2. Basis encephali. - Now lay the brain ventral surface upward and note the following: 
Fissura longitudinalis cerebri, fissura cerebri lateralis (Sylvii), and polus temporalis.

Hypophysis, infundibulum, and tuber cinereum.

Corpora mamillaria, pedunculi cerebri (Crura), and fossa interpeduncularis.

Pons (Varoli), sulcus basilaris, and brachia pontis. What is the relation of the pons to the cerebellum?

On the medulla oblongata ${ }^{x}$ note the pyramides, decussatio pyramidum, foramen caecum, and fissura mediana anterior. Olivae and sulci laterales and anteriores. On the lateral aspect note corpus restiforme and funiculus lateralis. What is the relation of the corpus restiforme to the cerebellum and medulla spinalis? Note fibers crossing the corpus restiforme transversely (fibrae arcuatae externae), giving it the appearance from which it derives its name. Whence come these fibers?

Identify the twelve pairs of nervi cerebrales, giving special attention to the distinguishing peculiarities of each.

I. Olfactory. On the ventral surface of the frontal lobe, and lying in the sulcus olfactorius, are the buibus olfactorius and tractus olfactorius. Note trigonum olfactorium with its striae medialis, intermedia, and lateralis. The Nn. olfactorii proper arise in the nasal epithelium (Regio olfactorii nasi) and terminate in the bulbus olfactorius.

II. N. Opticus, passing from the bulbus oculus (removed) to the chiasma opticum, thence the tractus opticus, passing around the pedunculus cerebri to the thalamus opticus and mesencephalon.

III. N. Oculomotorius, emerging through the substantia perforata posterior in the fossa interpeduncularis, and resting in the sulcus $\mathrm{N}$. oculomotorii.

IV. N. Trochlearis, small nerve arising from the dorsal aspect in the region of the inferior colliculi of the corpora quadrigemina, and emerging along the anterior border of the pons.

'The medulla oblongata (myelencephalon) extends from the posterior border of the pons down to and including the decussatio pyramidum. Beyond this is medulla spinalis. 
V. N. Trigeminus, the largest of the nervi cerebrales, enters the pons on its lateral aspect, passing through the anterior portion of the brachium pontis. Note that it has two roots, a smaller motor (portio minor) and a large sensory root (portio major). The fibers of the portio major have their origin in the large ganglion semilunare (Gasserian ganglion), which, in the removal of the brain, was left in its position at the base of the cranium (impressio trigemini of the os temporale).

VI. N. Abducens, leaves the medulla oblongata nearer the middle line and just under the posterior border of the pons.

VII. N. Facialis, leaves the medulla from its lateral aspect, at about the same level as the abducens. Occasionally a portion of the $\mathrm{N}$. facialis ( $\mathrm{N}$. intermedius) passes through the posterior border of the pons.

VIII. N. Acusticus, enters the medulla on its extreme lateral aspect, a part of it passing around the corpus restiforme to the dorsal aspect. It has two roots, radix cochlearis and radix vestibularis.

IX. N. Glossopharyngeus, also enters the medulla on its lateral aspect and between the oliva and corpus restiforme.

$X$. N. Vagus, larger than the glossopharyngeus, and enters the medulla in the same line and so near to the glossopharyngeus as to often make the two appear as the fila of one nerve.

XI. Accessorius, arises from the medulla oblongata and the adjoining portion of the medulla spinalis by a series of rootlets. These join to form the common trunk which runs parallel to the medulla oblongata up to the level of the vagus, where it turns outward parallel with that nerve.

XII. N. Hypoglossus, arises nearer the mid-line. It also is formed by a series of rootlets (fila radicularia) which leave the medulla oblongata between the oliva and pyramis. In its origin it closely resembles the motor root (radix anterior) of a spinal nerve.

Observe that, exclusive of the Ist and IId, the nervi cerebrales enter or leave the encephalon along two parallel lines, a lateral line and a ventro-lateral line. The IIId, VIth, and 
XIIth emerge along the ventro-lateral line, while the Vth, VIIth, VIIIth, IXth, Xth, and XIth enter and emerge respectively along the lateral line. Consult a descriptive text for the origin, function, and distribution of each of the nervi cerebrales. Make a sketch of the basis encephali, illustrating the position and peculiarities of the nerves.

\section{DIVISIONS OF THE ENCEPHALON.}

With a sharp knife sever the right pedunculus cerebri immediately posterior to the corpora mamillaria. Then turn the specimen dorsal surface upward, press open the fissura longitudinalis cerebri to expose the corpus callosum, and carefully divide the corpus callosum along the mid-line. Proceed slowly. Note, lying just under the corpus callosum, another tract of white substance, the fornix. Under the fornix, note the ventriculus tertius, a cavity between the thalami optici. The thalami are composed of gray substance. Note that they are united across the ventricle by the massa intermedia (middle commissure). If the fornix be divided carefully, there will be found just under it a non-nervous membrane spreading over the cavity of the ventriculus tertius. This membrane is the tela choroidea ventriculi tertii (velum interpositum). At the posterior end of the ventriculus tertius (recessus pinealis) is the corpus pineale. Let this longitudinal incision join the first, or transverse incision through the pedunculus cerebri, so as to leave the corpus pineale intact and resting in position upon the corpora quadrigemina (see fig. 2). Continue the division so that the knife passes between the corpora mamillaria, splits the tuber cinerium in halves, and passes through the middle of the chiasma opticum. Return the half of the prosencephalon thus removed to the formalin solution for later use.

Now identify the following divisions of the encephalon:

(a) Rhombencephalon.

I. Myelencephalon (medulla oblongata).

2. Metencephalon.

Pons (Varoli).

Cerebellum.

3. Isthmus rhombencephali. 
(b) Cerebrum.

1. Mesencephalon.

Corpora quadrigemina.

Pedunculi cerebri.

2. Prosencephalon.

Diencephalon (Thalamencephalon, etc.).

Telencephalon.

For further detail as to the subdivisions see neurological nomenclature, and figs. 3 and 4, pp. I 43 and I 44. Identify the structures composing the so-called Rhinencephalon.

III. STUDY OF THE DIVISIONS OF THE ENCEPHALON.

(a) Rhombencephalon and mesencephalon. - Lift the posterior overhanging portion of the cerebellum and observe that it overlies the ventriculus quartus. Divide the cerebellum along the vermis superior, taking care that the knife, in passing through the vermis inferior, does not injure the floor of the ventriculus quartus, but does divide the velum medullare anterius (valve of Vieussens) up to the colliculi inferiores of the mesencephalon. Then remove the cerebellar hemisphere by severing the cerebellar peduncles, viz., brachium conjunctivum (superior), brachium pontis (middle), and corpus restiforme (inferior peduncle). These come together as one and can be distinguished only by careful examination after the incision.

(b) Make a drawing of the parts of the rhombencephalon now exposed, illustrating the appearance, position, and relations of the following structures:

1. The dorsal and lateral surface of the medulla oblongata showing the funiculus cuneatus and tuberculum cuneatum, funiculus gracilis and clava, and the fissura mediana posterior; the ventriculus quartus with its calamus scriptorius, taenia ventriculi quarti, sulcus longitudinalis, fossae rhomboideae, striae medullares (striae acusticae), colliculi faciales, and foveae superior and inferior; the corpus restiforme and tuberculum acusticum.

2. The Pons, with brachium pontis and brachium conjunctivum.

3. The Cerebellum, showing the vermis superior with its 
lingula, lobus centralis, and monticulus; the vermis inferior, with its nodulus, uvula, pyramis, and tuber vermis. In the mesial aspect (cut surface) of the hemisphere show further the arbor vitae, consisting of corpus medullare, laminae medullares, and substantia corticalis (cerebellar cortex). Identify the flocculus. What is the nature of the velum medullare anterius and its relation to the brachium conjunctivum?

4. Isthmus rhombencephali, showing velum medullare anterius, brachium conjunctivum, anterior portion of ventriculus quartus leading into the aqueductus cerebri (aqueduct of Sylvius), and fila lateralia pontis.

5. The mesencephalon, showing the N. trochlearis and corpora quadrigemina consisting of colliculi inferiores (testes) and colliculi superiores (nates); the brachium quadrigeminum superius and inferius, and corpus pineale.

Include also corpora geniculata mediale and laterale, and pedunculus cerebri. The corpora geniculata and corpus pineale belong to the thalamencephalon. A part of the overhanging occipital lobe and a part of the thalamus opticus should be included to show the relation of the mesencephalon to the parts anterior to it.

What structures are to be observed on the ventral surface of the mesencephalon? Identify the trigonum habenulae.

(c) Prosencephalon-- Facies medialis: Sever the remaining pedunculus cerebri, taking care not to injure the mesencephalon and thalamencephalon. Return the rhombencephalon and mesencephalon thus detached to the formalin solution. Make a drawing of the entire mesial surface of the prosencephalon now exposed, illustrating the shape and position of the following structures :

Commissura anterior, and corpus callosum consisting of splenium, truncus, genu, and rostrum corporis callosi.

Septum pellucidum, lamina rostralis, and lamina terminalis.

Tela choroidea ventriculi tertii, thalamus opticus, massa intermedia (middle or soft commissure), and chiasma opticum.

Remove a portion of the septum pellucidum to show a part 
of the nucleus caudatus situated in the ventriculus lateralis. Locate the foramen interventriculare (foramen of Monro).

Ventriculus tertius, tuber cinerium, infundibulum, and hypophysis.

Corpus mamillare and fornix, showing columna fornicis and taenia fornicis.

Gyri and sulci: sulcus corporis callosi, gyrus cinguli (gyrus fornicatus), gyrus hippocampi, and fissura hippocampi; sulcus cinguli (calloso-marginal), gyrus frontalis superior, lobulus paracentralis, praecuneus, sulcus subparietalis, fissura parieto-occipitalis, cuneus, fissura calcarina, and gyrus lingualis.

What is the relation of the sulcus centralis to the lobulus paracentralis? From what does the cuneus derive its name? What is the relation or the tractus opticus to the thalamus opticus? The fornix to the corpus mamillare?

2. Lobi cerebri--Determine the lobes of the Telencephalon and their component parts as follows:

a. Lobus frontalis. - Convex surface: gyrus centralis anterior (bounded posteriorly by sulcus centralis or fissure of Rolando), gyrus frontalis superior, sulcus frontalis superior, gyrus frontalis medius, sulcus frontalis inferior, and gyrus frontalis inferior with pars opercularis, pars triangularis, and pars orbitalis.

Mesial surface: gyrus frontalis superior, lobulus paracentralis, and sulcus rostralis.

Ventral surface: gyri orbitales, sulci orbitales, sulcus olfactorius, and gyrus rectus.

B. Lobus parietalis.-Convex surface: gyrus centralis posterior (bounded anteriorly by sulcus centralis), lobulus parietalis superior, lobulus parietalis inferior, and sulcus interparietalis.

Mesial surface: praecuneus (bounded posteriorly by fissura parieto-occipitalis) and sulcus subparietalis.

$\gamma$. Lobus occipitalis.-Convex surface: gyri occipitales superiores, sulci occipitales superiores, gyri and sulci occipitales laterales.

Mesial surface: Cuneus, fissura calcarina, and gyrus lingualis. 
8. Lobus temporalis, separated from lobi frontalis and parietalis by fissura cerebri lateralis (Sylvii). Identify gyrus temporalis superior, sulcus temporalis superior, gyrus temporalis medius, sulcus temporalis inferior, and gyrus temporalis inferior.

$\epsilon$. Insula (Island of Reil, central lobe).--Open the sylvian fissure by pulling aside the lobus temporalis sufficiently to expose the Insula to view, and note sulcus circularis (limiting sulci), gyrus longus insulae, gyrus brevis insulae, and limen insulae.

$\zeta$. Rhinencephalon (limbic lobe). - Lobus olfactorius, consisting of bulbus olfactorius, tractus olfactorius, and trigonum olfactorium with its striae medalis, intermedia, and lateralis. Area parolfactoria (Broca's area), sulcus parolfactorius, substantia perforata anterior, and limen insulae. Gyrus cinguli, gyrus hippocampi, fimbria and fascia dentata hippocampi, fornix, corpus mamillare, and lamina rostralis.

\section{SECTIONS OF ENCEPHALON.}

With the aid of a dissecting lens make careful drawings of the cut surfaces exposed in the sections made as suggested below. Pay special attention to the identification and interrelationship of the structures enumerated under each section. Attach the names to all the structures identified and number the drawings in series. The first drawing will be No. 5, thus including in the series the four drawings of the sections of the medulla spinalis.

To better realize or keep in mind the relation of each section to the part from which it is taken and to the section preceding, it is advised that the sections be rendered one at a time. Complete the study and the drawing of each section before the next is removed from the specimen.

It must be remembered that of the various structures present in a section only the coarser and more evident structures are enumerated under that section. The more detailed study necessitates the special methods for the preparation of the tissue and the use of the compound microscope. 
Transfer the specimen from the preserving solution of formalin to water while the study is being made. Do not let it become dry.

In making the sections use a "brain knife" or a sharp knife with a long thin blade. A section should be made at a single stroke, if possible.

(a) Rhombencephalon.-It is supposed that the following transverse sections are to be taken from the specimen, consisting of the Rhombencephalon and Mesencephalon as detached from the Prosencephalon in III, $c$, above. Use fig. I as a guide in making the sections.

Section 5, to pass transversely through the decussatio pyramidum.

Draw, showing the form, position, and relations of the following structures :

Fissura mediana anterior and fissura mediana posterior (septum posterius of medulla spinalis ).

Pyramis, decussatio pyramidum, columna anterior, formatio reticularis, substantia gelatinosa (Rolandi), canalis centralis, and substantia grisea centralis.

Funiculus gracilis, nucleus funiculi gracilis, funiculus cuneatus, nucleus funiculi cuneati, fibrae arcuatae internae, and lemniscus (fillet).

Tractus spinalis $N$. trigemini (ascending root of the $V$ th nerve), funiculi laterales, and fila radicularia $\mathrm{N}$. accessorii.

Carefully compare the drawing with that made from the section through the pars cervicalis medullae spinalis, and especially note all modifications which have resulted in the transition of medulla spinalis into medulla oblongata. Has the position of the canalis centralis changed? How has the septum posterius now become the fissura mediana posterior? Where are the columnae posterior and anterior (dorsal and ventral horns)? What is the relation of the decussatio pyramidum to the funiculi laterales? What is the meaning of the nuclei funiculi gracilis and funiculi cuneati? What is the lemniscus? 
Section 6, to pass through the lower extremity of the oliva and the point of the calamus scriptorius

Draw, giving special attention to the following structures:

Fissura mediana anterior, pyramis, raphe, and calamus scrip torius.

Nucleus funiculi gracilis and nucleus funiculi cuneati, fibrae arcuatae internae, and decussatio lemniscorum.

Tractus spinalis N. trigemini and substantia gelatinosa.

Corpus restiforme, fibrae arcuatae externae, nucleus olivaris inferior (oliva), and nuclei laterales.

What has become of the canalis centralis and the fissura mediana posterior? How do the pyramides differ from those of the last section? What is the significance of the decussatio lemnisco-

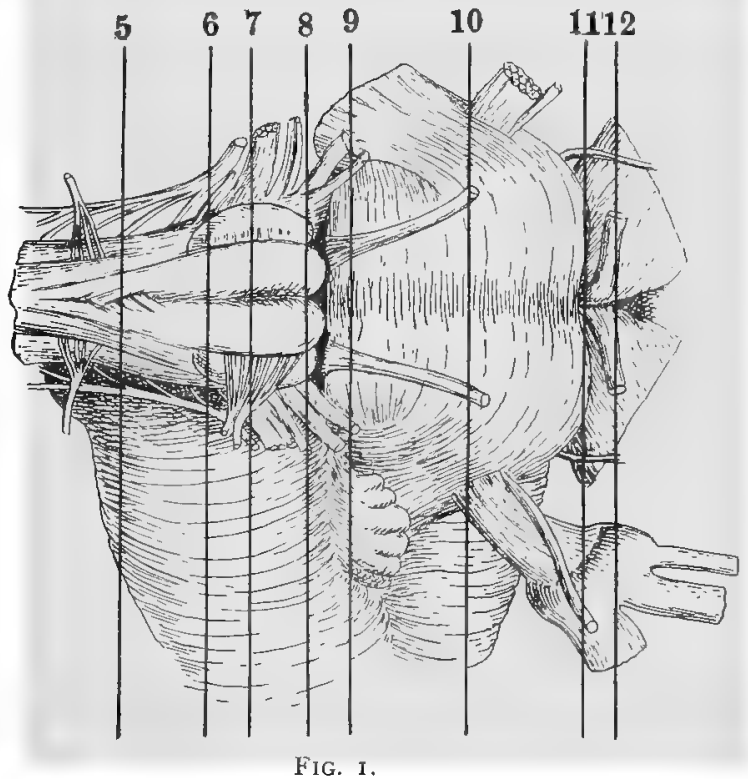

Slightly diagrammatic representation of the ventral aspect of the Rhombencephalon and Mesencephalon. The verticals indicate the levels at which Sections 5 to I 2 are to be taken. The figure is to be used supplementary to the directions given under each section. In certain cases the plane of the section will slant somewhat.

rum? Whence come the fibers composing it? Are there any evidences of nervi cerebrales other than of the trigeminus? What is the relation of the substantia gelatinosa to the tractus spinalis N. trigemini?

Section 7, to pass transversely through the middle of the oliva. Let the section involve the overhanging cerebellar hemisphere. 
Draw, giving special attention to the following structures:

Pyramis, lemniscus, decussatio lemniscorum, fasciculus longitudinalis, fibrae arcuatae internae and externae, nucleus olivaris inferior and olivaris accessorius, and corpus restiforme.

Ventriculus quartus with tela choroidea ventriculi quarti.

Fila radicularia $\mathrm{N}$. hypoglossi and nucleus $\mathrm{N}$. hypoglossi. Radix spinalis $\mathrm{N}$. trigemini (ascending root of $\mathrm{Vth}$ nerve), substantia reticularis grisea, and tractus solitarius.

What has become of the funiculi posteriores (gracilis and cuneatus)? What is the destination of the corpus restiforme? What is the tractus solitarius? In the section of the cerebellum, note gyri and sulci cerebelli, substantia corticalis, and laminae medullares.

Section 8, to pass through the upper extremity of the oliva and through the lower border of the entering roots of the $\mathrm{N}$. acusticus. The plane will pass near the middle of the cerebellar hemisphere.

Draw, paying special attention to the following structures:

Pyramis, lemniscus, fasciculus longitudinalis, fibrae cerebelloolivaris (arcuatae), corpus restiforme, and nucleus olivaris inferior.

N. acusticus: radix cochlearis, nucleus ventralis, and striae medullares (striae acusticae); radix vestibularis and nucleus dorsalis.

Fila radicularia $\mathrm{N}$. glossopharyngei (?), nucleus $\mathrm{N}$. glossopharyngei, tractus solitarius, and radix N. trigemini with substantia reticularis grisea.

Cerebellum: sulci and gyri cerebelli, vermis superior and uvula vermis; corpus dentatum, corpus medullare, laminae medullares, and substantia corticalis.

What changes are to be noted in the general shape of the section of the medulla oblongata? Compare the pyramis here with that in Section 6. Explain the increase in the size of the corpus restiforme. What becomes of the auditory fibers contained in the striae medullares? What is the nucleus dentatus?

Section 9 , to pass through the lower border of the pons just 
above the roots of $\mathrm{N}$. abducens. Will pass through the cerebellum, involving the cerebellar peduncles.

Draw, illustrating the appearance and position of the following structures:

Fibrae-pontis superficiales, fasciculi pyramidales pontis, lemniscus, fasciculus longitudinalis medialis, and raphe pontis.

Radix vestibularis $N$. acusticae and nucleus $N$. vestibuli lateralis (Deiter's nucleus). Look for a fiber tract passing from Deiter's nucleus to the cerebellum by way of the corpus restiforme and connecting with the "roof nuclei" of the cerebellum.

Fila radicularia $\mathrm{N}$. abducentis and nucleus $\mathrm{N}$. abducentis.

Radix N. facialis (genu and pars secunda), colliculus facialis, and nucleus N. facialis.

Radix N. trigemini and nucleus sensibilis N. trigemini (substantia gelatinosa?).

Nucleus olivaris superior and corpus trapezoideum.

Cerebellum: corpus restiforme, brachium pontis, and brachium conjunctivum (superior cerebellar peduncle); lingula cerebelli, vermis superior, corpus medullare, etc.

What is the course of the radix $\mathrm{N}$. facialis between its origin in the nucleus $\mathrm{N}$. facialis and its emergence on the ventral aspect of the medulla oblongata? Note the difference in the positions of the nuclei $\mathrm{N}$. facialis and N. abducentis. Why has the radix spinalis $\mathrm{N}$. trigemini increased in size? What is the office of the nucleus olivaris inferior? Nucleus olivaris superior?

Section $I O$, to pass through the middle of the pons.

Draw, giving special attention to the following structures:

Fibrae pontis superficiales and profundae, fasciculi pyramidales pontis, and raphe pontis.

Lemniscus medialis, lemniscus lateralis, fasciculus longitudinalis medialis, radix descendens $\mathrm{N}$. trigemini, radix N. trochlearis, and decussatio $\mathrm{Nn}$. trochlearum.

Velum medullare anterius, ventriculus quartus (upper portion), stratum griseum centrale, and substantia ferruginea.

Cerebellum with brachium conjunctivum. 
Note the increase in the area of the cross-section of "pyramidal fibers" occurring in the pons as compared with those in section 8. Explain the change in the shape of the section and the contraction of the ventriculus quartus. What are the relative positions in the section of the sensory (ascending) fiber bundles and the descending fiber bundles? What is the brachium conjunctivum? What is the occasion of the change in the name of the radix $N$. trigemini?

(b) Mesencephalon.

Section $I I$, to pass at the immediate upper border of the pons and through the inferior corpora quadrigemina (colliculi inferiores). The plane will slant backward slightly.

Draw, giving special attention to the following structures:

Fossa interpeduncularis, basis pedunculi, and substantia nigra.

Lemniscus medialis and lateralis, fasciculus longitudinalis medialis, radix descendens $\mathrm{N}$. trigemini, and decussatio brachii conjunctivi.

Aqueductus cerebri (Sylvii), stratum griseum centrale, nucleus $\mathrm{N}$. trochlearis, stratum zonale, and nucleus colliculi inferioris.

What must be the course of the radices nervorum trochlearum? What fasciculi are contained in the basis pedunculi? What is the significance of the decussatio brachii conjunctivi? What is the aqueductus cerebri?

Section I2, to pass through the region of the emergence of the Nn. oculomotorii and through the superior corpora quadrigemina (colliculi superiores) Will involve the corpus pineale.

Draw, paying special attention to the following:

Basis pedunculi, substantia nigra, fasciculus longitudinalis medialis, lemniscus, and radix descendens $\mathrm{N}$. trigemini.

Aqueductus cerebri, stratum griseum centrale, nucleus $\mathrm{N}$. oculomotorii, and fila radicularia N. oculomotorii.

Nucleus ruber (tegmenti), brachium quadrigeminum inferius, and fibers of the commissura posterior.

Colliculi superiores, corpus geniculatum mediale, tractus 
opticus, corpus pineale, and a part, perhaps, of the tela choroidea ventriculi tertii (velum interpositum).

What is the relation of the nucleus ruber to the brachium conjunctivum? To what is the name "substantia nigra" due? What can be said of the distribution of the radix of the $N$. trigeminus? What is the relation of the tractus opticus to the colliculus superior? What is the office of the fasciculus longitudinalis medialis?

The corpus pineale and corpus geniculatum laterale belong to the thalamencephalon.

(c) Prosencephalon (telencephalon, thalamencephalon, and diencephalon).

Using fig. 2 as a guide, take frontal sections from the half of the prosencephalon (cerebral hemisphere) detached in II. above. Sections made with a single stroke of a long knife will be best in that their surfaces will be more perfect. In every case study that face of the section which is exposed on the frontal side of the knife. Identify the larger blood vessels occurring in each section.

Section 13 , to pass through the splenium corporis callosi and about the middle of the praecuneus near the ramus sulci cinguli which separates the praecuneus from the lobus paracentralis. The plane may slant slightly toward the posterior region.

Draw, giving special attention to the appearance and position of the following structures:

Substantia corticalis (cerebral cortex), substantia alba, corpus callosum (splenium), radiatio corporis callosi, and radiatio occipito-thalamica (optic radiation).

Sulcus corporis callosi, gyrus and sulcus cinguli, and praecuneus.

Sulcus interparietalis, fissura cerebri lateralis (Sylvii), gyri temporales superior, medius, and inferior, and the sulci separating them.

Cornu posterior ventriculi lateralis, plexus choroideus, calcar avis, hippocampus and gyrus hippocampi, and gyrus fusiformis. 
Does the substantia corticalis vary in thickness? Why? What is the significance of the radiatio occipito-thalamica?

Section I4, to pass through the superior extremity of the gyrus centralis posterior, the posterior portion of the thalamus opticus (pulvinar), and on the ventral surface to pass through or involve a portion of the cut surface of the pedunculus cerebri.

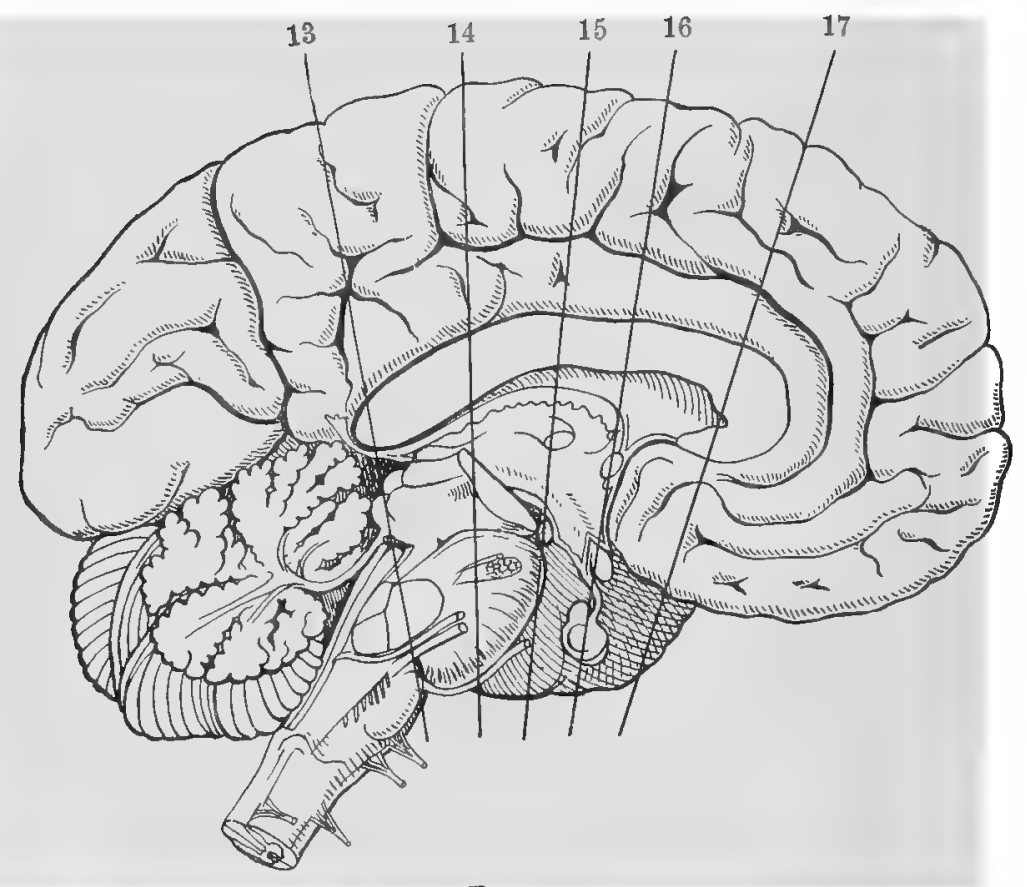

FIG. 2.

Slightly diagrammatic representation illustrating the division of the encephalon as directed in II, p. I2I. The lines passing through the specimen indicate the planes in which sections of the prosencephalon ( 13 to 17 ) are to be taken.

Draw, giving special attention to the following structures:

Corona radiata, corpus callosum, fornix, tela choroidea ventriculi tertii (velum interpositum), thalamus (pulvinar), pedunculus cerebri, tractus opticus, capsula interna, and claustrum.

Cornu inferius ventriculi lateralis, cauda nuclei caudati, plexus 
choroideus, gyrus hippocampi, and fimbria and fascia dentata hippocampi.

Include and name other gyri and sulci involved in the section.

What is the relation of the tractus opticus to the pulvinar? What is the nature of the lining of the ventriculus lateralis? What is the function of the corpus callosum? What is the relation of the pedunculus cerebri to the capsula interna? Look for the commissura posterior. This may have been removed with the mesencephalon and corpus pineale.

Section 15, to pass through the corpus mamillare, the massa intermedia, and the anterior portion of the lobulus paracentralis.

Draw, giving special attention to the following structures:

Corona radiata, capsula interna, corpus callosum, columna fornicis, ventriculus tertius, massa intermedia (middle commissure), thalamus opticus, stratum zonale, lamina medullaris, and stria medullaris thalami; nucleus hypothalamicus, basis pedunculi, tractus opticus, and corpus mamillare.

Corpus striatum and radiatio corporis striati.

Insula, gyri insulae, claustrum, capsula externa, nucleus lentiformis, composed of putamen and globus pallidus. Ventriculus lateralis with its pars centralis under the corpus callosum and its cornu inferius containing the hippocampus. Look for the fasciculus thalamo-mamillaris.

What is the relation of the corpus mamillare to the fornix and to the thalamus? By what fibers is the substantia corticalis connected with the ganglia below and with the medulla oblongata? What is the nature of the claustrum? What is the difference between the capsula interna and externa? What masses compose the corpus striatum?

Attach the names of all gyri and sulci involved in the section.

Section I6, to pass through the chiasma opticum and the commissura anterior.

Draw, giving special attention to the following structures:

Corpus callosum, columna fornicis, ventriculus lateralis (cornu anterius), septum pellucidum, plexus choroideus. 
Corpus striatum, nucleus caudatus (caput), capsula interna, nucleus lentiformis (putamen and globus pallidus).

Capsula externa, claustrum, insula and gyri insulae.

Commissura anterior, substantia perforata anterior, chiasma opticum, and recessus opticus ventriculi tertii.

Include all larger structures unmentioned, but occurring in the section.

What opposite lobi cerebri are connected by the commissura anterior? "What is the relation of the commissura anterior to the capsula interna? Identify and determine the office of the foramen interventriculare (foramen of Monro). Explain the change in the appearance of the section of the fornix. What has become of the thalamus opticus?

Section 17 , to pass through the rostrum corporis callosi and the trigonum olfactorium.

Draw, giving special attention to the following:

Corpus callosum (genu), septum pellucidum, rostrum corporis callosi, gyrus subcallosus, area parolfactoria (Broca's area), and trigonum olfactorium (striae medialis and lateralis).

Corṇu anterius ventriculi lateralis, caput nuclei caudati, capsula interna, nucleus lentiformis (putamen only), capsula externa, and claustrum.

Explain the fact that the fissura cerebri lateralis (Sylvii) occurs twice in the section. What does the septum pellucidum separate? What produced the globus pallidus? What must be the shape of the ventriculus lateralis?

V. TORN PREPARATION OF PROSENCEPHALON.

Use the half of the prosencephalon (cerebral hemisphere) detached from the rhombencephalon in III, $c$, above.

By means of the necessary tearing and teasing, determine the relations between the structures mentioned in the following groups :

(a) Corpus callosum, centrum semiovale, and substantia corticalis (cerebral cortex). Leave the fornix intact.

(b) Ventriculus lateralis, plexus choroideus, nucleus caudatus, 
and thalamus opticus. Make a drawing illustrating the shape and extent of the intraventricular portion of the nucleus caudatus.

(c) Tractus opticus, chiasma opticum, thalamus opticus (pulvinar), radiatio occipito-thalamica, and lobus occipitalis. What is the shape of the thalamus opticus?

(d) Commissura anterior, nuclei caudatus and lentiformis, capsula interna, and lobus temporalis.

(e) Bulbus and tractus olfactorius, trigonum olfactorium, hippocampus, fornix, corpus mamillare, and tuberculum anterius thalami. What is the course of olfactory fibers to the temporal lobe (uncus)?

$(f)$ Pedunculus cerebri, capsula interna, nuclei caudatus and lentiformis, corona radiata, and substantia corticalis.

How may the cortical subśtance of the different lobes be associated? Note fibrae arcuatae cerebri (fibrae propriae) associating neighboring gyri.

VI. RECONSTRUCTIONS.

Lay all the drawings in series, and, after careful study and with the aid of descriptive texts, construct diagrams of the central nervous system illustrating the course of the following neurone systems or conduction pathways:

(a) General sensory (ascending) nerve pathways from the skin, etc., to the cerebral cortex (substantia corticalis cerebri).

I. Sensory neurones of the first order: nervi spinales, ganglia spinalia, radices posteriores (dorsal roots), funiculi posteriores (gracilis and cuneatus).

2. Sensory neurones of the second order: nucleus funiculi gracilis, nucleus funiculi cuneati, fibrae arcuatae, decussatio lemniscorum, lemniscus (fillet), and thalamus.

3. Sensory neurones of the third order: thalamus, capsula interna, corona radiata, and gyri (centrales) cerebri.

(b) Indirect sensory pathway via cerebellum: Ganglia spinalia, radices posteriores, nucleus dorsalis (Clarke's column), fasciculus cerebello-spinalis (direct cerebellar tract), fasciculus antero-lateralis (Gowers' tract), corpus restiforme, nucleus den- 
tatus, substantia corticalis cerebelli (vermis ?), brachium conjunctivum, decussatio brachii conjunctivi, nucleus ruber, and gyri (centrales) cerebri.

(c) General motor (descending) pathways from cerebral cortex to muscles, etc.

I. Neurone systems involving nuclei of origin of the motor nervi cerebrales: Gyri (centrales) cerebri (pyramidal cells), corona radiata, capsula interna (pars occipitalis), basis pedunculi to the nuclei of the oculomotorius, trochlearis, trigeminus (portio minor), abducens, facialis, glossopharyngeus, vagus (nucleus ambiguus), accessorius, and hypoglossus, and the roots arising from these nuclei.

2. Motor neurone systems involving the nervi spinales: Gyri (centrales) cerebri (pyramidal cells), lobulus paracentralis, corona radiata, capsula interna (pars occipitalis), basis pedunculi, pyramides, decussatio pyramidum, fasciculi cerebro-spinales (lateralis and anterior), columnae anteriores (ventral horns), and radices anteriores (ventral roots).

(d) Special conduction pathways.

I. Olfactory: Regio olfactorii nasi, nervi olfactorii, bulbus olfactorius, tractus olfactorius, trigonum olfactorium, and lobus temporalis (uncus); area parolfactoria (Brocae), gyrus cinguli, hippocampus, fornix, etc. For other connections see Rhinencephalon.

2. Visual: Retina, N. opticus, chiasma opticum, tractus opticus, corpus geniculatum laterale, colliculus superior, pulvinar, capsula interna (pars occipitalis), radiatio occipito-thalamica, and lobus occipitąlis (cuneus, etc.).

3. Auditory: Organon Corti, ganglion spirale, N. cochleae (cochlea root of VIIIth), nucleus ventralis $\mathrm{N}$. acusticae, nucleus dorsalis cochleae, striae medullares, nucleus olivaris superior, corpus trapezoideum, lemniscus lateralis, colliculi inferiores, brachium quadrigeminum inferius, corpus geniculatum mediale, capsula interna, corona radiata, and lobus temporalis (gyrus temporalis superior). Determine the origin and central distribution of the $N$. vestibularis. 
(e) General connecting pathways.

I. "Projection fibers": substantia corticalis, corona radiata, capsula interna, and pedunculi cerebri.

2. Commissural fibers: corpus callosum, commissura anterior passing through centrum semiovale to substantia corticalis.

3. Association fibers: (a) Long paths: cingulum (in gyrus cinguli); fasciculus longitudinalis superior, connecting lobus frontalis with lobus occipitalis; and fasciculus longitudinalis inferior, connecting lobus temporalis with lobus occipitalis. ' $(\beta)$ Short paths: fasciculus uncinatus, connecting uncus with lobus frontalis; fornix, connecting hippocampus with corpus mamillare, substantia perforata anterior and vicinity; and fibrae arcuatae cerebri (fribrae propriae) connecting neighboring gyri. 
Digitized by Microsoft巴 


\section{ANATOMICAL NOMENCLATURE [BNA] FOR THE NERVOUS SYSTEM AND SENSE ORGANS.}

Much confusion has resulted in the anatomical literature from the use of various names for the same organ or structure. To obviate this it became necessary that scientists should agree upon some one set of terms. To this end the Basel Commission of Anatomists was convened. After the expenditure of much care and labor, the commission selected a nomenclature for the gross anatomy of the entire body. This nomenclature is now being adopted by anatomists generally. It is commonly known . as the [BNA] which is an abbreviation for "Die in Basel angenommenen nomina anatomica."

It was necessary that the names be of uniform construction and in a language which would most easily permit of their universal adoption. The Latin was chosen, therefore, both because an acquaintance with that language is more nearly universal than with others, and because of the prevalence of Latin in the anatomical nomenclature already existing.

That part of the [BNA] which pertains to the nervous system and sense organs is given here, with the hope that it will be of convenience to both instructors and students. If not already familiar with the nomenclature, one will certainly have frequent need to refer to a classified list of the terms. In the literature it will be found that the [BNA] is becoming more and more used, while the older or more conservative text-books do not use the nomenclature strictly, nor do they contain a list of the terms for reference.

The following list of terms is taken from that part of the [BNA] contained in Professor His's paper on anatomical nomenclature. ${ }^{x}$

"Wilhelm His, "Die anatomische Nomenclatur," Archiv. für Anat. und Physiol., Anat. Abthl. Suppl., 1895. Also separately bound ; Veit \& Comp, Leipzig, 1895 . 
It is earnestly advised that the student familiarize himself with the nomenclature and do all he can to promote its adoption.

With the exception of the addition of reference numbers and letters for the various heads and sub-heads, and a few minor changes in the arrangement of the subjects, the list is taken verbatim from the [BNA] as given in Professor His's paper.

The arrangement of the terms applying to the Encephalon is based upon the development of the various parts (see figs. 3 and 4 ). In other cases an arrangement is made which more nearly follows the order in which the various structures are taken up in the study of the anatomy of the organs.

\section{NEUROLOGIA.}

Nervus

Ganglion

Substantia alba

Substantia grisea

Substantia gelatinosa

Taenia telarum

Ependyma ventriculorum

Sulcus limitans ventriculorum

Nuclei nerỵorum cerebralium
Nuclei originis

Nuclei terminales

Ramus communicans

Ramus anastomoticus

Ramus muscularis

Nervus cutaneus

Nervus articularis

Plexus nervorum spinalium

\section{SYSTEMA NERVORUM CENTRALE.}

A. Medulla spinalis.

I. External form.

Pars cervicalis

Intumescentia cervicalis

Pars thoracalis

Pars lumbalis

Intumescentia lumbalis

Conus medullaris

Filum terminale

Ventriculus terminalis

Fissura mediana anterior
Sulcus medianus posterior

Sulcus lateralis anterior

Sulcus lateralis posterior Sulcus intermedius posterior (Sulcus intermedius anterior) Funiculi medullae spinalis Funiculus anterior Funiculus lateralis Funiculus posterior 
II. Sections of Medulla spinalis.

Canalis centralis

Substantia grisea centralis

Conımissura anterior alba

Commissura anterior grisea

Commissura posterior

Columnae griseae

Columna anterior

Columna lateralis

Columna posterior

Cervix columnae posterioris

Apex columnae posterioris

Substantia gelatinosa [Rolandi]

Nucleus dorsalis [Stillingi, Clarkii]

Formatio reticularis

Funiculus anterior

Fasciculus cerebrospinalis anterior [pyramidalis anterior]

Fasciculus anterior proprius

[Flechsigi]

Funiculus lateralis

Fasciculus cerebrospinalis lateralis [pyramidalis lateralis ]

Fasciculus cerebellospinalis Fasciculus anterolateralis superficialis [Gowersi]

Fasciculus lateralis proprius [Flechsigi]

Funiculus posterior

Fasciculus gracilis [Golli]

Fasciculus cuneatus [Burdachi] 


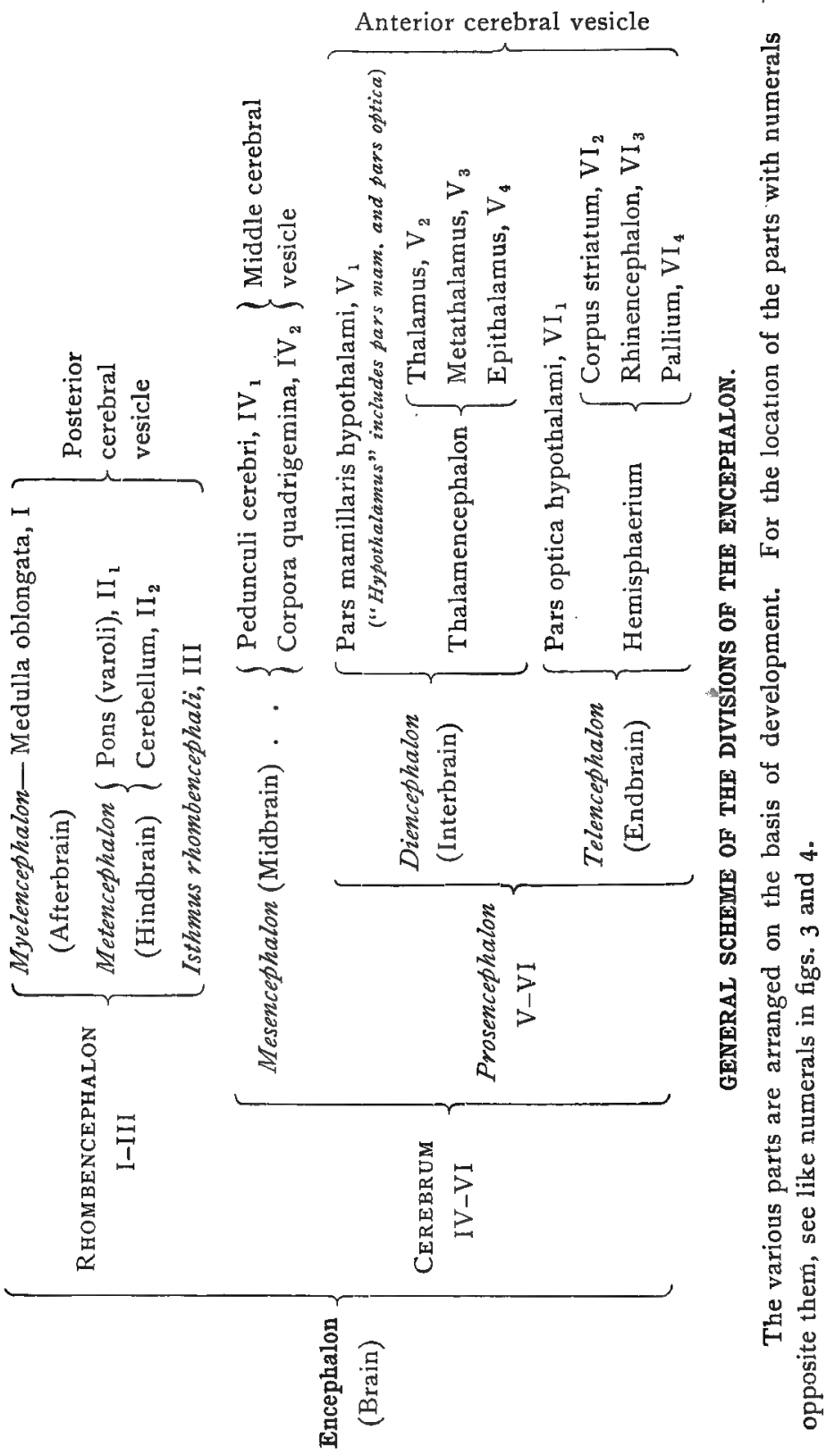




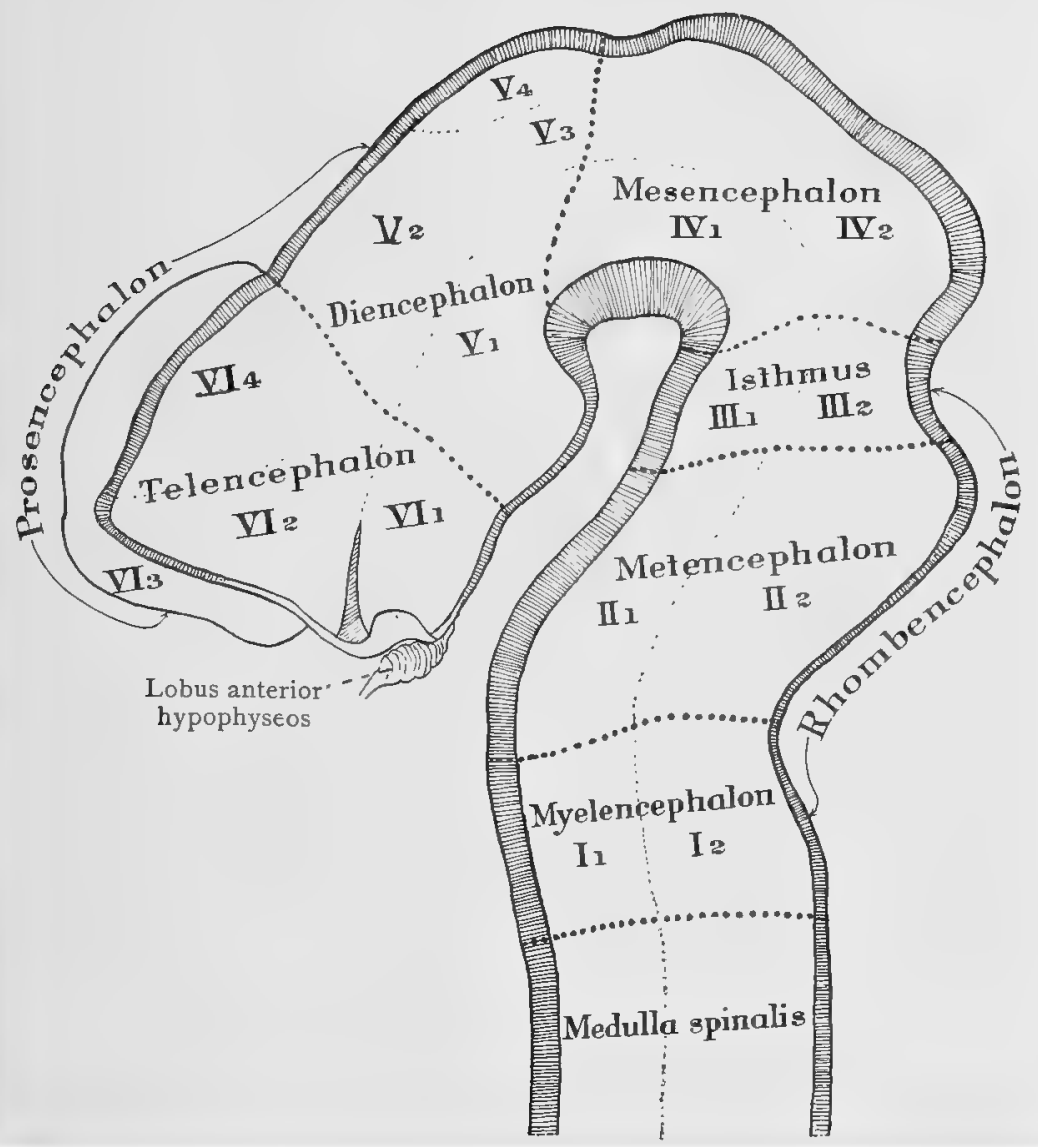

FIG. 3 .

Median section through embryo human brain at the end of the first month, showing the derivatives of the three primary brain vesicles. The reference numbers indicating the various regions correspond with the numbers opposite the names of those regions as given in the scheme on p. 142. (After His.) 


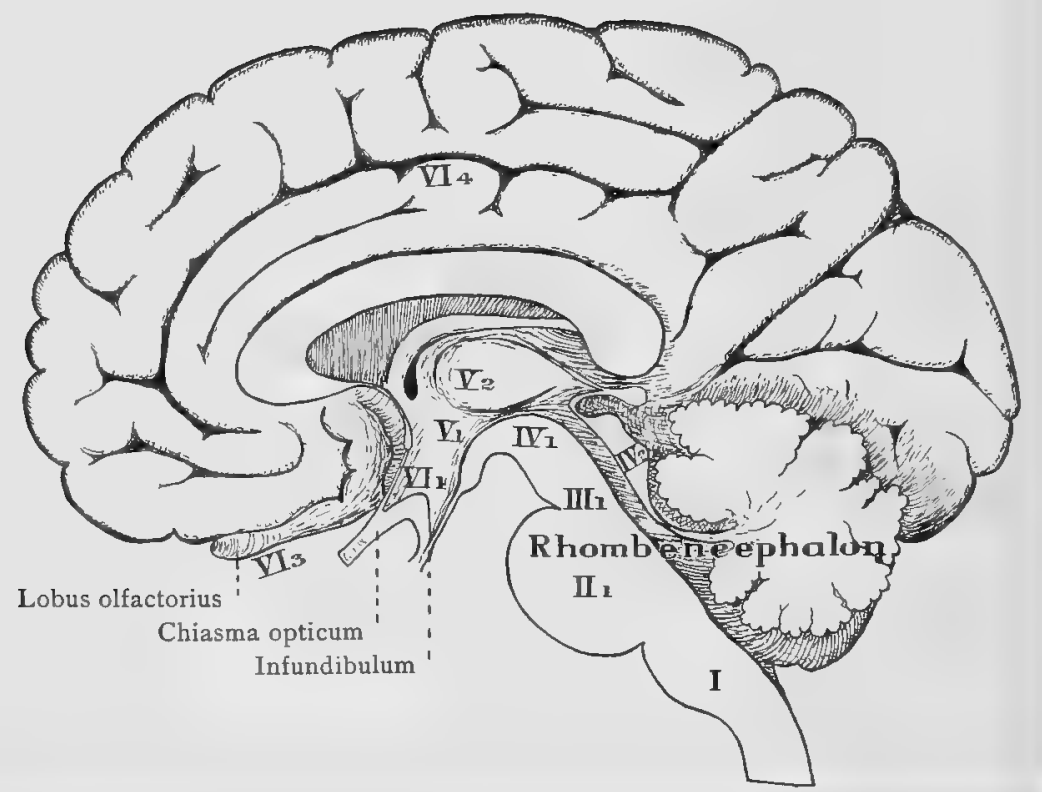

FIG. 4.

Median section through the adult human brain, showing the various regions or 'derivatives in the adult form as compared with the embryonic form shown in fig. 3. The reference numbers are to be interpreted in the same way as for fig. 3. (After His.) 


\section{B. Encephalon (the brain).}

I. RHOMBENCEPHALON.

a. Myelencephalon.

I. Medulla oblongata. a. External form.

Pyramis [medullaeoblongatae] Oliva

Decussatio pyramidum

Sulcus lateralis anterior

Sulcus lateralis posterior

Fissura mediana posterior

Fissura mediana anterior

Foramen caecum
Corpus restiforme

Funiculus lateralis

Funiculus cuneatus

Tuberculum cinereum

Funiculus gracilis

Clava

Fibrae arcuatae externae

$\beta$. Sections of medulla oblongata.

Raphe

Stratum nucleare

Nucleus n. hypoglossi

Nucleus ambiguus

Nucleus alae cinereae

Tractus solitarius

Nucleus tractus solitarii

Tractus spinalis $\mathrm{n}$. trigemini

Nucleus tractus spinalis $\mathrm{n}$. trigemini

Nucleus funiculi gracilis

Nucleus funiculi cuneati

Nuclei laterales

Nucleus olivaris inferior

Hilus nuclei olivaris

Nucleus olivaris accessorius
Nucleus olivaris accessorius dorsalis

Nuclei arcuati

Fibrae arcuatae internae

Substantia reticularis grisea

Substantia reticularis alba

Fasciculus longitudinalis medialis

Stratum interolivare lemnisci

Decussatio lemniscorum

Corpus restiforme

Fasciculi corporis restiformis

Fibrae cerebello-olivares

Fasciculi pyramidales

Fibrae arcuatae externae medialis 
2. Ventriculus quartus.

Fossa rhomboidea

Pars inferior fossae rhomboideae [Calamus scriptorius ]

Pars intermedia fossae rhomboideae

Recessus lateralis fossae rhomboideae

Pars superior fossae rhomboideae

Sulcus limitans [fossae rhomboideae]

Fovea inferior

Fovea superior

Trigonum n. hypoglossi

Striae medullares
Eminentia medialis

Colliculus facialis

Ala cinerea

Area acustica

Locus caeruleus

Tegmen ventriculi quarti

Velum medullare posterius

Taenia ventriculi quarti

Obex

Lamina chorioidea epithelialis (Apertura medialis ventriculi quarti [Foramen Magendii])

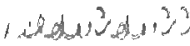

(Apertura lateralis ventriculi quarti)

Fastigium

b. METENCEPHALON.

I. Pons [Varoli].

a. External form.

Sulcus basilaris

Fasciculus obliquus [pontis]
(Fila lateralia pontis)

Brachium pontis

\section{$\beta$. Sections of pons.}

i. Pars dorsalis pontis. Radix n. facialis

Raphe

Nucleus n. abducentis

Nuclei motorii n. trigemini

Radix descendens [mesencephalica] n. trigemini '

Tractus spinalis $\mathrm{n}$. trigemini

Nucleus tractus spinalis $n$. trigemini

Nucleus n. facialis
Pars prima

Genu [internum]

Pars secunda

Nuclei n. acustici

Nuclei n. cochlearis

Nuclei $n$. vestibularis

Nucleus olivaris superior

Nucleus lemnisci lateralis

Fasciculus longitudinalis medialis 
Formatio reticularis

Corpus trapezoideum

Lemniscus

Lemniscus medialis [sensitivus ]

Lemniscus lateralis [acusticus ] ii. Pars basilaris pontis.

Fibrae pentis profundae

Fasciculi longitudinales [pyramidales ]

Nuclei pontis

Fibrae pontis superficiales

2. Cerebellum.

a. External form.

i. Partes generales.

Gyri cerebelli

Sulci cerebelli

Vallecula cerebelli

Incisura cerebelli anterior

Incisura cerebelli posterior

Sulcus horizontalis cerebelli

Fissura transversa cerebelli

ii. Vermis.

Lingula cerebelli

Vincula lingulae cerebelli

Lobulus centralis

Monticulus

Culmen

Declive

Folium vermis

Tuber vermis

Pyramis [vermis]
Uvula [vermis]

Nodulus

iii. $\mathrm{He} \mathrm{m}$ is $\mathrm{ph}$ aer i $\mathrm{m}$

cerebelli.

Facies superior

Ala lobuli centralis

Lobulus quadrangularis

Pars anterior

Pars posterior

Lobulus semilunaris superior

Facies inferior

Lobulus semilunaris inferior

Lobulus biventer

Tonsilla cerebelli

Flocculus

(Flocculi secundarii)

Pedunculus flocculi

Nidus avis

B. Sections of cerebellum.

Corpus medullare

Laminae medullares

Arbor vitae

Substantia corticalis

[Lamina basalis]

[Stratum cinereum]

[Stratum gangliosum]

Stratum granulosum
Nucleus dentatus

Hilus nuclei dentati

Nucleus fastigii

Nucleus globosus

Nucleus emboliformis

Capsula nuclei dentati 
c. ISTHMUS RHOMBENCEPHALI.

I. External form.

Brachium conjunctivum [cere- Velum medullare anterius belli]

Lemniscus

Lemniscus lateralis

Lemniscus medialis

Trigonum lemnisci
Frenulum veli medullaris anterioris

2. Sections of isthmus.

[vide Pedunculus cerebri.]

Ganglion interpedunculare Nucleus n. trochlearis

II. CEREBRUM.

Facies convexa cerebri

Basis cerebri

Facies medialis cerebri

a. MESENCEPHALON.

I. Facies inferior.

Fossa interpeduncularis

Recessus posterior

[Tarini]

Recessus anterior

Substantia perforata posterior

2. Pedunculus cerebri.

a. External form.

Aquaeductus cerebri [Sylvii] Sulcus n. oculomotorii Sulcus lateralis

B. Sections of pedunculi cerebri.

i. Tegmentum.

Stratum griseum centrale

Formatio reticularis

Fasciculus longitudinalis medialis

Radix descendens $n$. trigemini

Nucleus radicis descendentis $n$. trigemini

Nucleus n. oculomotorii
Nuclei tegmenti

Nucleus ruber

Decussationes tegmentorum

Decussatio brachii conjunctivi

Lemniscus lateralis

Lemniscus medialis

ii. Substantia nigra.

iii. Basis pedun'culi. 
3. Corpora quadrigemina.

a. External form.

Lamina quadrigemina

Colliculus superior

Colliculus inferior

Brachium quadrigeminum superius

Brachium quadrigeminum inferius $\beta$. Sections of corpora quadrigemina.

Stratum zonale

Stratum griseum colliculi superioris

Nucleus colliculi inferioris

Stratum album profundum

b. PROSENCEPHALON.

I. DIENCEPHALON.

a. Ventriculus tertius.

Aditus ad aquaeductum cerebri Massa intermedia

Commissura posterior [cerebri] Recessus opticus

Foramen interventriculare

Recessus infundibuli

[Monroi]

Sulcus hypothalamicus

Commissura anterior [cerebri]

[Monroi]

Recessus triangularis

B. Pars mamillaris hypothalami.

Corpus mamillare.

$\gamma$. Thalamencephalon.

i. Thalamus.

Pulvinar

Tuberculum anterius thalami

Taenia thalami

Stria medullaris

Lamina chorioidea epithelialis

ii. Metathala mus.

Corpus geniculatum mediale Corpus geniculatum laterale

iii. Epithalamus.

Corpus pineale
Recessus pinealis

Recessus suprapinealis

Habenula

Commissura habenularum

Trigonum habenulae

iv. Sections Thalamen-

$$
\text { cephalon. }
$$

Stratum zonale

Nucleus anterior thalami

Nucleus medialis thalami

Nucleus lateralis thalami 
Laminae medullares thalami Nucleus habenulae

Nucleus corporis geniculati medialis

Nucleus corporis geniculati

Fasciculus retroflexus

[Meynerti] lateralis

HYPOTHALAMUS. ${ }^{x}$

Pars mamillaris hypo- Corpus mamillare $\mathrm{th}$ al a $\mathrm{mi}$ Par's optica hypothalami Sections of hypothalamus.

Nucleus hypothalamicus [Corpus Luysi]

Pars grisea hypothalami

Commissura superior [Meynerti]

Commissura inferior [Guddeni] Nuclei corporis mamillaris

Fasciculus thalamomamillaris
Fasciculi pedunculomamillares Pars tegmentalis Pars basilaris Ansa peduncularis Ansa lenticularis Pedunculus thalami inferior [Vicq' d'Azyri]

2. TELENCEPHALON.

a. Pars optica hypothalami.

Tuber cinereum

Infundibulum

Hypophysis

Lobus anterior. Lobus posterior
Tractus opticus

Radix medialis

Radix lateralis

Chiasma opticum

Lamina terminalis

\section{$\beta$. Hemisphaerium.}

i. Pallium (general features).

Fissura longitudinalis cerebri Fossa cerebri lateralis [Sylvii] Fissura transversa cerebri Gyri cerebri

Gyri profundi

Gyri transitivi

Sulci cerebri

Impressio petrosa

'On the basis of development, the pars manillaris hypothalami is classified under the Diencephalon, and the pars optica hypothalami under the Telencephalon. 
ii. Lobi cerebri.

aa. Lobus frontalis.

Gyrus centralis anterior

Polus frontalis

Sulcis praecentralis

Gyrus frontalis superior

Sulcus frontalis superior

Gyrus frontalis medius

Pars superior

Pars inferior

Sulcus frontalis inferior

Gyrus frontalis inferior

Pars opercularis

Pars triangularis

Pars orbitalis

Gyrus rectus

Sulcus olfactorius

Gyri orbitales

Sulci orbitales

bb. Lobus parietalis.

Gyrus centralis posterior

Lobulus parietalis superior

Sulcus interparietalis

Lobulus parietalis inferior

Gyrus supramarginalis

Gyrus angularis

cc. Lobus occipitalis.

Polus occipitalis
Sulcus occipitalis transversus

Gyri occipitales superiores

Sulci occipitales superiores

Gyri occipitales laterales

Sulci occipitales laterales

$d d$. Lobus temporalis.

Polus temporalis

Sulci temporales transversi

Gyri temporales transversi

Gyrus temporalis superior

Sulcus temporalis superior

Gyrus temporalis medius

Sulcus temporalis medius

Gyrus temporalis inferior

Sulcus temporalis inferior

Fissura collateralis

Gyrus fusiformis

Gyrus lingualis

$$
\text { ee. Insula. }
$$

Gyri insulae

Gyrus longus insulae

Gyri breves insulae Sulcus circularis [Reili]

Operculum

Pars frontalis

Pars parietalis

Pars temporalis

iii. Facies medialis hemisphaerii.

aa. Sulci and gyri.

Sulcus corporis callosi

Sulcus cinguli

Pars subfrontalis

Pars marginalis

Sulcus subparietalis
Fissura hippocampi

Gyrus fornicatus

Gyrus cinguli

Isthmus gyri fornicati

Gyrus hippocampi

Uncus [gyri hippocampi] 
Substantia reticularis alba

[Arnoldi]

Lobulus paracentralis

Praecuneus

Fissura parieto-occipitalis

Fissura calcarina

Cuneus

bb. Corpus callosum.

Splenium corporis callosi

Truncus corporis callosi

Genu corporis callosi

Rostrum corporis callosi

Lamina rostralis

Striae transversae

Striae longitudinalis médialis

Stria longitudinalis lateralis

Fasciola cinerea

$$
\text { cc. Fornix. }
$$

Crus fornicis

Corpus fornicis

Taenia fornicis

Columna fornicis

Pars libera columnae fornicis

Pars tecta columnae fornicis

dd. Septum pellucidum.

Lamina septi pellucidi

Cavum septi pellucidi

ee, Ventriculus lateralis.

Pars centralis

Cornu anterius

Cornu posterius

Cornu inferius

Corpus striatum
Nucleus caudatus

Caput nuclei caudati

Cauda nuclei caudati

Stria terminalis

Lamina affixa

Taenia chorioidea

Lamina chorioidea epithelialis

Calcar avis

(Bulbus cornu posterioris)

Eminentia collateralis

Trigonum collaterale

Hippocampus

Fimbria hippocampi

Taenia fimbriae

Digitationes hippocampi

Fascia dentata hippocampi

Commissura hippocampi

$f f$. $\mathrm{R} h$ in en cephalon.

Sulcus parolfactorius anterior

Pars anterior [rhinencephali]

Lobus olfactorius

Bulbus olfactorius

Tractus olfactorius

Trigonum olfactorium

Stria medialis

Stria intermedia

Area parolfactoria [Brocae]

Sulcus parolfactorius posterior

Pars posterior [rhinencephali]

Gyrus subcallosus [Pedunculus corporis callosi]

Substantia perforata anterior

Stria olfactoria lateralis

Limen insulae 
$\gamma$. Sections of Telencephalon.

Substantia corticalis

Centrum semiovale

Decursus fibrarum cerebralium

Fibrae arcuatae cerebri

Cingulum

Fasciculus longitudinalis superior

Fasciculus longitudinalis inferior

Fasciculus uncinatus

Radiatio corporis callosi

Pars frontalis

Pars parietalis

1 Pars temporalis

Pars occipitalis

Tapetum

Nucleus lentiformis

Putamen

Globus pallidus

Claustrum
Capsula externa

Capsula interna

Genu capsulae internae

Pars frontalis capsulae internae

Pars occipitalis capsulae internae

Nucleus amygdalae

Corona radiata

Pars frontalis

Pars parietalis

Pars temporalis

Pars occipitalis

Radiatio corporis striati

Radiatio occipito-thalamica [Gratioleti]

Commissura anterior [cerebri]

Pars anterior

Pars posterior

\section{Meninges.}

Dura mater encephali

Falx cerebri

Tentorium cerebelli

Falx cerebelli

Diaphragma sellae

Foramen diaphragmatis

$$
\text { [sellae] }
$$

Incisura tentorii

Dura mater spinalis

Filum durae matris spinalis

Cavum epidurale

Cavum subdurale

Arachnoidea spinalis
Arachnoidea encephali

Cavum subarachnoideale

Cisternae subarachnoidales

Cisterna cerebellomedullaris

Cisterna fossae lateralis cerebri [Sylvii]

Cisterna chiasmatis

Cisterna interpeduncularis

Cisterna venae magnae

cerebri

Granulationes arachnoideales

[Pacchioni]

Pia mater spinalis 
Lig. denticulatum

Septum cervicale intermedium

Pia mater encephali

Tela chorioidea ventriculi quarti

Plexus chorioideus ventriculi

$$
\text { quarti }
$$

Tela chorioidea ventriculi tertii
Plexus chorioideus ventriculi tertii

Plexus chorioideus ventriculi lateralis

Glomus chorioideum

Acervulus

\section{SYSTEMA NERVORUM PERIPHERICUM.}

\section{A. Nervi celebrales.}
I. NN. ${ }^{2}$ OLFACTORI.
II. N. ${ }^{2}$ opticus.
III. N. OCULOMOTORIUS.

Ramus inferior

Ramus superior

Radix brevis ganglii ciliaris

IV. N. TROCHLEARIS.

Decussatio nervorum trochlearium

V. N. TRIGEMINUS.

Portio major

Portio minor

Ganglion semilunare [Gasseri]

$a$. N. OPHTHALMicus.

I. Primary divisions.

N. tentorii

N. lacrimalis

Ramus anastomoticus cum $\mathbf{n}$. zygomatico

$\mathrm{N}$. frontalis

N. supraorbitalis

Ramus frontalis

N. supratrochlearis

N. nasociliaris

Radix longa ganglii ciliaris

$\mathrm{Nn}$. ciliares longi ${ }^{x} \mathrm{Nn}$., nervi. $\quad{ }^{2} \mathrm{~N}$., nervus. $\quad{ }^{3} \mathrm{G}$., ganglion.

N. ethmoidalis posterior

$\mathrm{N}$. ethmoidalis anterior Rami nasales anteriores Rami nasales interni Rami nasales laterales Rami nasales mediales Ramus nasalis externus N. infratrochlearis Ramus palpebralis superior $R$. palpebralis inferior 2. G. ${ }^{3}$ c iliare. $\mathrm{Nn}$. ciliares breves 
b. N. MAXILLARIS.

I. Primary divisions. Rami labiales superiores

$\mathrm{N}$. meningeus [medius]

N. zygomaticus

Ramus zygomaticotemporalis

Ramus zygomaticofacialis

Nn. sphenopalatini

$\mathrm{Nn}$. alveolares superiores

Rami alveolares superiores posteriores

$N$. infraorbitalis

$R$. alveolaris superior medius

Rami alveolares superiores anteriores

Plexus dentalis superior

Rami dentales superiores

Rami gingivales superiores

Rami palpebrales inferiores

Rami nasales externi

Rami nasales interni

2. Ganglion. sphenopalatinum.

Rami orbitales

$\mathrm{N}$. canalis pterygoidei [Vidii]

N. petrosus superficialis major

N. petrosus profundus

Rami nasales posteriores superiores laterales

Rami nasales posteriores superiores mediales

N. nasopalatinus[Scarpae]

Rami nasales posteriores inferiores [laterales]

Nn. palatini

N. palatinus anterior

N. palatinus medius

N. palatinus posterior

c. N. MANDIBULARIS.

I. Primary divisions.

N. spinosus.

N. masticatorius

N. massetericus

Nn. temporales profundi

N. temporalis profundus posterior

$\mathrm{N}$. temporalis profundus anterior

$\mathrm{N}$. buccinatorius

N. pterygoideus externus

N. pterygoideus internus

N. auriculotemporalis
N. meatus auditorii externi R. membranae tympani

Rami parotidei

Rami anastomotici cum n. faciali

$\mathrm{Nn}$. auriculares anteriores

Rami temporales superficiales

N. lingualis

Rami isthmi faucium

Rami anastomotici cum $\mathrm{n}$. hypoglosso

N. sublingualis

Rami linguales 
$\mathrm{N}$. alveolaris inferior

Plexus dentalis inferior

Rami dentales inferiores

Rami gingivales inferiores

N. mylohyoideus

$\mathrm{N}$. mentalis

Rami mentales

Rami labiales inferiores

2. Ganglion oticum.

N. petrosus superficialis minor

N. tensoris veli palatini
N. tensoris tympani

Ramus anastomoticus cum n. spinoso

R. anastomoticus cum $n$. auriculotemporali

Ramus anastomoticus cum chorda tympani

3. Ganglion submaxillare. Rami communicantes cum $n$. linguali

Rami submaxillares

VI. N. ABDUCENS.

VII. N. FACIALIS.

a. Primary branches.

Geniculum n. facialis

Ganglion geniculi

N. stapedius

Ramus anastomoticus cum

plexu tympanico

$\mathrm{N}$. auricularis posterior

Ramus occipitalis

Ramus digastricus

Ramus stylohyoideus
Ramus anastomoticus cum $\mathbf{n}$. glossopharyngeo

Plexus parotideus

Rami temporales

Rami zygomatici

Rami buccales

Ramus marginalis mandibulae Ramus colli

$b$. N. intermedius.

Chorda tympani

VIII. N. ACUSTICUS.

a. Primary divisions.

Radix cochlearis

Radix 'vestibularis

Fila anastomotica

b. N. cochleae.

Ganglion spirale

N. saccularis c. N. vestibuli.

Ganglion vestibulare

N. utricularis

$\mathrm{N}$. ampullaris superior

N. ampullaris lateralis

N. ampullaris inferior 
IX. IV. GLOSSOFHARYNGEUS.

Ganglion superius

Ganglion petrosum

N. tympanicus

Intumescentia tympanica

Plexus tympanicus [Jacobsoni]

N. caroticotympanicus superior

$\mathrm{N}$. caroticotympanicus inferior
Ramus tubae

R. anastomoticus cum ramo auriculari $n$. vagi

Rami pharyngei

Ramus stylopharyngeus

Rami tonsillares

Rami linguales

X. N. VAGUS.

Ganglion jugulare

Ganglion nodosum

Ramus meningeus

Ramus auricularis

R. anastomoticus cum n. glossopharyngeo

Rami pharyngei

Plexus pharyngeus

N. laryngeus. superior

Ramus externus

Ramus internus

Ramus anastomoticus cum $\mathrm{n}$. laryngeo inferiore

Rami cardiaci superiores

(N. depressor)

N. recurrens

Rami cardiaci inferiores

Rami tracheales
Rami oesophagei

N. laryngeus inferior

Ramus anterior

Ramus posterior

Rami bronchiales anteriores

Rami bronchiales posteriores

Plexus pulmonalis anterior

Plexus pulmonalis posterior

Rami oesophagei

Plexus oesophageus anterior

Plexus oesophageus posterior

Rami gastrici

Plexus gastricus anterior

Plexus gastricus posterior

Rami hepatici

Rami coeliaci

Rami lienales

Rami renales

XI. N. ACCESSORIUS.

Ramus internus

Ramus externus

XII. N. HYPOGLOSSUS.

Ramus descendens

Ansa hypoglossi

Ramus thyreohyoideus

Rami linguales 


\section{B. Nervi spinales.}

Termini generales.

Fila radicularia

Radix anterior

Radix posterior

Ganglion spinale

Ramus anterior
Ramus posterior

Ramus communicans

Ramus meningeus

Cauda equina

Ansae

\section{NN. CERVICALES.}

General primary divisions.

Rami posteriores

Ramus medialis
Ramus lateralis

Rami anteriores

a. N. suboccipitalis

$\mathrm{N}$. occipitalis major

$\mathrm{N}$. occipitalis minor

(N. occipitalis tertius)

b. Plexus cervicalis.

N. occipitalis minor

N. auricularis magnus

Ramus posterior

Ramus anterior

N. cutaneus colli

Rami superiores

Rami inferiores

Nn. supraclaviculares
Nn. supraclaviculares anteriores

$\mathrm{Nn}$. supraclaviculares medii

$\mathrm{Nn}$. supraclaviculares posteriores

N. phrenicus

Ramus pericardiacus

Rami phrenico-abdominales

c. Plexus brachialis.

I. Pars supraclavicularis. N. thoracodorsalis

$\mathrm{Nn}$. thoracales posteriores

N. axillaris

N. dorsalis scapulae

Rami musculares

$\mathrm{N}$. thoracalis longus

$\mathrm{N}$. cutaneus brachii lateralis

$\mathrm{Nn}$. thoracales anteriores

N. subclavius

$\mathrm{N}$. suprascapularis

2. Pars infraclavicularis

Nn. subscapulares

Fasciculus lateralis

Fasciculus medialis

Fasciculus posterior 
N. musculocutaneus

Rami musculares

N. cutaneus antibrachii lateralis

$\mathrm{N}$. cutaneus brachii medialis

$\mathrm{N}$.cutaneus antibrachii medialis

Ramus volaris

Ramus ulnaris

3. N. medianus.

Rami musculares

$\mathrm{N}$. interosseus [antibrachii] volaris

Ramus palmaris n. mediani

Ramus anastomoticus cum $\mathrm{n}$. ulnari

Nn. digitales volares communes

Nn. digitales volares proprii

$$
\text { 4. N. ulnaris. }
$$

Ramus cutaneus palmaris
Ramus dorsalis manus

$\mathrm{Nn}$. digitales dorsales

Ramus volaris manus

Ramus superficialis

$\mathrm{Nn}$. digitales volares communes

Nn. digitales volares proprii

Ramus profundus

Rami musculares

5. N. radialis.

$\mathrm{N}$. cutaneus brachii posterior

Rami musculares

$\mathrm{N}$. cutaneus antibrachii dorsalis

Ramus profundus

$\mathrm{N}$. interosseus [antibrachii] dorsalis

Ramus superficialis

Ramus anastomoticus ulnaris $\mathrm{Nn}$. digitales dorsales

II. NN. THORACALES.

Rami posteriores

Ramus cutaneus lateralis

Ramus cutaneus medialis

Rami anteriores [Nn. intercostales ]

Rami musculares

Ramus cutaneus lateralis

[pectoralis et abdominalis ]
Ramus posterior

Ramus anterior

Rami mammarii laterales

$\mathrm{N}$. intercostobrachiales

Ramus cutaneus anterior

[pectoralis et abdominalis ]

Rami mammarii mediales

III. NN. LUMBALES, SACRALES, COCCYGEI.

a: Termini generales.

I. NN. LUMBALES.

Rami posteriores

Ramus medialis

Ramus lateralis

$\mathrm{Nn}$. clunium superiores
2. NN. SACRALES ET COCCYGEUS. Rami posteriores

Ramus medialis

Ramus lateralis

$\mathrm{Nn}$. clunium medii

Rami anteriores 
b. Plexus lumbosacrales.

I. Plexus lumbalis.

a. N. iliohypogastricus.

Rami musculares

Ramus cutaneus lateralis

Ramus cutaneus anterior

$\beta$. N. ilioinguinalis.

Rami musculares

Nn. scrotales anteriores

Nn. labiales anteriores

$\gamma . N$. genitofemoralis.

$\mathrm{Nn}$. lumboinguinalis

N. spermaticus externus $\delta . N$. cutaneus femoris lateralis. $\epsilon . N$. obturatorius.

Ramus anterior

Ramus cutaneus

Ramus posterior

$$
\zeta . N \text {. femoralis. }
$$

Rami cutanei anteriores

Rami musculares

$\mathrm{N}$. saphenus

Ramus infrapatellaris

Rami cutanei cruris mediales

2. PLEXUS SACRALIS.

Truncus lumbrosacralis

N. glutaeus superior

N. cutaneus femoris posterior

N. glutaeus inferior

$\mathrm{Nn}$. clunium inferiores

Rami perineales

a. N. ischiadicus.

i. N.peronaeus communis. Nn. digitales dorsales hallucis

Rami musculares

$\mathrm{N}$. cutaneus surae lateralis

Ramus anastomoticus peronaeus

ii. N. peronaeus superficialis.

Rami musculares

N. cutaneus dorsalis medialis

$\mathrm{N}$. cutaneus dorsalis intermedius

Nn. digitales dorsales pedis

iii. N. peronaeus profundus.

Rami musculares lateralis et digiti secundi medialis

$$
\text { iv. N. tibialis. }
$$

Rami musculares

$\mathrm{N}$. interosseus cruris '

$\mathrm{N}$. cutaneus surae medialis

[N. suralis ]

Rami calcanei laterales

$\mathrm{N}$. cutaneus dorsalis lateralis

Rami calcanei mediales

v. N. plantaris medialis .

Nn. digitales plantares communes 
Nn. digitales plantares proprii

vi. N. plantaris lateralis. Ramus superficialis
Nn. digitales plantares communes

Nn. digitales plantares proprii

Ramus profundus

3. PLEXUS PUDENDUS.

Nn. haemorrhoidales medii

N. perinei

$\mathrm{Nn}$. vesicales inferiores

$\mathrm{Nn}$. vaginales

Nn. scrotales posteriores

N. pudendus

Nn. labiales posteriores

Nn. haemorrhoidales inferi- N. dorsalis clitoridis ores

c. N. Coccygeus.

Plexus coccygeus

$\mathrm{Nn}$. anococcygei

C. Systema nervorum sympathicum.

Termini generales.

Truncus sympathicus

Ganglia trunci sympathici
Plexus sympathici

Ganglia plexuum sympathicorum

\section{PARS CEPHALICA ET CERVICALIS S. SYMPATHICI.}

Ganglion cervicale superius

$N$. jugularis

N. caroticus internus

Plexus caroticus internus

Plexus cavernosus

Plexus arteriae cerebri anteri oris

Plexus arteriae cerebri mediae

Plexus arteriae chorioideae

Plexus ophthalmicus

Radices sympathicae ganglii ciliaris

Nn. carotici externi

Plexus caroticus externus
Plexus thyreoideus superior

Plexus lingualis

Plexus maxillaris externus

Radix sympathica ganglii submaxillaris

Plexus occipitalis

Plexus auricularis posterior

Plexus temporalis superficialis

Plexus maxillaris internus

Plexus meningeus

Plexus caroticus communis

Rami laryngopharyngei

Plexus pharyngeus ascendens

N. cardiacus superior 
Ganglion cervicale medium

N. cardiacus medius

Ganglion cervicale inferius

Ansa subclavia [Vieussenii]

$\mathrm{N}$. cardiacus inferior
Plexus subclavius

Plexus mammarius internus

Plexus thyreoideus inferior

Plexus vertebralis

\section{PARS THORACALIS S. SYMPATHICL.}

Ganglia thoracalia

N. splanchnicus major

Ganglion splanchnicum

N. splanchnicus minor

Ramus renalis

(N. splanchnicus imus)

Plexus aorticus thoracalis

Plexus cardiacus
Plexus coronarius cordis anterior

Ganglion cardiacum [Wrisbergi]

Plexus coronarius posterior

Rami pulmonales

Plexus pulmonalis

III. PARS ABDOMINALIS ET PELVINA S. SYMPATHICI.

Ganglia lumbalia

Ganglia sacralia

Plexus aorticus abdominalis

Plexus coeliacus

Ganglia coeliaca

Ganglion mesentericum superius

Plexus phrenicus Ganglia phrenica

Plexus hepaticus

Plexus lienalis

Plexus gastricus superior

Plexus gastricus inferior

Plexus suprarenalis

Plexus renalis

Plexus spermaticus

Plexus arteriae ovaricae

Plexus mesentericus superior

Plexus myentericus

Plexus submucosus

Plexus mesentericus inferior
$\mathrm{Nn}$. haemorrhoidales superiores

Plexus haemorrhoidalis superior

Plexus iliacus

Plexus hypogastricus

Plexus haemorrhoidalis medius

Plexus prostaticus

Plexus deferentialis

Plexus uterovaginalis

Plexus vesicalis

$\mathrm{Nn}$. vesicales superiores

$\mathrm{Nn}$. vesicales inferiores

Plexus cavernosus penis

$\mathrm{N}$. cavernosus penis major

$\mathrm{Nn}$. cavernosi penis minores

Plexus cavernosus clitoridis

$\mathrm{N}$.cavernosus clitoridis major

$\mathrm{Nn}$. cavernosi clitoridis $\mathrm{mi}-$ nores

Plexus femoralis

Plexus popliteus 


\section{ORGANA SENSUUM ET INTEGUMENTUM COMMUNE.}

\section{A. Organon olfactus.}

B. Organon visus.

I. APPARATUS LACRIMALIS.

GIandula lacrimalis superior

Glandula lacrimalis inferior

(Gl. lacrimales accessoriae)

Ductuli excretorii [gl. lacrimalis ]

Rivus lacrimalis

Lacus lacrimalis

Puncta lacrimalia
Ductus lacrimales

Papillae lacrimales

Ampulla ductus lacrimalis

Saccus lacrimalis

Fornix sacci lacrimalis

Ductus nasolacrimalis

Plica lacrimalis [Hasneri]

Lacrimae

\section{Conjunctiva.}

Plica semilunaris conjunctivae Fornix conjunctivae superior

Caruncula lacrimalis

Tunica conjunctiva bulbi

Fornix conjunctiva inferior

Tunica conjunctiva palpebra- Noduli lymphatici conjunctivarum les (Pinguecula)

III. ORGANA OCULI ACCESSORIA.

a. MUSCULI OCULI, FASCIAE ORBITALES.

M. orbitalis

M. rectus superior

M. rectus inferior

M. rectus medialis

M. rectus lateralis

Lacertus musculi recti lateralis

Annulus tendineus communis

$$
\text { [Zinni] }
$$

M. obliquus superior

b. SUPERCILIUM.

\section{Palpebrae}

Palpebra superior

Palpebra inferior
Trochlea

M. obliquus inferior

M. levator palpebrae superioris

Periorbita

Septum orbitale

Fasciae musculares

Fascia bulbi [Tenoni]

Spatium interfasciale [Tenoni]

Corpus adiposum orbitae
Facies anterior palpebrarum Facies posterior palpebrarum Rima palpebrarum 
Commissura palpebrarum late- Tarsus superior ralis

Tarsus inferior

Commissura palpebrarum me- Lig. palpebrale mediale dialis

Raphe palpebralis lateralis

Angulus oculi lateralis

Angulus oculi medialis

Limbi palpebrales anteriores

Limbi palpebrales posteriores

Glandulae tarsales [Meibomi]

Sebum palpebrale

M. tarsalis superior

M. tarsalis inferior

IV. OCOLUS.

a. N. OPTICUS.

Vaginae n. optici

Spatia intervaginalia

b. BUlbus Oculi.

Polus anterior

Polus posterior

Aequator

Meridiani

Axis oculi externa
Axis oculi interna

Axis optica

[Linea visus]

Vesicula ophthalmica

Caliculus ophthalmicus

c. TUNICA FIBROSA OCULI.

I. Sclera.

Sulcus sclerae

Rima cornealis

Sinus venosus sclerae [Canalis Schlemmi, Lauthi]

Lamina fusca

Lamina cribosa sclerae

(Raphe sclerae)

(Funiculus sclerae)
2. Cornea.

Annulus conjunctivae

Vertex corneae

Limbus corneae

Facies anterior

Facies posterior

Epithelium corneae

Lamina elastica anterior [Bowmani]

Substantia propria

Lamina elastica posterior

[Demoursi, Descemeti]

Endothelium camerae anterioris 
$d$. TUNICA VASCULOSA OcUli.

I. Chorioidea.

Lamina suprachorioidea

Spatium perichorioideale

Lamina vasculosa

Lamina choriocapillaris

Lamina basalis

(Raphe chorioideae)

2. Corpus ciliare.

Corona ciliaris

Processus ciliares

Plicae ciliares

Orbiculus ciliaris

M. cilaris

Fibrae meridionales

[Brueckei]

Fibrae circulares [Mülleri]

Plexus gangliosus ciliaris
3. Iris.

Margo pupillaris

Margo ciliaris

Facies anterior

Facies posterior

Annulus iridis major

Annulus iridis minor

Plicae iridis

Pupilla

M. sphincter pupillae

Stroma iridis

M. dilatator pupillae

Lig. pectinatum iridis

Spatia anguli iridis [Fontanae]

Circulus arteriosus major

Circulus arteriosus minor

Membrana pupillaris

e. STRATUM PIGMENTI.

Stratum pigmenti retinae

Stratum pigmenti iridis

Stratum pigmenti corporis cili-

aris

f. RETINA.

I. Partes generales.

Pars optica retinae

Ora serrata

Pars ciliaris retinae

Papilla n. optici

Excavatio papillae n. optici

Macula lutea

Fovea centralis

2. Vasa sanguinea retinae.

Circulus vasculosus n. optici

[Halleri]

Arteriola [Venula] temporalis retinae inferior

Arteriola [Venula] nasalis retinae superior

Arteriola [Venula] nasalis retinae inferior

Arteriola [Venula] macularis superior

Arteriola [Venula] macularis inferior

Arteriola [Venula] retinae medialis

Arteriola [Venula] temporalis retinae superior 
g. CAMERAE.

I. Camera oculi anterior.

Angulus iridis

Humor aqueus
Axis lentis

Aequator lentis

Radii lentis

2. Camera oculi posterior.

a. Lens crystallina.

Substantia lentis

Substantia corticalis

Nucleus lentis

Fibrae lentis

Epithelium lentis

Capsula lentis

Polus anterior lentis

Polus posterior lentis

Facies anterior lentis

Facies posterior lentis ß. $\dot{Z}$ onula ciliaris [ $\mathrm{Z}$ i n n i ].

Fibrae zonulares Spatia zonularia

$\gamma$. Corpus vitreum.

A. hyaloidea

Canalis hyaloideus

Fossa hyaloidea

Membrana hyaloidea

Stroma vitreum

Humor vitreus

\section{Organon auditus.}

Lobulus auriculae

Cartilago auriculae

Helix

Crus helicis

Spina helicis

Cauda helicis

Anthelix

Fossa triangularis [auriculae]

Crura anthelicis

Scapha

Concha auriculae

Cymba conchae

Cavum conchae

Antitragus

Tragus

Incisura anterior [auris]

I. AURICULA.

Incisura intertragica

(Tuberculum auriculae [Darwini])

(Apex auriculae [Darwini])

Sulcus auriculae posterior

(Tuberculum supratragicum)

Isthmus cartilaginis auris

Incisura terminalis auris

Fissura antitragohelicina

Sulcus anthelicis transversus

Sulcus cruris helicis

Fossa anthelicis

Eminentia conchae

Eminentia scaphae

Eminentia fossae triangularis 
Ligg. auricularia [Valsalvae]

Lig. auriculare anterius

Lig. auriculare superius

Lig. auriculare posterius

M. helicis major

M. helicis minor

M. tragicus
(M. pyramidalis auriculae [Jungi])

M. antitragicus

M. transversus auriculae

M. obliquus auriculae

(M. incisurae helicis [Santorini])

I. Meatus acusticus externus.

Porus acusticus externus

Incisura tympanica [Rivini]

Meatus acusticus externus cartilagineus
Cartilago meatus acustici

Incisurae cartilaginis meatus acustici externi [Santorini]

Lamina tragi

III. CAVUM TYMPANI.

a. PARIETES.

I. Paries tegmentalis.

Recessus epitympanicus

Pars cupularis

2. Paries jugularis.

Prominentia styloidea

3. Paries labyrinthica.

Fenestra vestibuli

Fossula fenestrae vestibuli

Promontorium

Sulcus promontorii

Subiculum promontorii

Sinus tympani

Fenestra cochleae

Fossula fenestrae cochleae

Crista fenestrae cochleae

Processus cochleariformis
4. Paries mastoidea.

Antrum tympanicum

Prominentia canalis semicircularis lateralis

Prominentia canalis facialis

Eminentia pyramidalis

Fossa incudis

Sinus posterior

Apertura tympanica canaliculi chordae

Cellulae mastoideae

Cellulae tympanicae

5. Paries carotica.

6. Paries membranacea.

\section{b. MEMBRANA TYMPANI.}

Pars flaccida

Pars tensa

Limbus membranae tympani
Plica malleolaris anterior Plica malleolaris posterior Prominentia malleolaris 
Stria malleolaris

Umbo membranae tympani

Stratum cutaneum

Annulus fibrocartilagineus
Stratum radiatum

Stratum circulare

Stratum mucosum

c. ossicula auditus.

I. Ossicula.

a. St a pes.

Capitulum stapedis

Crus anterius

Crus posterius

Basis stapedis

$\beta$. Incus.

Corpus incudis

Crus Iongum

Processus lenticularis

Crus breve

$$
\gamma . \mathrm{Malleus} \text {. }
$$

Manubrium mallei

Capitulum mallei

Collum mallei

Processus lateralis

Processus anterior [Folii]

2. Articulationes ossiculorum auditus.

Articulatio incudomalleolaris

Articulatio incudostapedia

Syndesmosis tympanostapedia
Lig. mallei superius

Lig. mallei laterale

Lig. incudis superius

Lig. incudis posterius

Membrana obturatoria (stapedis)

Lig. annulare baseos stapedis

[M. ${ }^{3}$ fixator baseos stapedis]

4. Musculi ossiculorum auditus.

M. tensor tympani

M. stapedius

5. Tunica mucosa tympanica.

(G1.4 tympanicae)

Plica malleolaris posterior

Plica malleolaris anterior

Recessus membranae tympani anterior

Recessus membranae tympani superior

Recessus membranae tympani posterior

Plica incudis

Plica stapedis

Membrana tympani secundaria

3. Ligg. ${ }^{x}$ ossiculorum auditus.

Lig. ${ }^{2}$ mallei anterius

' Ligg., Ligamenta. ' 


$$
\text { d. tuba auditiva [eustachil]. }
$$

Ostium tympanicum tubae auditivae

Pars ossea tubae auditivae

Isthmus tubae auditivae

Cellulae pneumaticae tubariae

Pars cartilaginea tubae auditivae

Cartilago tubae auditivae Lamina [cartilaginis] medialis

IV. AURIS INTERNA.

a. LABYRINTHUS OSSEUS.

I. Vestibulum.

Recessus sphaericus

Recessus ellipticus

Crista vestibuli

Pyramis vestibuli

Recessus cochlearis

Maculae cribrosae

Macula cribrosa superior

Macula cribrosa media

Macula cribrosa inferior

Canales semicirculares ossei

Canalis semicircularis superior

Canalis semicircularis posterior

Canalis semicircularis lateralis

Ampullae osseae

Ampulla ossea superior Ampulla ossea posterior Ampulla ossea lateralis
Lamina [cartiliginis] lateralis.

Lamina membranacea

Tunica mucosa

Gl. mucosae

Noduli lymphatici tubarii

Ostium pharyngeum tubae auditivae 
Fundus meatus acustici interni

Crista transversa

Area n. facialis

Area cochlea

Tractus spiralis foramino sus

b. LABYRINTHUS MEMBRANACEUS.

Ductus endolymphaticus

Saccus endolymphaticus

Ductus utriculosaccularis

Utriculus

Ductus semicirculares

Ductus semicircularis superior

Ductus semicircularis posterior

Ductus semicircularis lateralis

Ampullae membranaceae

Sulcus ampullaris

Crista ampullaris

Ampulla membranacea superior

Ampulla membranacea posterior

Ampulla membranacea lateralis

Sacculus

Ductus reuniens [Henseni |

Maculae acusticae

c. VASA AURIS INTERNAE.

A." auditiva interna

Rami vestibulares

Ramus cochleae

Glomeruli arteriosi cochleae $\mathrm{Vv}^{2}{ }^{2}$ auditivae internae
Area vestibularis superior Area vestibularis inferior

Foramen singulare
Macula acustica utriculi

Macula acustica sacculli

Otoconia

Endolympha

Perilympha

Spatium perilymphaticum

Ductus perilymphatici

Ductus cochlearis

Caecum cupulare.

Caecum vestibulare

Lamina basilaris

Membrana vestibularis [Reissneri]

Lig. spirale cochleae

Prominentia spiralis

Stria vascularis

Sulcus spiralis

Labium tympanicum

Foramina nervosa

Labium vestibulare

Ganglion spirale cochleae

Organon spirale [Cortii]
V. ${ }^{3}$ spiralis modioli

Vas prominens

$\mathrm{Vv}$. vestibulares

V. aquaeductus vestibuli

V. canaliculi cochleae

A., Arteria.

Vv., Venae.

3 V., Vena. 


\section{Organon gustus.}

Calyculi gustatorii.

E. Integumentum commune.

I. cUTIS.

a. External appearances.

Sulci cutis

Cristae cutis

Retinacula cutis

Toruli tactiles

Foveola coccygea

Lig. caudale

b. Epidermis.

Stratum corneum

Stratum germinativum

[Malpighii]

c. Corium.

Tunica propria

Lanugo

Capilli

Supercilia

Cilia

Barba

Tragi

Vibrissae

Hirci

Pubes

Folliculus pili
Corpus papillare

Papillae

d. Tela subcutanea.

Panniculus adiposus

e. Corpuscula nervorum terminalia.

Corpuscula bulboidea

$$
\text { [Krausii] }
$$

Corpuscula lamellosa [Vateri, Pacini]

Corpuscula tactus [Meissneri] Corpuscula nervorum genitalia Corpuscula nervorum articularia

II. PILI.

Fundus folliculi pili

Collum folliculi pili

Papilla pili

Scapus pili

Radix pili

Bulbus pili

$\mathrm{Mm}$. arrectores pilorum

Flumina pilorum

Vortices pilorum

(Vortex coccygeus)
Matrix unguis

Cristae matricis unguis Sulcus matricis unguis

Vallum unguis

Corpus unguis

Radix unguis
III. UNGUES.

Lunula

Margo occultus

Margo liber

Margo lateralis

Stratum corneum unguis

Stratum germinativum unguis 
IV. GLANDULAE CUTIS.
a. Gl. glomiformes.
Corpus mammae

Gl. sudoriferae

Corpus gl. sudoriferae

Lobi mammae

Ductus sudoriferus

Lobuli mammae

Porus sudoriferus

Ductus lactiferi

Sudor

Sinus lactiferi

Gl. ciliares [Molli]

Lac femininum

Gl. circumanales

Colostrum

Gl. ceruminosae

Areola mammae

Cerumen

b. Glandulae sebaceae.

Gl. sebaceae

Gl. areolares [Montgomerii]

Mamma virilis

(Mammae accessoriae [mulie-

c. Mamma. bres et viriles])

Papilla mammae 


\section{TABLES OF EQUIVALENT WEIGHTS AND MEASURES.}

I. Equivalent Measures of Length, Metric and English.

$$
\begin{aligned}
\text { I inch } & =25.40 \text { millimeters }(\mathrm{mm} .) \\
\text { I foot } & =30.48 \text { centimeters }(\mathrm{cm} .) \\
\text { I yard } & =91.44 \text { centimeters }(\mathrm{cm} .) \\
\text { I millimeter }(\mathrm{mm} .) & =0.039 \text { inch. } \\
\text { ro millimeters }(\mathrm{I} \mathrm{cm} .) & =0.394 \text { inch. } \\
\text { I oo millimeters }(1 \mathrm{dm} .) & =3.937 \text { inches. }
\end{aligned}
$$$$
10 \text { millimeters ( } 1 \mathrm{~cm} .)=0.394 \text { inch. }
$$$$
\mathbf{I}, 000 \text { millimeters (I meter) }=39.370 \text { inches. }
$$

2. Equivalent Weights, Metric and Apothecaries'.

$$
\begin{aligned}
& \text { I grain }=0.065 \text { gram (g.). } \\
& \text { I ounce }=31.104 \text { grams (g.). } \\
& \text { I pound }=273.236 \text { grams }(\mathrm{g} .) \text {. } \\
& \text { I milligram (mg.) }=0.015 \text { grains. } \\
& \text { I centigram (cg.) }=0.154 \text { grains. } \\
& \text { I decigram (dg.) }=\text { I } .543 \text { grains. } \\
& \text { I } \operatorname{gram}(\mathrm{g} .)=\text { I } 5.432 \text { grains. } \\
& \text { Ioo grams }(\mathrm{hg} .)=\left\{\begin{array}{r}
\mathrm{I}, 543.235 \text { grains, or } 3 \text { ounces, } \\
\text { I dram, and } 43 \text { grains. }
\end{array}\right. \\
& I, \infty 00 \text { grams (kilo) }=\left\{\begin{array}{r}
15,432.349 \text { grains, or } 2 \text { pounds, } \\
8 \text { ounces, } I \text { dram, and } 12 \text { grains. }
\end{array}\right.
\end{aligned}
$$

3. Equivalent Weights, Metric and Avoirdupois.

$$
\begin{aligned}
\text { I grain } & =0.065 \text { gram }(\mathrm{g} .) \\
\text { I ounce } & =28.35 \text { grams }(\mathrm{g} .) \\
\text { I pound } & =453.59 \text { grams }(\mathrm{g} .) \\
\text { I gram }(\mathrm{g} .) & =15.43 \text { grains. } \\
\text { I00 grams }(\mathrm{hg} .) & =3 \text { ounces, } 230 \text { grains. } \\
\text { 1,000 grams (kilo) } & =35 \text { ounces, I } 20 \text { grains. }
\end{aligned}
$$


4. Equivalent Liquid Measures, Metric and Apothecaries'.

$$
\begin{aligned}
\text { I minim } & =0,06 \mathrm{cc} . \\
\text { I fluid ounce } & =29.57 \mathrm{cc} . \\
\text { I pint } & =433.1 \mathrm{I} \mathrm{cc} . \\
\text { I gallon } & =3,784.88 \mathrm{cc} .
\end{aligned}
$$

I cubic centimeter $(\mathrm{cc})=.\mathrm{I} 6.23$ minims.

I 00 cubic centimeters $(\mathrm{dl})=$.3.38 fluid ounces.

\begin{tabular}{|c|c|c|c|c|c|}
\hline C. & F. & c. & F. & c. & F. \\
\hline$-40^{\circ}$ & $=-40^{\circ}$ & $15^{\circ}=$ & $59^{\circ}$ & $50^{\circ}=$ & $=122^{\circ}$ \\
\hline-35 & $=-31$ & $20=$ & 68 & $55=$ & $=13 I$ \\
\hline-30 & $=-22$ & $25=$ & 77 & $60=$ & $=140$ \\
\hline-25 & $=-13$ & $30=$ & 86 & $65=$ & $=149$ \\
\hline-20 & $=-4$ & $35=$ & 95 & $70=$ & $=158$ \\
\hline-15 & $=+5$ & $36=$ & 96.8 & $75=$ & $=167$ \\
\hline-10 & $=I 4$ & $37=$ & 98.6 & $80=$ & $=176$ \\
\hline-5 & $=23$ & $38=$ & 100.4 & $85=$ & $=185$ \\
\hline & $=$ & $39=$ & I 02.2 & $90=$ & $=194$ \\
\hline+5 & $=$ & $40=$ & 104 & $9.5=$ & $=203$ \\
\hline 10 & $=$ & $45=$ & J 13 & $100=$ & $=212$ \\
\hline
\end{tabular}

I,000 cubic centimeters (liter) $=33.8$ I fluid ounces or 2. I I pints.

5. Table of Equivalent Thermometric Scales, Centigrade and Fahrenheit. 
I N D EX

Digitized by Microsoft $\circledast$ 
Digitized by Microsoft $\circledast$ 


\section{INDEX.}

A.

Action of reagents -

PAGE

Acusticus N., nomenclature for

Albumen water method for fastening sections -

Alcohol as a fixing agent

grades of

formula and table for making grades

for dehydration

for hardening

for washing

uses of

Ammonium picrate for methylen-blue $\quad 43$

Anatomical nomenclature [BNA] -

Aniline-alcohol 2I

Aniline-xylol $\quad 84$

Apáthy's fixing fluid 31

Apáthy's gold chloride method 3 3

Architecture of peripheral ganglia, method for $\quad 43$

Axone, method for course and terminations $\quad 43$

Axone, Kupffer's method for

B.

Bethe's fixing fluid $\quad 43$

Bethe's method - - 25

results from $\quad 30$

Bichromate of potassium, action of $\quad 6$

for Golgi method - $\quad 55$

$\begin{array}{lr}\text { [BNA] nomenclature } & \text { I39 }\end{array}$

Brain, directions for removal of 106 outline for dissection of

C.

Carbol-xylol

Cedar oil and xylol, mixture of

Celloidin, thin solution

thick solution

sections

to imbed in

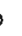

tral nervous system, outline for removal of 
Cerebellum, nomenclature for

Cerebral nerves, nomenclature for -

Clearing mixture or fluid

Clearing, why necessary

Colophonium -

Corrosive sublimate, action of

Counterstain for Weigert's hæmatoxylin -

Cross of Ranvier, method for

D.

Degenerating nerves, method for 75

Degeneration, method for process of

Dehydration

Diencephalon, nomenclature for

Diffusion currents, action of

Dissection, general directions for

Dissection of nervous system, outline for

Double impregnation, Golgi

Dry method, to fasten sections by

Dry preparations for museum specimens

E.

Ear, nomenclature for I66

Embryos, method for treatment of removal of

Encephalon, divisions of

outline for dissection of

sections of

scheme of divisions

Equivalent weights and measures, tables of

F.

Facialis N., nomenclature for -

Fatty degeneration, method for

Fixation, definition of

nature of

theories of

Fixing agents, classes of 
Fœtal nervous tissue, removal of

PAGE

Fœtuses, fixation of

table for length, weight, and age of

IOI

Formalin, advantages of

IOI

for purposes of dissection

for "dry preparations"

I03

103

for gold chloride method

for Golgi method

for Weigert's bæmatoxylin

Io per cent. solution of

Formic acid solutions

Formula for graded alcohols

for slide-cleaning fluid

Freezing microtome

Frommann's lines, method for

Frozen sections for methylen-blue

Gehuchten's fluid, Van

G.

General instructions

Giacomini's method

Glands of skin, nomenclature for

Glossopharyngeus, nomenclature for

Glycerine jelly, Kaiser's formula

Gold chloride, Apáthy's after-gilding

Gold-chloride method, a

Golgi method, the

Golgi sections, mounting of

H.

Haematoxylin, aqueous solution of

Hair, nomenclature for 
I.

Imbedding in celloidin

in paraffin

paper boxes for

Immersion, methylen-blue by

Injection of methylen-blue

Integumentum commune

Iodine solution for washing

Iron-hæmatoxylin method

PAGE

64

16

I7

46

44

I 7 I

$3 \mathrm{I}$

63

K.

Kaiserling method, the

Kaiserling's fluid

Kaiser's glycerine jelly

Kupffer's method

I.

Lavdowsky's mixture

98

Lithium carbonate solution

Lobi cerebri, identification of nomenclature for

Lugol's solution

M.

Mallory's method for neuroglia

Marchi's method

Serial sections for

Medulla spinalis, nomenclature for

outline for dissection of

removal of

sections of

Medulla oblongata, nomenclature for sections of

Medullary sheath, method for

Medullated nerve tracts, method for

Meninges, nomenclature for

Mercuric bichloride, action of

Mesencephalon, nomenclature for sections of

Methylen-blue, intra vitam

Methylen-blue, intra vitam injection immersion

Methylen-blue, formula for Nissl's method 2 I

Meyer's albumen fixative

Metencephalon, nomenclature for 
Mixture for clearing celloidin sections

Mounting cellordin sections

Golgi sections -

Müller's fluid, formula

Muscle-nerve terminations by gold chloride

by methylen-blue

Museum specimens by Giacomini's method

Myelencephalon, nomenclature for

N.

Need and action of reagents

Nerve roots for teasing

Nerve terminations by gold chloride $4 I$ by methylen-blue 51

Nervi cerebrales, nomenclature for identification of

Nervi spinales, division of nomenclature for

Neuro-fibrillæ, Apáthy's method for

Bethe's method for -

Neuroglia, Mallory's method for

Neurosomes, Held's method for

Nissl method, the

Normal salt solution

use of in dissection

O.

Oculus, nomenclature for

Organa sensuum, nomenclature for -

Organon auditus

visus

Osmic acid, action of to make solutions of

Osmotic action

P.

Pal's differentiating fluids

Pal-Weigert method, the

Paper boxes for imbedding

Peripheral plexuses, method for

Physiological salt solution

Picrate of ammonia for methylen-blue

Potassium bichromate, action of 
Prosencephalon, nomenclature for -

torn preparation of -

sections of

R.

Rapid Golgi method

Reagents, amounts to be used

fixing value of

time for action of

Reconstructions of central nervous system

References, explanation of

Regeneration, method for process of

Removal of spinal cord and brain

Rhombencephalon, nomenclature for sections of

Scheme for divisions of encephalon

Section, to, after gold chloride

after methylen-blue, intra vitam

in celloidin

in oil

in paraffin

Sections, albumen water method for

dry method for

frozen, for methylen-blue

of silvered nerve

serial celloidin

Shrinkage, cause of

Silvered nerve, sections of

Silver nitrate method, a

Silver nitrate solution for Golgi

Size of pieces of tissue to be used

Skin, nomenclature for

Slide-cleaning fluid

Spinal cord, directions for removal

Spinal cord, nomenclature for outline for dissection of sections of 
T.

Table for graded alcohols

PAGE

Table for ages of fotuses

Tables of equivalent weights and measures

ror

Teasing gold chloride material

Teasing of nerve fibers

Telencephalon, nomenclature for

Thalamencephalon, nomenclature for

Theories of fixation

Tigroid masses, Nissl method for

Tissues, selective staining of

Torn preparation of prosencephalon

Trigeminus, nomenclature for

U.

Upson's carmine

V.

Vagus, nomenclature for

Van Gehuchten's fluid

W.

Washing with alcohol with water

Weigert's hæmatoxylir method

Weigert's hæmatoxylin after formalin

Weigert's method for neuroglia

Weights and measures, tables for

$\mathrm{X}$.

Xylol for clearing

$\mathrm{Xylol}$ and carbolic acid

Z.

Zenker's fluid

98

Zinc chloride solution

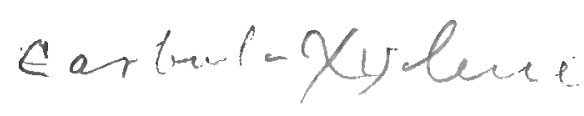


Digitized by Microsoft巴 
Digitized by Microsoft ${ }^{\circledR}$ 
Digitized by Microsoft巴 
6)

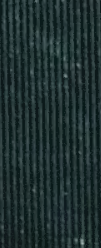

(1)

1 II

1.
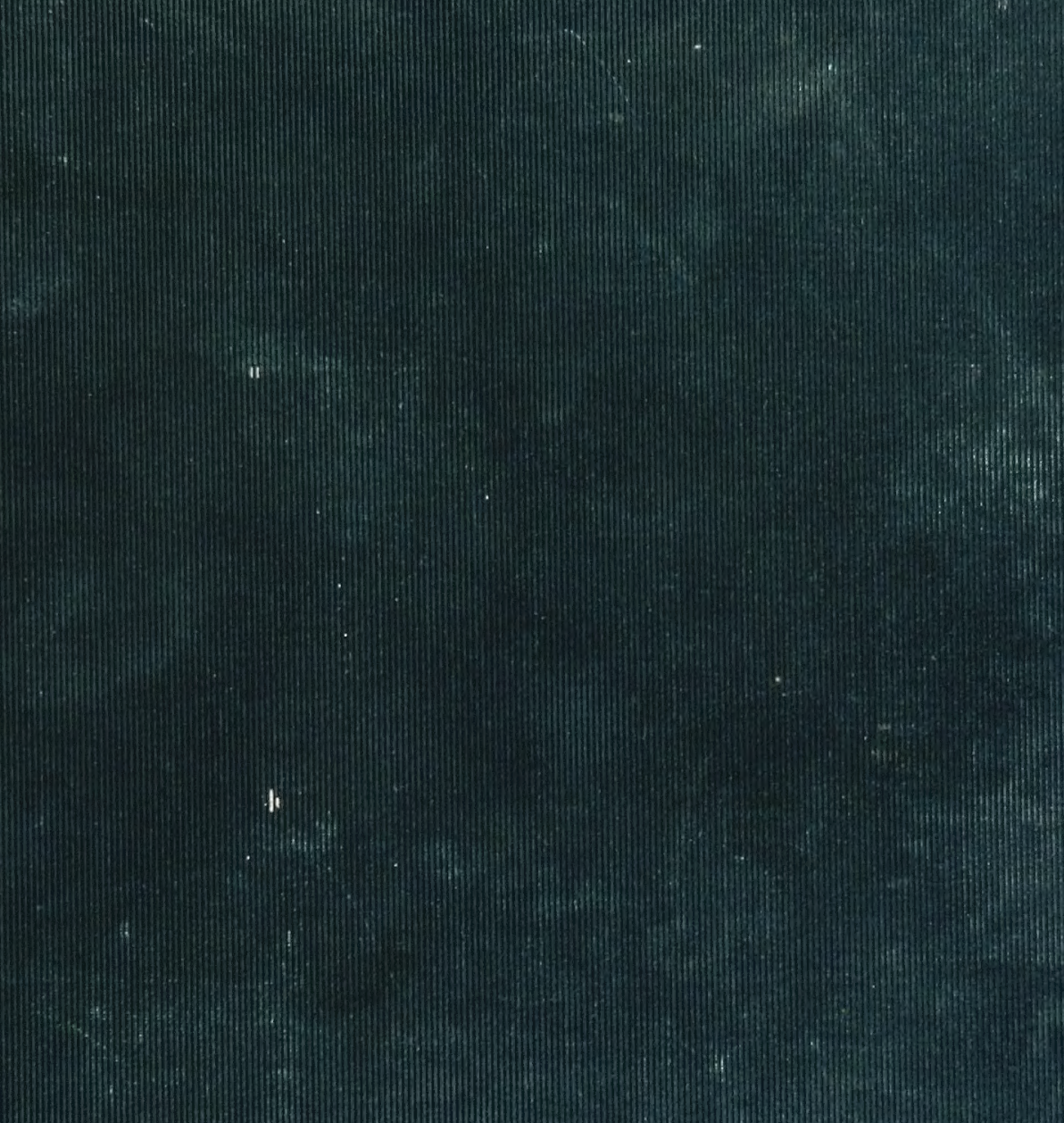

1.

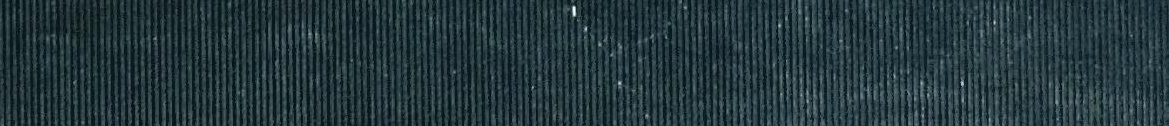

1.1. D. (1)

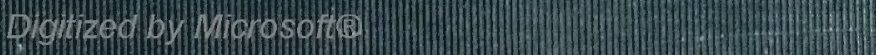

